\title{
Gender and Social Movements OVERVIEW REPORT
}

JESSICA HORN

2013
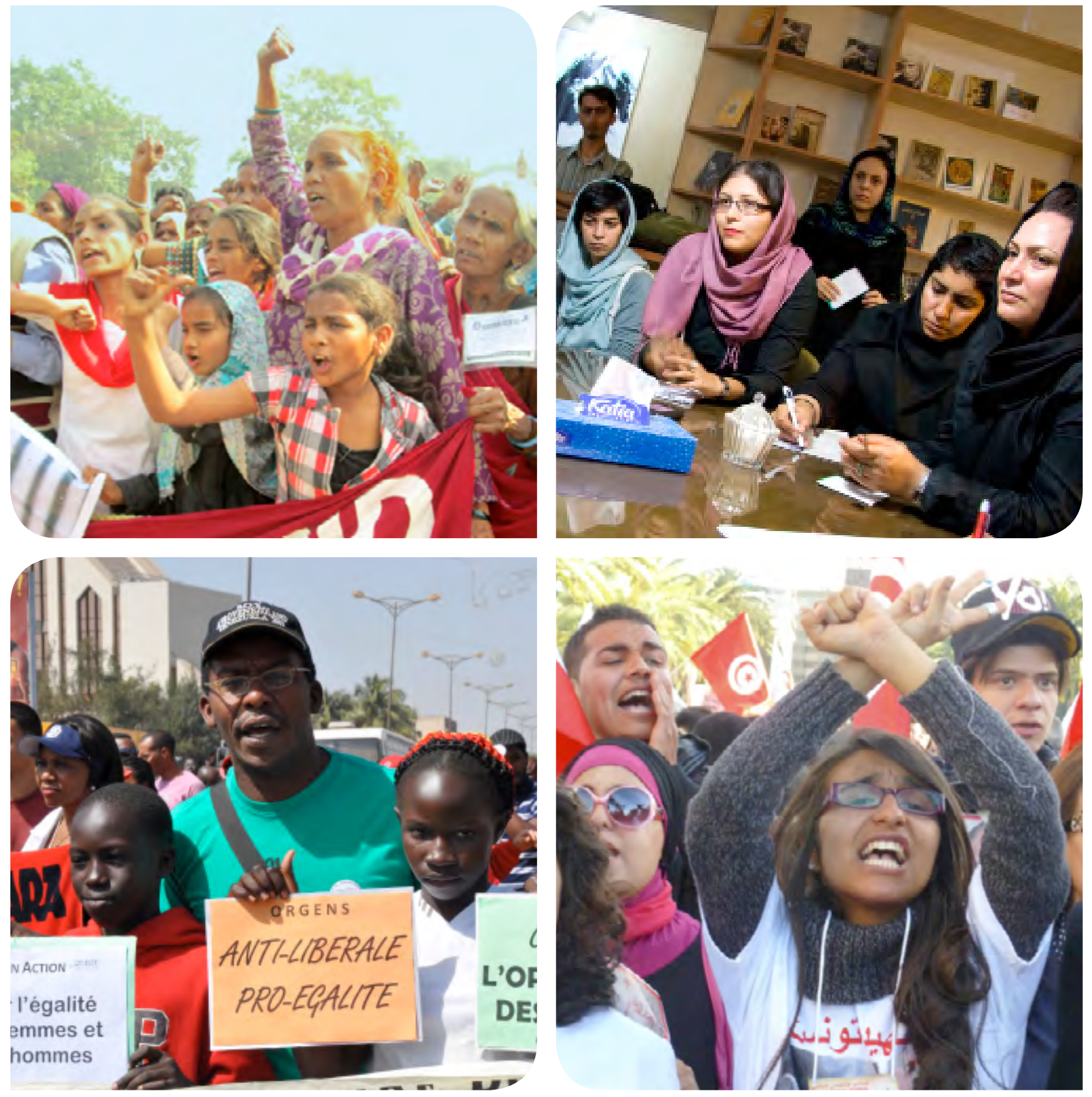


\section{Gender and Social Movements OVERVIEW REPORT}

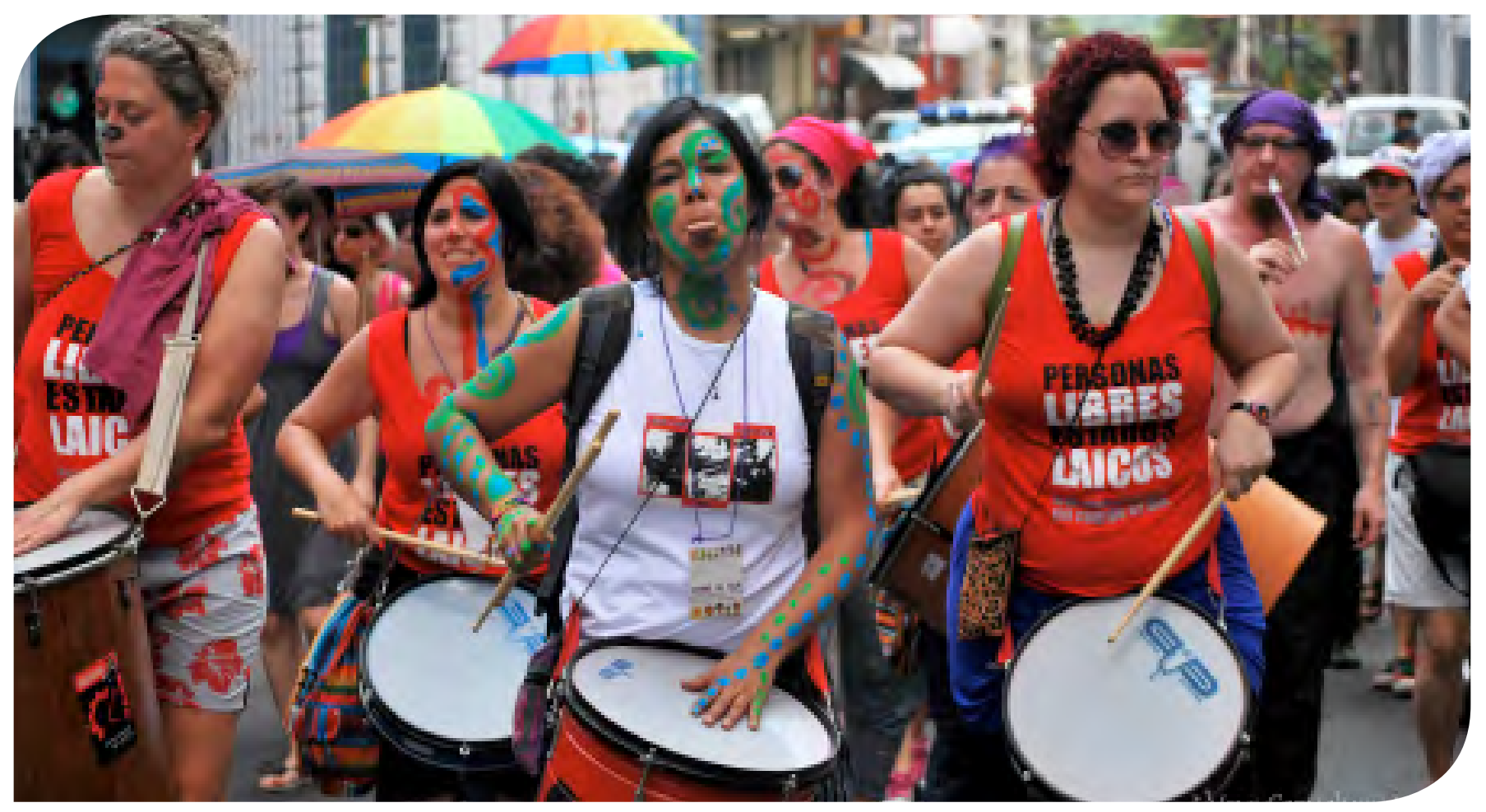

The power of the march, the power of the drums.

Photographer: Verónica Capriglioni

JESSICA HORN

2013 


\section{BRIDOGE \\ development - gender}

BRIDGE supports the gender advocacy and mainstreaming efforts of policymakers and practitioners by bridging the gaps between theory, policy and practice with accessible and diverse gender information. It is a specialised gender and development research and information service, one of a family of knowledge services based at the Institute of Development Studies (IDS) in the United Kingdom.

Other recent publications in the Cutting Edge series:

- Gender and Climate Change, 2011

- Gender and Governance, 2009

- Gender and Care, 2009

- Gender and Indicators, 2007

- Gender and Sexuality, 2007

- Gender and Trade, 2006

- Gender and Migration, 2005

- Gender and ICTs, 2004

- Gender and Citizenship, 2004

All BRIDGE publications can be downloaded free from the BRIDGE website. A limited number of paper copies are available on request to organisations based in the South (contact BRIDGE for more details).

\section{(6) II}

This publication is licensed under a Creative Commons Attribution 3.0 Unported Licence. This means that you are free to share and copy the content provided BRIDGE and originating authors are acknowledged.

Development Studies

(C) Institute of Development Studies 2013. IDS is a charity registered in England and Wales no. 306371 ISBN 978-1-78118-124-9

This Overview Report has been produced with the financial support of the Swedish International Development Cooperation Agency (SIDA) and the UK Department for International Development's (DFID) Mobilising Knowledge for Development Programme. Thanks also to the Swiss Agency for Development and Cooperation (SDC) and Irish Aid for their ongoing support of the BRIDGE programme. The views expressed in this publication do not necessarily reflect the official government policies of our funders.

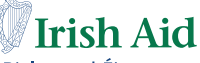

Rialtas na hÉireann Government of Ireland
Schweizerische Eidgenossenschaft
Confédération suisse

Confederaziun svizra

Front cover images clockwise from top right

- Journalists, lawyers and women's rights activists discuss Iran's polygamy laws. By Raha Asgarizadeh

- Young woman at the opening march of the World Social Forum, Tunis, 2013. By Jessica Horn

- During the World Social Forum in Dakar, 2011, families demand equality. By Marie Devers

- A new generation of young female activists in Bhopal accompanied by prominent women activists. By Reena Shadaan

Back cover images left to right

-The Madres de Plaza de Mayo, Buenos Aires, Argentina. By Natashe Dekker

- A young woman marching during the World Social Forum in Dakar, 2011. By Marie Devers

Copy editing by The Write Effect, design by Nim Design 


\section{Contents}

FOREWORD BY SRILATHA BATLIWALA i

ABOUT THE REPORT $\quad$ v

ACRONYMS Ix ix

$\begin{array}{lr}\text { EXECUTIVE SUMMARY } & 1\end{array}$

1 INTRODUCTION

$\begin{array}{ll}\text { 1.1. Why 'gender and social movements'? } & 9\end{array}$

$\begin{array}{ll}\text { 1.2. Why are social movements relevant? } & 10\end{array}$

1.3. Why are women's rights and gender justice critical 12 concerns for progressive social movements?

$\begin{array}{ll}\text { 1.4. What questions does this report explore? } & 13\end{array}$

1.5. What is meant by 'gender' in this report? 14

$\begin{array}{ll}\text { 1.6. Who is the overview report for? } & 15\end{array}$

$\begin{array}{ll}\text { 1.7. Scope, structure and additional resources } & 15\end{array}$

2 ENGENDERING SOCIAL MOVEMENTS:
EVOLUTION, DEBATES, DEFINITIONS AND RESOURCES

$\begin{array}{ll}\text { 2.1. How and why do social movements emerge and grow? } & 19\end{array}$

2.2. What are the defining features of social movements? 22

2.3. Fundamental concepts for understanding social movements 25

2.3.1. Common cause or common political agenda 25

2.3.2. Issues of representation: who can lead, who can speak for whom? 26

2.3.3. Social movements, inclusion and intersectionality 28

2.3.4. The 'deep structures' of movements 29

2.4. Relationships between social movements and organisations 30

2.4.1. The interconnectedness of movements and organisations 30

2.4.2. Tensions in the movement-organisation relationship 32

2.5. Social movements and money 33 
3.1. What are the defining features of women's and feminist movements?

3.2. How have feminist and women's movements evolved?

3.3. Intersectionality and inclusion in women's movements

3.3.1. Sexual orientation, gender identity and evolving understandings of gendered power

3.3.2. Men, masculinities and challenging patriarchal power

3.4. The impact of women's, feminist and gender justice movements

3.5. How are women's rights and gender justice included in the broader social movement spectrum?

3.5.1. Women-led movements for broad social change agendas

3.5.2. Men's movements for women's rights and/or gender justice

3.5.3. Mixed-gender movements that do not have women's rights or gender justice as a foundational focus

3.5.4. Mixed-gender movements with women as active leaders and members but without a central focus on gender justice

3.5.5. Mixed-gender movements with gender justice as a foundational axis

3.5.6. Alliances between women-led movements and other social justice movements

4.1. Barriers around the recognition of gender equality and

women's active participation as key issues within movements

4.1.1. Identifying inequalities 'among equals'

4.1.2. Instrumentalising women's participation

4.1.3. Divide and rule tactics around gender and sexuality

4.2. Gendered attitudes, behaviour and stereotypes ingrained within the 'deep structure' of a movement

4.2.1. Stereotypes about and backlash toward feminism

4.2.2. Sexual harassment and violence within social movements

4.3. Barriers posed by ideas around gender, culture, tradition and the private sphere 
4.4. Disparities and competition in movement priorities, allegiances and alliances

4.4.1. Hierarchies in movement priorities $\quad 57$

$\begin{array}{lr}\text { 4.4.2. Negotiating competing alliances } & 59\end{array}$

4.4.3. Differences within and between women's movements 59

4.5. Difficulties maintaining change and achievements in the longer term 60

4.5.1. Sustaining an intersectional approach 60

4.5.2. Sustaining gender transformation 'after the revolution' 61

4.5.3. Scaling up from initial change to movement wide transformation 63

5.1. What does a gender-just movement look like?

5.2. Recognise and transform culture, power dynamics and hierarchies within movements 66

5.2.1. Engage with the deep structure 66

$\begin{array}{ll}\text { 5.2.2. Politicise the personal } & 67\end{array}$

5.2.3. Acknowledge that change is emotional 68

$\begin{array}{ll}\text { 5.2.4. } & \text { Rethink masculinities }\end{array}$

5.2.5. Interrogate the gendered division of labour in movement practices 70

$\begin{array}{lll}\text { 5.3. } & \text { Support internal activism for change } & 70\end{array}$

5.3.1. Build collective power among women 70

$\begin{array}{ll}\text { 5.3.2. Build and support feminist leadership } & 71\end{array}$

$\begin{array}{ll}\text { 5.3.3. Develop women's platforms and caucuses } & 71\end{array}$

5.3.4. Work on movement politics, not just representation of women 73

5.3.5. Support and learn from individual change-makers 73

$\begin{array}{ll}\text { 5.3.6. Anticipate and respond to backlash } & 74\end{array}$

5.3.7. Acknowledge women's agency and avoid a 'victim' approach 75

5.4. Draw the line on impunity for gender-based violence 75

5.5. Develop the politics and make the arguments on gender and movements 76

5.5.1. Make women's rights and gender justice visible in movement agendas 77

5.5.2. Openly discuss what women's rights and gender justice means 77 for the movement

5.5.3. Agree movement-wide political positions and/or policies on gender 
5.6. Build inclusive alliances, shared analysis and common cause 79

5.6.1. Create spaces for dialogue to build understanding between 79 movements and activists

5.6.2. Use intersectional analysis to find areas of common struggle 80

5.6.3. Highlight the history of women's activism in forging alliances 80

5.7. Expand inclusion within women's movements 82

5.8 Operationalise gender justice within movements and movement-linked organisations 83

5.8.1. Harness and adapt organisational change strategies and techniques 83

5.8.2. Measure and track movements' records on women's rights and gender justice 83

5.9. Remain attentive to movement-organisation power relations 84

5.9.1. Better align donor practice with movement methods and needs 84

5.9.2. Consider how organisational resources can contribute to movement-building 85

5.10. Stay with it, and support change over time 86

6 REFLECTIONS AND AREAS FOR FURTHER EXPLORATION 88

$\begin{array}{llr}\text { 6.1. } & \text { Reflections } & 89\end{array}$

\begin{tabular}{ll} 
6.2. & Areas for further exploration \\
\hline
\end{tabular}

7 BIBLIOGRAPHY

8 


\section{Foreword by Srilatha Batliwala}

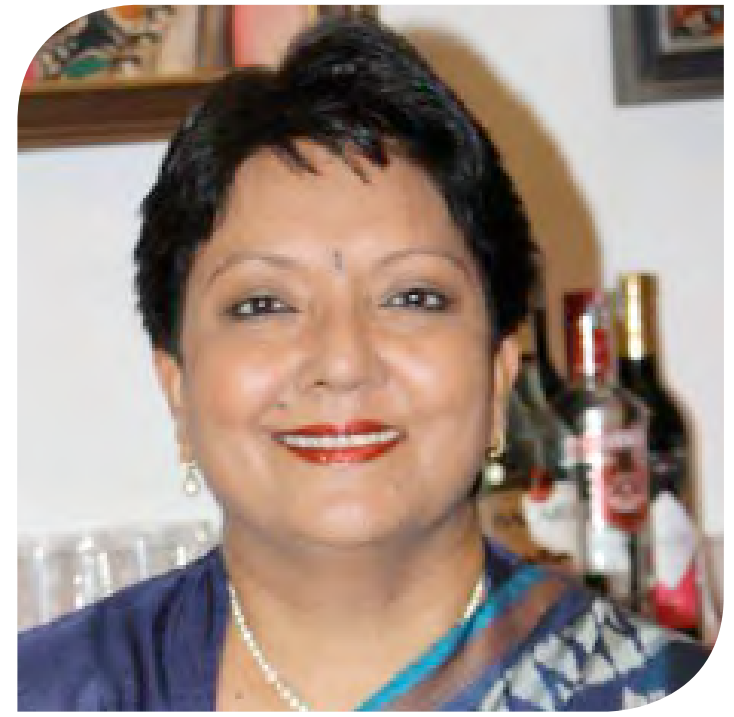

Lead adviser for the BRIDGE

Cutting Edge programme on

Gender and Social Movements

On December 16th 2012, in India's capital city of New Delhi, a young girl was gangraped and brutally assaulted for resisting her attackers. She died a few weeks later from the severe internal injuries inflicted upon her - but not before cities across the nation erupted in a wave of protests that brought men and women of all ages and classes onto the streets, demanding an end to violence against women and more stringent laws to punish the guilty. People like me, veterans of the Indian women's movement, were amazed and bemused by this spontaneous demonstration of outrage, around what had just a decade earlier been considered a 'women's issue'. We watched the media coverage and could barely comprehend the meaning of the vast sea of men in the protesting crowds - especially young men, marching or sitting in vigil beside young women, and hoisting placards that read 'When will we learn' and 'Harming women does not make you a man - only a demon.' One middleaged man had his head shaved in public, a traditional act of mourning.

\author{
'If I should cease to work, these \\ worlds would fall in ruin and I should \\ be the creator of disordered life and \\ destroy these people' \\ (Lord Krishna to Prince Arjuna \\ in The Bhagavad Gita, III.24).
}

Somehow, somewhere, a powerful shift had occurred - this young girl's rape and murder, and the thousands of rapes, murders, and more mundane indignities women and girls suffer in daily life, was no longer a women's issue, or the responsibility of women's rights organisations or women's movements at large. It was everyone's issue, because it was everyone's shame. In fact, the traditional feminist groups of Delhi and elsewhere were barely visible in the media coverage, nor was their role pivotal on the ground. As protesters sat in candlelight vigils, there was passionate discussion: this was a product of the society that we had all constructed, together; we had all colluded in sustaining or escalating this mass injustice, mostly through our silence or indifference. The problem did not lie in weak laws or their poor implementation - though both these were certainly in urgent need of reform - but in the cultural and social norms that sanctioned the subordination of women in multiple forms, and provided unquestioned privileges to men. 
Even as my heart broke for that young woman struggling for life, it rejoiced at the words of the young women and men interviewed on television, at the words inscribed on countless placards: 'Teach your sons not to rape', 'Teach your sons to respect women', 'I am a woman, I am free, I will go anywhere, anytime'. Protests, marches, and vigils were being organised by groups across the widest possible spectrum - from neighbourhood residents' associations to human rights groups and youth organisations. It seemed as though our feminist dream that one day, all society would wake up and take ownership of the need to empower women and guarantee gender equality, had actually come true.

Watching and listening to these dramatic events unfold, my thoughts inevitably drifted back to a time, fifteen years earlier, when I was on the faculty of the National Institute of Advanced Studies (NIAS) in Bangalore, in South India. I had the unenviable task of teaching the modules on 'The Status of Women in India' in the executive education courses run by NIAS for senior government officials, defence and police officers, and corporate CEOs. The participants were all male - with one or two exceptions - and this was always the least popular set of sessions in the entire three-week course. "Another of those aggressive man-hating, biased feminists, giving us a lot of lies and distorted facts" they would snigger in the hallways, irked by the relentless picture of discrimination that I painted through their own statistics: of declining sex ratios, huge levels of maternal and female infant mortality, the disproportionately high drop-out rates of girls between primary and middle school, the feminisation of the child labour force as girls were sent out for waged work so their brothers could stay in school, and the increasing crimes against women, accompanied by pathetically low prosecution rates.

But while some were dismissive, others were deeply disturbed by this seemingly silent, unrecognised war against women. Inevitably, one of them would ask: "What is the women's movement doing about this? How can they keep quiet if the situation is this bad?" This was the opening I was waiting for, and I would relate my customary parable...

"Let us assume there is an outbreak of rabies in the city. A number of rabid street dogs have been biting innocent pedestrians. Who is responsible for tackling this problem - the rabies survivors, or perhaps their families? Or the entire city administration, the health department, and citizens' groups in every neighbourhood?" The penny had always dropped by this point, of course, so that I was able to ask: "Why is it that when it comes to crimes against women, or the systematic discrimination against women that is embedded in all our institutions - from the family and household, to our economic, health and education systems, or the unfair way resources are owned and distributed - we seem to feel it is the women's movement's responsibility to remedy this injustice?"

This, in a sense, is the question at the heart of this report - but we are asking it of our seemingly natural allies: the leaders and activists of other social justice movements. What responsibility have you taken to relieve the world of its most persistent, widespread, resilient and deep-rooted social injustice - the subordination of one half of humanity?

There is a strange character to injustice - it often seems to blind its victims to other forms of injustice. Movements against injustice carry the same trait: even as they mobilise outrage and a demand for change among their own constituency, they can be blind to other injustices, and especially to those practiced within and by their own ranks. The sense of righteousness about their cause often results in a narrow, myopic, and exclusionary view - a hierarchy of injustices where theirs sits at the top, 
more urgently in need of redress than any other. This syndrome is especially evident in the context of gender relations because women's subordinate position, and the gendered division of labour, privilege, decision-making power and leadership, has been so normalised, so deeply embedded in the fabric of daily life, that it is invisible unless we consciously search for its manifestations.

So even as social justice movements engage in struggles for a diversity of economic, social and political rights, the aspirations and interests of women within these are either forgotten, assumed to be the same as men's, or equally advanced by the movement's strategic agenda. Worse, many movements have actively opposed a focus on gender issues as divisive and disruptive of the larger struggle, and ironically, accuse women's movements of being too exclusive and myopic in their focus. The result is that there are very few social justice movements in the world that have authentically integrated gender justice within their worldview and strategies for change.

What is remarkable though, is that while this problematic has existed for a long time, and has been a source of great tension between women's movements and other social justice movements, it has never been systematically analysed, much less addressed. This is why we owe a huge debt to the BRIDGE programme at the Institute for Development Studies - for recognising the huge gap in our understanding of this dynamic, and for initiating a truly global and participatory process for addressing it constructively.

The BRIDGE Gender and Social Movements Cutting Edge programme has been path breaking at many levels. It began with constituting a committed international team of advisers who come from both women's movements and other social justice struggles - but each of us cared deeply about the subject at hand, and gave the process our utmost. Another unique feature of the methodology was the use of e-discussions to amplify different voices and perspectives on the issues at stake. Participants in the e-discussions came from North and South, from every corner of the globe, and represented an extraordinary range of experiences and perspectives as activists, advocates and scholars. What was a genuine surprise, however, was the incredible energy, enthusiasm and even passion that the discussions elicited. It was immediately clear that this was a long-awaited space for a long-awaited debate - there was a depth and breadth of experience on gender and social movements that was waiting to be articulated, shared, analysed, and understood. It is no wonder then that the discussions themselves became a rich source of research data for this report, contributing authentic experiences and ideas from diverse political and movement locations.

The case studies commissioned as part of the programme were also revelatory. The challenges that women face in being heard or advancing their interests within movements like Occupy and Via Campesina, despite being a huge part of the mass base of those movements, are sobering reminders of how far we have to go before even our more progressive and radical struggles for social justice can claim to have addressed the patriarchies within. The case study of Amnesty International, a key organisation of the human rights movement, provides an example of the journey (albeit uneven and as yet incomplete) of an organisation and the movement it represents to uproot its internal asymmetries and begin to move towards a more gendered approach.

The report you are about to read is a brilliant synthesis of this enormous breadth and depth of information. Our skilled author, Jessica Horn, takes us on a fascinating journey that traverses every facet of the gender and social movement conundrum and presents 
us with a unique gift: a state-of-the-art document on a critical issue whose time has come. This report represents the most comprehensive and multi-faceted analysis, to date, of the challenges of and pathways to mainstreaming gender justice goals and practices in social movements. Its power lies in understanding that gender justice falls off the agenda of progressive movements not because they don't care, but more often because they don't know how to situate and integrate it within other movement goals and processes. By offering strategies that have been harvested from the wisdom and practices of many committed activists and movements around the world, it bridges this gap, and gently compels others to follow suit.

While social movements will gain a lot of strategic insights on how to strengthen their work on gender, they are not the sole audience that this report was written to influence. Women's movements will equally benefit from the analysis and ideas it offers - not only on how to build relationships with and gain support from other movements, but to introspect on their own exclusionary practices.

Donors who are committed to supporting progressive social justice work also have a good deal to build on from the report's analysis of what obstructs and what facilitates social movements to better embrace and effectively advance gender equality goals from within all their varied locations and agendas.

The world and its people are transiting through one of the most difficult and precarious moments in history - there is a worldwide economic and financial system crisis; an environmental and climate change crisis; wars and conflicts abound; criminal and terror networks and fundamentalisms of various hues are gaining ground. At no time in human history has there been greater prosperity or more destitution. Women, especially poor women, and people of non-male genders, are the worst affected by all these forces. Even as - or perhaps because - the past century of women's movements have made unprecedented gains for women, the ferociousness of the backlash against them, including in the form of increasing violence against women and girls and those who defend women's human rights, is intensifying and spreading across the globe in frightening ways.

So it is time. Time for all right thinking people and their struggles for social justice to listen and learn from the young people on Delhi's street corners - to realise, once and for all, that gender justice is their issue. It cannot wait to be addressed 'after the revolution' - it is an integral part of the revolution. There can be no social justice without gender justice. We are proud that this report helps show the way forward for all those who wish to act on this simple but profound truth.

Srilatha Batliwala

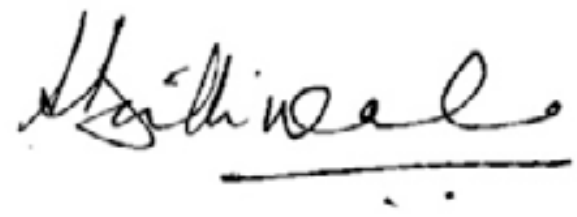

July 2013

Bangalore, India 


\section{About the Report}

This report has been developed as part of the BRIDGE Cutting Edge Programme on Gender and Social Movements. Over a three year period, we have taken a collaborative and participatory approach, working with over 150 social movement activists, practitioners, scholars and supporters from around the globe.

This approach has resulted in the multiplicity of voices, experiences, ideas and previously unpublished insights that you will find in the report, and it means that the findings and recommendations have been developed as part of a rich participatory process. Below are details of the key actors in the development of this report.

\section{The Author}

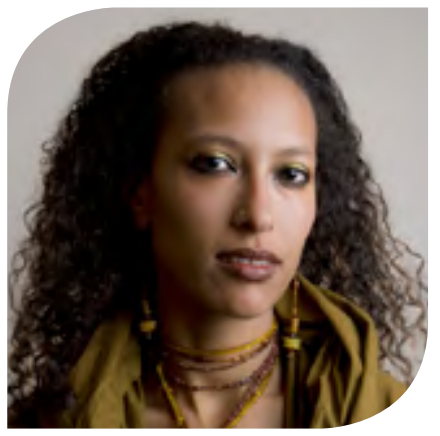

Jessica Horn is a women's rights consultant and writer. She has worked with NGOs, progressive donors, and the United Nations around rights, justice and the body advancing sexual rights, ending violence against women, supporting women living with HIV, researching religious fundamentalisms and ensuring women's rights in conflict-affected contexts. Jessica is a founding member of the African Feminist Forum, and was lead curriculum developer and trainer for Fahamu's flagship Movement Building Bootcamp for African activists. She serves Jessica Horn as board member of women's funds Mama Cash and Urgent Action Fund-Africa, and is co-editor of the Our Africa platform on openDemocracy. Jessica holds a BA in Anthropology from Smith College and an MSc in Gender and Development from the London School of Economics.

\section{The programme advisory group}

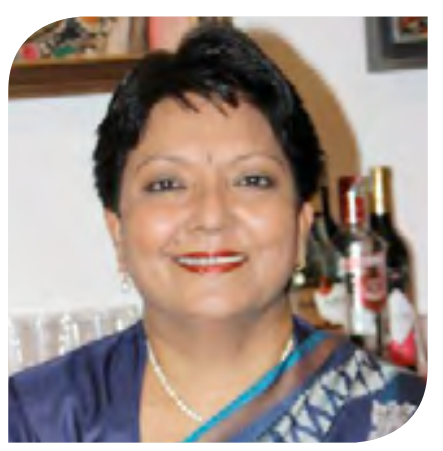

Srilatha Batliwala (Lead Adviser)
Srilatha is a feminist activist and researcher who is currently Scholar Associate with the Association for Women's Rights in Development (AWID). Srilatha has worked for gender equality and women's empowerment for the last 40 years through grassroots activism, advocacy, research, training, building theory from practice, and organisational capacity building. Srilatha has written extensively on women's issues and is well known for her publications on women's empowerment, transnational civil society, women's movements, feminist leadership, and monitoring and evaluation of women's rights. Her current work focuses on feminist movement building, measuring the impact of women's rights work, and building the analytical and strategic capacity of young women activists. 


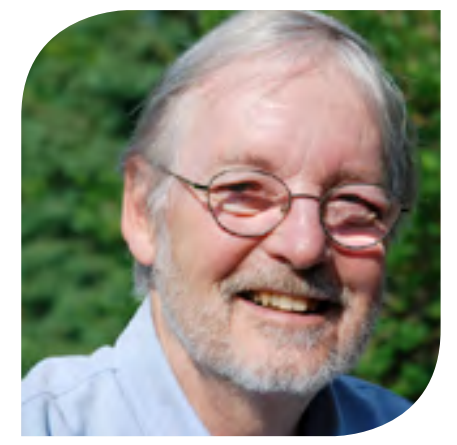

David Kelleher

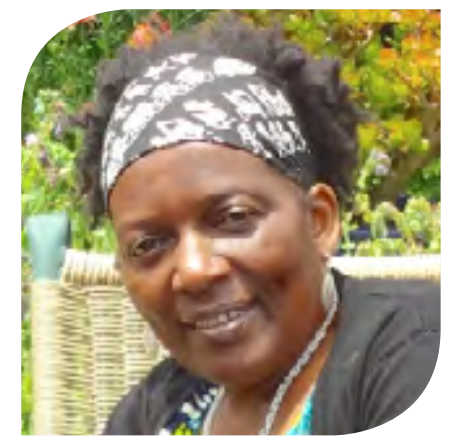

Hope Chigudu

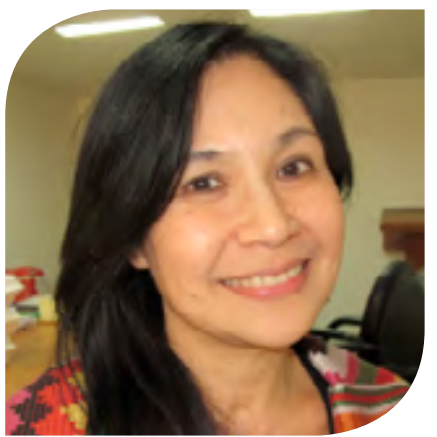

Marivic Raquiza
David is an organisational consultant and a co-founder and Senior Associate of Gender at Work, a global knowledge and capacity-building network on institutional change for gender equality. For more than 35 years, David has worked with numerous nongovernment and public organisations helping them build their capacity to further social change. He has served in various roles with Amnesty International including as President of the Board of Directors for Amnesty Canada and has been a member of the Board of Directors and Executive Committee of the Association of Women's Rights in Development (AWID).

A sociologist by training, Hope holds a MA in Development Studies. After a start in the corporate world, feminism opened Hope's eyes and she joined the Ministry of Women's Affairs in Zimbabwe. Later she became a founding member of the Zimbabwe Women's Resource Centre and Network. As a renowned gender equality activist and consultant, Hope has supported a great many African and international justice groups, working in most African countries from Ghana to South Africa and serving on the boards of the Global Fund for Women, Just Associates and Urgent Action Fund and on the working committee of the African Feminist Forum.

Marivic is Assistant Professor at the National College of Public Administration and Governance of the University of the Philippines. As co-Convenor of Social Watch Philippines, she actively campaigns for policies and engages in political action to combat poverty and inequality, and fights for women's rights at national, regional and global levels. Marivic has sat on the boards and leadership bodies of various civil society organisations at national, regional and global levels. She has a MA in Development Studies and is currently pursuing her Ph.D. studies at the City University of Hong Kong. 


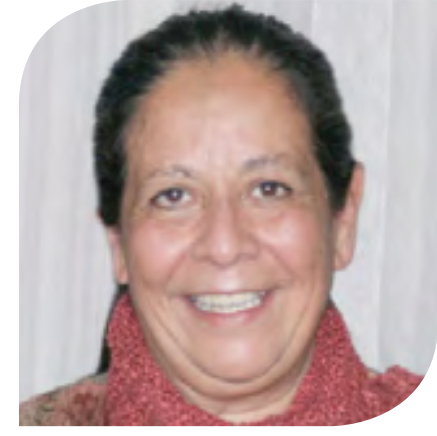

Patricia Ardón

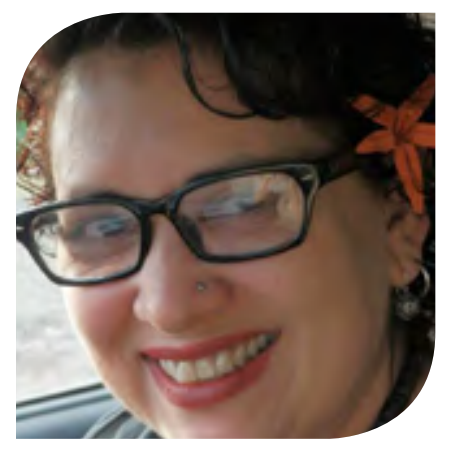

Sharon Bhagwan Rolls

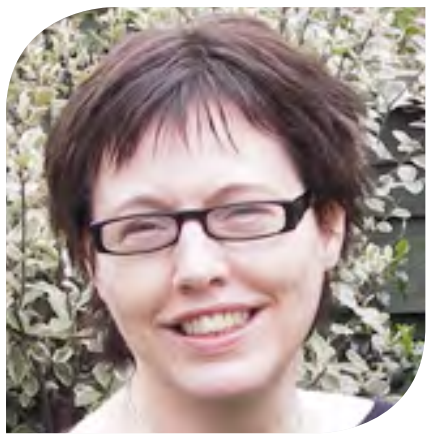

Hazel Reeves

(Programmatic Adviser)
Patricia has been working in development, women's rights and human rights and peace building initiatives with national, regional and international organisations as well as at the community level for more than 30 years. She is the founding Director of Sinergia No'j of Guatemala, which works to strengthen the leadership of women, especially indigenous women. At present, she is an adviser and a member of the Mesoamerican team of the international women's network Just Associates (JASS) which provides leadership training and political support for women's rights.

Sharon is a media professional who initiated the establishment of FemLINKPACIFIC - a feminist community media NGO that works to increase the visibility of gender issues and women's stories and to ensure conflict prevention through community media initiatives. She set up the regional women's media and policy network on UN Security Council Resolution 1325 and was subsequently appointed to the UN Civil Society Advisory Group on UNSCR 1325 Women, Peace and Security. Since December 2010 Sharon has been the co-chair of a Pacific Working Group on Women, Peace and Security.

Hazel is a consultant and member of the BRIDGE International Advisory Committee. She was formerly Programme Manager at the Institute of Development Studies with the Pathways of Women's Empowerment research consortium and was the manager of BRIDGE for many years. Hazel has extensive experience in research and communications aimed at engaging policy actors and others in the international policy arena and of coordinating policy-oriented communications on issues of gender equality and women's empowerment. 


\section{The community of practice}

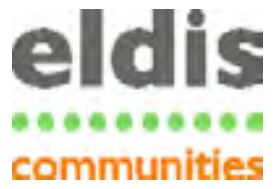

\section{The BRIDGE team}

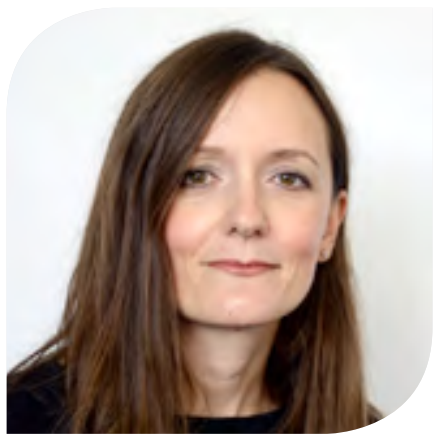

Jenny Birchall

(Programme Manager)
Over 150 scholars, activists and practitioners came together during the programme to form a community of practice on gender and social movements. Members of this group took part in a series of five e-discussions in order to discuss, debate and document the challenges, barriers and success stories around integrating women's rights and gender justice into social movements' external agendas and internal politics. Two initial global e-discussions were held, followed by more tailored discussions for young activists, Spanish speaking activists and scholars, and gender equality advocates working within mixed-gender social movements. Community of practice members have also created a range of fascinating and informative case studies and audio visual materials, all of which can be found at our gender and social movements website. A full list of participants can be found at the end of the report.

Jenny is Gender Convenor at BRIDGE and has worked for the last ten years in the field of equality and human rights. She has written on gender and public space, equality and the workplace and gender and migration. She has a Ph.D. in Women's Studies from the University of Manchester.

Jenny received vital support and advice throughout the programme from several colleagues and external specialists including Alyson Brody, Adrian Bannister, Alia Khan, Amy Hall, Amy Thompson, Angela de Prairie, Aurélie Cailleaud, Devangana Kalita, Elaine Mercer, Emily Esplen, Georgina Aboud, Helen Dixon, Laura Asturias, Paola Brambilla and Peter Mason, as well as the BRIDGE International Advisory Committee.

Our partners at SendasAL and Genre en Action played important roles in the programme, advising on methods to reach non-English speaking contributors and audiences and hosting e-discussions. 


\section{Acronyms}

AIDS Acquired Immunodeficiency Syndrome

CEDAW Convention on the Elimination of All Forms of Discrimination against Women

CLOC Coordinadora Latinoamericana de Organizaciones del Campo (Coordinating Network for Latin American Rural Organisations)

GPPAC Global Partnership for the Prevention of Armed Conflict

HIV Human Immunodeficiency Virus

ICTs Information and communication technologies

LGBTI Lesbian, gay, bisexual, transgender and intersex

LGBTIQ Lesbian, gay, bisexual, transgender, intersex and queer

NGO Non-governmental organisation

UN United Nations

WSF World Social Forum 


\section{Executive Summary}

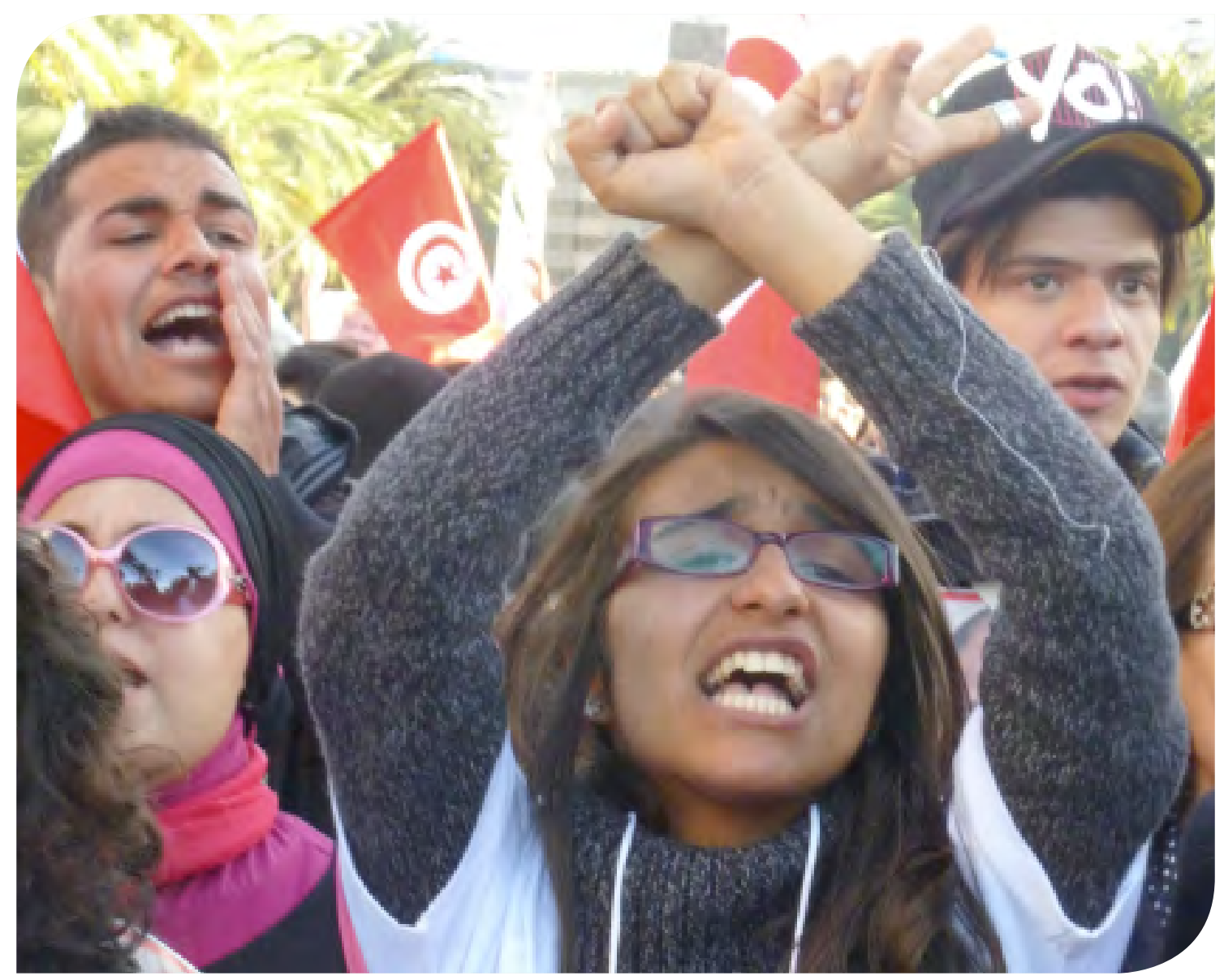

Young Tunisian woman at the opening march of the World Social Forum, Tunis, March 2013.

Photographer: Jessica Horn

\section{Why gender and social movements?}

Across the world there is an active, mass-based demand for an end to gendered injustice in all domains of our social, economic, political and cultural lives.

Social movements - led by feminist, women's and gender justice activists and movements - have been pivotal in demanding, making and sustaining these changes.

However, while women's rights and gender justice are 'on the agenda' in many arenas, activists still encounter strong resistance to changing gendered politics and practices within movements and allied organisations. When it comes to making an impact on transforming gender power relations, social movements matter.

Social movements are forms of collective action that emerge in response to situations of inequality, oppression and/or unmet social, political, economic or cultural demands. They are comprised of 'an organised set of constituents pursuing a common political agenda of change through collective action' (Batliwala 2012: 3). Social movements are not inherently progressive. Religious fundamentalisms, neo-Nazism and ethnic nationalism have all been rooted in and propagated by social movements. Drawing on first-hand examples from different global regions, this report considers enabling factors and barriers encountered when attempting to integrate women's rights and gender justice into progressive social movements that have a base of common politics that affirms inclusion, rights and the equitable redistribution of power. 


\section{Why are women's rights and gender justice important concerns for social movements?}

In order for any action or intervention around rights, democracy and equality to be successful, it must include and value gender equality as part of its analysis and methodology for change. Without this, interventions are unlikely to succeed in their goals of contributing to equality ${ }^{1}$ for all and more holistic and complete social transformation.

Integrating gender perspectives is not just about 'including' women or 'thinking about' men and gender minorities but, rather, considering what a gendered politics provides in terms of alternative ways of being, seeing and doing that in themselves serve to transform patriarchal power relations. ${ }^{2}$

\section{How do progressive social movements think about and act on women's rights and gender justice?}

There is great diversity in the ways that women's rights and gender justice issues have been approached in movements with different gender constituencies ${ }^{3}$ and political foci, as the box below demonstrates.

\section{Women's rights and gender justice across the social movement spectrum}

Women's movements for women's rights and gender justice

The majority of historical and contemporary activism on gender justice has been led by women and in all-women movements for change. Progressive women's movements are united around a common cause of challenging gender inequalities and injustices in society, although there is diversity in perspectives on this, including from the vantage points of race, class, ability, age and sexual orientation.

Women-led movements for broad social justice agendas

Women have also led activism for broader social and political change using approaches that acknowledge both gender inequities and political, social or economic issues, resulting in broad societal or political change and increased rights and justice for women.

Men's movements for women's rights and/or gender justice

Male gender equality activists have developed theoretical and practical insights into the ways patriarchal power affects men and boys, questioning definitions of masculinity, including social norms, expectations and behaviours around men's labour, relationships in the family, sexuality, self-care and violence and aggression; and considering how men can relate to women in more egalitarian ways.

1 An equal society is one in which everyone can flourish. The diverse needs, situations and goals of individuals are recognised, discrimination and prejudice are removed, and the economic, political, legal, social and physical barriers that limit what people can do and be are tackled (Burchardt and Vizard 2007).

2 The term patriarchy is used to describe systemic and institutionalised male domination and the cultural, political, economic and social structures and ideologies that perpetuate gender inequality and women's subordination (Just Associates 2012).

3 The term movement constituencies means the individuals and groups that make up the membership of a social movement. 


\section{Mixed-gender movements that do not have women's rights and gender justice as a} foundational focus

Historically, most progressive social movements have not embraced a commitment to consider gender inequality or challenge patriarchy from the outset. Frequently, gender analysis and action begins in mixed movements when women activists start to question why they are being left out of movement visions or not acknowledged in movement leadership.

Mixed-gender movements with women as active leaders and members but without a central focus on gender justice

There are many examples of progressive social movements where women play active roles by making up the majority of movement membership or acting as movement leaders, and yet the movements do not have an explicit gender focus. This underscores the point that the presence of women in a movement does not guarantee that they or the movement will have an explicit focus on women's rights and gender justice.

Mixed-gender social movements with gender justice as a foundational axis Although less common, there are movements that are founded on intersectional politics, including analysis and action on gendered power as central. These tend to be movements that have a direct political continuity with spheres of action where feminism has broken ground - for example, on bodily integrity and autonomy and gender identity - and movements where feminists have been influential as founders.

Alliances between women's movements and other movements for change

Women's movements may form short- or long-term alliances with other social movements in the context of campaigns, uprisings and protests or as part of general solidarity and seeking common cause. Positive results can emerge from such alliances, although women's movements sometimes face the challenge of reciprocal solidarity - where women's movement actors often stand 'side by side' with broader movements, other social movement actors will not always step up in defence of women's movement agendas.

\section{What are the challenges for social movements in integrating gender perspectives?}

Women's rights and gender justice advocates experience some common challenges when working to build commitment in their movements to gendered political concerns. These can be grouped into the following areas:

\section{Barriers around the recognition of gender equality and women's active participation as key issues in movements}

Resistance to integrating women's rights and gender justice as a key movement priority can often take the form of dismissing the significance of gender equality - for example, it is argued that there are already plenty of women movement members; therefore, gender can't be a problem; or specific actions on women's rights and gender justice are not necessary because the movement is already about democracy or inclusion. 


\section{Gendered attitudes, behaviour and stereotypes ingrained within the 'deep structure' of a movement}

The ideas and behaviours existing at informal level within a movement's 'deep structure $^{4}$ can create profound challenges for the realisation of women's rights and gender justice as external and internal priorities. Within movements many women face the expectation of playing caring roles, providing emotional support for movement members or taking on the 'back office' administrative tasks. Deeply ingrained ideas on gender roles can lead to, and allow impunity for, sexist, discriminatory and even violent behaviour towards women and minority groups. Such behaviour is political in its impact, with the effect of re-entrenching deeply held normative beliefs around gendered roles.

\section{Barriers posed by ideas around gender, culture, tradition and the private sphere}

Advocates for women's rights and gender justice within movements face particular challenges around making gender inequality in the private sphere visible and recognised. Ideas about tradition, culture and religion can be used to marginalise and silence those who speak up about gendered power in areas such as the family and on topics such as abortion, making it extremely difficult for such areas to become accepted and common topics in movement agendas and discussions.

\section{Disparities and competition in movement priorities, allegiances and alliances}

Integrating women's rights and gender justice into movement agendas is made more difficult where gender equality is seen as a moveable priority. Across history, women who have participated in community struggles have faced the suggestion that women's rights are issues to be dealt with 'after the revolution'. It is also often the case that 'trade-offs' take place in movement agendas, with gender equality issues dropped when their presence threatens solidarities with other constituencies or demands. Even within women's and feminist movements there are disagreements and hierarchies, particularly around recognising and acknowledging women's diverse identities. This inhibits the potential for women's and other social justice movements to build strong, progressive alliances.

\section{Difficulties in maintaining change in the long term}

Even as social movements succeed in attracting women members, building women's leadership and encouraging thinking about what gender equality means in the context of their agendas, challenges arise in keeping up momentum. It is often difficult to sustain progress after a shorter change goal is achieved, to maintain an intersectional approach $^{5}$ or to build on initial achievements to ensure that women's rights and gender justice remain a constant area of focus.

4 'Deep structure' describes hidden layers within organisations and movements where unconscious or even conscious but hidden processes occur, including assumptions taken for granted about gender roles and the place of women (Rao and Kelleher 2005; Srilatha Batliwala, BRIDGE e-discussion March 2012).

5 Intersectionality is a conceptual framework that makes visible the multiple discriminations that people face, the ways in which systems of oppression (e.g. those framing gender, race, class, sexuality, ability) interact with each other, and thus the activist imperative to name and challenge multiple inequalities as part of seeking justice for different constituencies of women. 


\section{What does a gender-just social movement look like?}

While social movements vary in their outlook and methods across contexts, there are similarities in how movements respond to the question of gender and the emergence of challenges to patriarchal power both within movements and in the external environment that they are situated in. The following box suggests some possible components of gender-just movements. These components function like enabling conditions, creating a supportive environment that allows for deep reflection, revision and action, and sustains commitment to women's rights and gender justice over time.

\section{A gender-just social movement}

- Affirms the importance of tackling gender inequality and patriarchal power as an integral component of justice for all and names this as an explicit priority for action.

- Creates a positive environment for internal reflection and action on women's rights and gender justice.

- Provides active and formalised support for women's participation and leadership in all areas of movement practice.

- Consistently tackles gender-based violence and establishes zero tolerance for sexual harassment in movement spaces.

- Assesses gender bias in movement roles and redistributes labour along genderjust lines.

- Enables full participation of both women and men, taking into account care work and reproductive roles.

- Appreciates the gender dimensions of backlash and external opposition faced by activists.

- Engages with norms and notions around gender, taking into account context-specific gender identities, trans and intersex identities and shifting understandings of gender in social life and activism.

\section{How can we build gender-just social movements?}

There is tremendous diversity in social movement practice across contexts, so there is no straightforward 'recipe for change'. But experience shows that change is easier if a number of elements are in place to help alter both internal power dynamics and external strategies so that they are more inclusive of gendered politics.

\section{Recognise and transform culture, power dynamics and hierarchies within movements}

By making visible the way that gendered power is understood and practised in the 'deep structure' of movements we can challenge the hidden and invisible power dynamics that make movement participation uncomfortable or unbearable for women and gender minorities, allow gender-based violence to continue within activist spaces, and undermine the lived politics of a movement. 


\section{Support internal activism for change}

The most powerful accountability mechanism in any movement is its own constituency. It is, therefore, vital to consider and support initiatives by movement members that call for women's rights and gender justice to be addressed in their movements' politics and practices. This might involve supporting both women's collective power and individual change-makers, building feminist leadership, developing platforms and caucuses on equality, and anticipating and responding to backlash.

\section{Draw the line on impunity for gender-based violence}

Holding movement members to account for ethical conduct around gender relations be it in public or private - is essential in creating gender-just movements. This includes issues such as domestic violence or sexual harassment by movement members, be it to others in their movements or in their personal lives. It also includes challenging impunity and the failure of movement leadership to take a stand against discrimination or violence within movements.

\section{Develop the politics and make the arguments on gender and movements}

Political visions are what make a movement, and taking a position on gendered injustice and oppression is a necessary component of building gender-just movements. Elements of this process may include making women's rights and gender justice clearly visible in movements' external agendas, and creating spaces for learning and for open discussions on what a gender focus will mean in different movement contexts.

\section{Build inclusive alliances, shared analysis and common cause}

The important process of building alliances and finding common cause between feminist and other social movement politics involves openness to critique and a desire to listen and to change. Intersectional analysis is a useful tool for movements to help identify how different axes of power intersect and to define areas of common struggle between social movements. Common cause may be built around a need to unite against common adversaries, but in the process, movement actors may build longer-term relationships.

\section{Expand inclusion within women's and feminist movements}

Women's movements are not static; they emerge, grow and change in response to internal and external factors. Challenging inequalities and the exercise of discriminatory power within women's movements needs to be ongoing, as movements self-critique and work towards increasingly inclusive politics of transformation. This in turn strengthens solidarities with other movements that women's movement members are a part of, and contributes to pushing progressive politics forward.

\section{Operationalise gender justice in movements and movement-linked organisations}

In many cases movements have an organisational base or platform relevant to or influential in guiding movement thinking and practice. This base can play a key role in determining whether and how women's rights and gender justice are embraced. Organisational change strategies and auditing and evaluation approaches, if adapted and developed for specific movement contexts, can help to support this process, with senior-level commitment a key driver for strategies to transform internal culture and external political agendas. 


\section{Remain attentive to movement-organisation power relations}

Relationships between movements and organisations are multifaceted: organisations may support movements; movements may be allied with organisations or even create them. It is critical to be alert to the tremendous opportunities as well as tensions involved in these interactions. Organisations explicitly dedicated to movement-building and support should consider how they can encourage and support movements to be inclusive, tackle new forms of oppression and recognise emerging constituencies. Donors should take steps to align their practices with requirements for gender-just movement-building and longer-term transformation.

\section{Stay with it, and support change over time}

Time is an important factor in social movement development and success. While individual campaigns or instances of uprising for change may take place within a fixed timescale, the broader struggle for women's rights and gender justice remains ongoing. Success can bring backlash, and new forms of injustice, marginalisation and inequality emerge as mainstream power takes on new forms or extends its reach in new domains. While shifts in how movements engage with gender are important, the real test is sustaining this respect and working on the full integration of women's rights and gender justice over time.

\section{Areas for further exploration}

While this report begins a process of discussion on routes for gender-just change in social movements, it is clear that, going forward, further work in a number of areas would be extremely useful. These include:

- Practical guidance on methods and practices for transforming deep structures in social movement contexts.

- Discussions on ways to formalise accountability mechanisms on gender justice in movements.

- Deeper analysis on how to build effective and equitable alliances.

- Work to support and invest in the development of gender-just social movements.

- Further research, documentation and analysis on the history of women's and feminists' activist involvement in progressive social movements across the world.

It is hoped that the process begun in this report can continue and grow, and that more gender-just movements can be built, supported and experienced, ultimately contributing to changing our societies towards full justice and equality. 


\section{Introduction}

1

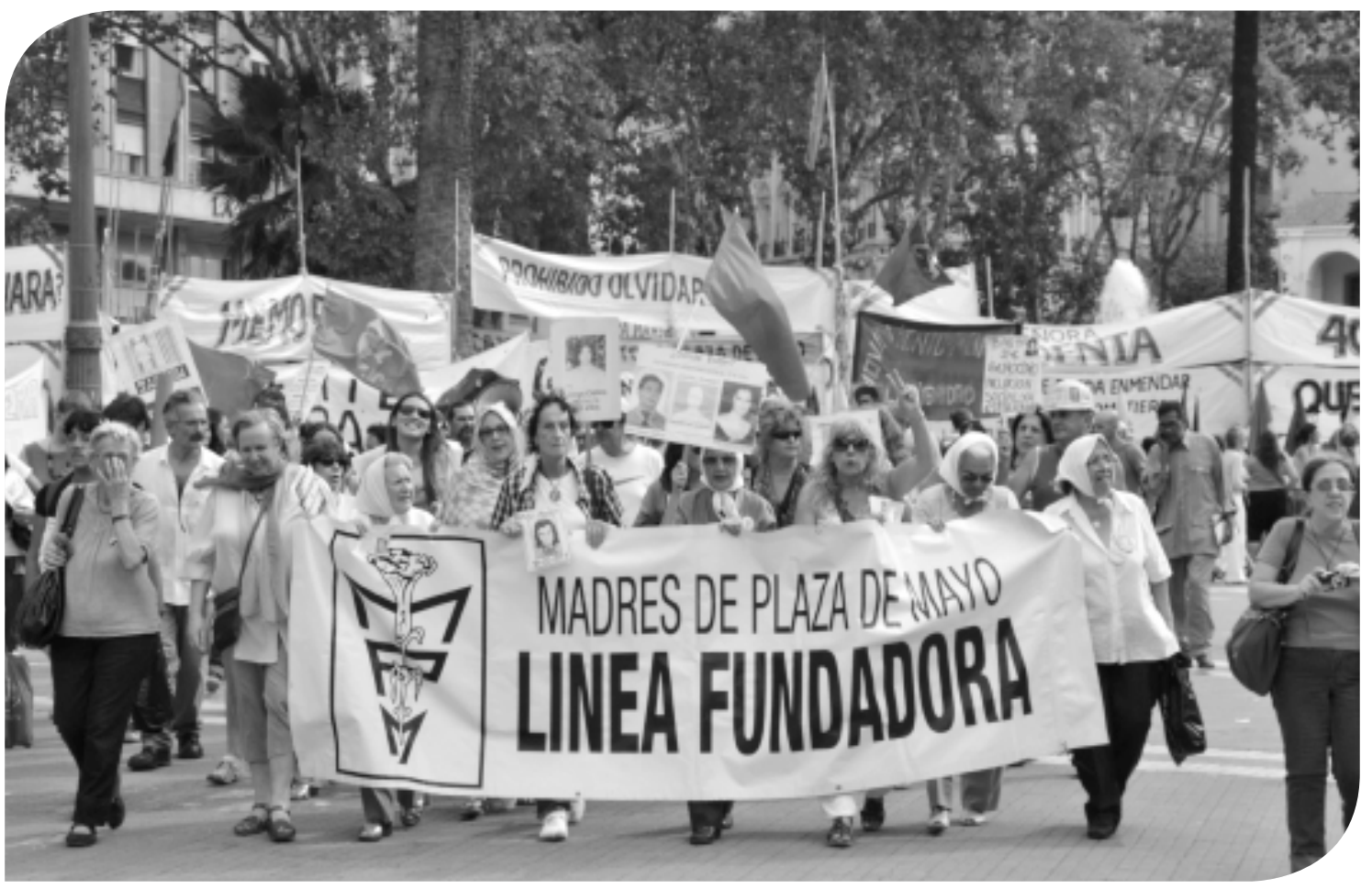

The Madres de Plaza de Mayo - Linea Fundadora - during their weekly Thursday march in Buenos Aires, Argentina.

Photographer: Natashe Dekker

'At the end of the [20th] century, we were not only witnesses, but also part of women's struggles for their rights on various fronts, starting with the family. From there to the streets. From there to the mountains. Today, some govern countries and others propose or promote a revolution of thought and language, and of patriarchal practices in the exercise of power.'

(Interview with Domingo Hernández Ixcoy, Maya-K’iche' leader; Ardón 2012) 


\subsection{Why 'Gender and Social Movements'?}

Social movements, defined as 'an organised set of constituents pursuing a common political agenda of change through collective action' (Batliwala 2012: 3), play a particularly important role, now more than ever, in global struggles for equality and transformation. Across the world there is an active, mass-based demand for an end to gendered injustice and a challenge to patriarchal power ${ }^{6}$ in all domains of our social, economic, political and cultural lives. In response to this demand there has also been significant progress in naming and taking action to challenge sexism, redistribute power and opportunities and respond to and prevent violations of women's and girls' rights. Social movements - led by feminist, women's and gender justice activists and their movements - have been pivotal in envisioning, instigating, making and sustaining these changes. When it comes to making an impact on transforming gender power relations, social movements matter.

Experience shows, however, that while women's rights and gender justice are 'on the agenda' - from the domestic sphere and the street to organised civil society debate and governmental platforms and policies - practitioners and activists still encounter tremendous resistance to changing gendered politics and practice, and shifting the 'deep structure $^{7}$ of movements and organisations affiliated to movement goals. As movement activists point out, 'social movements that commit to "gender equality" in words but don't come through [in practice] don't because there is no fundamental shift of hearts and minds' (Susanna George, BRIDGE e-discussion October 2011).

This report points to the fact that while progressive social movements are vital in forwarding visions of justice, they are themselves not immune to gender-based discrimination and inequality. In that light, the report makes the case for engaging with questions of women's rights and transforming gender power relations across social movements committed to progressive visions of society. To do so, it draws on effective and promising strategies and reflects on challenges from existing movement practice. It incorporates both social movement theory and experience and analysis from social justice activists from across the world, who are engaged in supporting the advancement of women's rights and gender justice as part of women's movements and other social movements working towards development, human rights, justice, sustainability and peace.

In their politics and practices women's and feminist movements create various forms of counter-culture and alternative power relations. Set in the context of other social movements, this implies that integrating gender perspectives is not just about 'including' women or 'thinking about' men and gender minorities but, rather, considering what a gendered politics provides in terms of alternative ways of being, seeing and doing that in themselves serve to transform patriarchal power relations.

There is already a growing body of work concerning the nature of women's and feminist movements and their characteristics and concerns (see, for example, Antrobus 2004; Batliwala 2012; Feree and Tripp 2006). This report takes a different approach that has so far received much less attention. It considers how broader social movements are thinking about women's rights and gender justice, and asks what solidarity with other movements means for the agendas of women's and gender justice movements. There is,

6 Patriarchy is used to describe systemic and institutionalised male domination and the cultural, political, economic and social structures and ideologies that perpetuate gender inequality and women's subordination (Just Associates 2012).

7 'Deep structure' describes hidden layers within organisations and movements where unconscious or even conscious but hidden processes occur, including taken for granted assumptions about gender roles and the place of women (Rao and Kelleher (2005); Srilatha Batliwala, BRIDGE e-discussion March 2012). 
of course, great diversity in the visions and strategies of progressive social movements. This report aims to draw out this complexity through case studies, comparative analysis, and reflections of activists engaged in social movements.

\subsection{Why are social movements relevant?}

Recent history has shown that social movements remain a significant force for challenging inequalities and exclusions in society and for proposing new models and visions for more egalitarian and just social, economic and political power relations. In the context of women's rights and gender justice, women's movements have led the way in pushing forward progressive agendas and challenging gender-biased social and cultural norms at a popular level as well as in law, policy and institutional practice, with tremendous strides made in establishing formal equality and shifting thinking and social practice in the past half century (see the box below and section 3.4. for further analysis).

Feminist movements - the leading factor in shaping progressive policy on violence against women

A recent statistical analysis drawing on data from studies over the past 20 years from 70 countries quantifies the leading role that autonomous women's and feminist movements have played in instigating government action on violence against women and girls. Surveying data over four decades (1975-2005), the study also shows that more comprehensive government responses emerge in countries with stronger women's and feminist movements working against violence against women. Autonomous feminist activism ${ }^{8}$ is also a more significant factor in influencing progressive policy than having progressive political parties in power, more women in the legislature, or overall improvements in national economic standing. (Source: Htun and Weldon 2012)

\section{A moment when movements are in the spotlight}

Thanks to recent mass uprisings such as the revolutions in North Africa and the Middle East, and the Occupy movement, ${ }^{9}$ there is renewed interest among development and human rights non-governmental organisations (NGOs) and donors in social movements on how to contribute to movement-building for gender equality and justice and rights overall. This presents an opportunity to refine understandings of social movements and how best to contribute to this momentum of investment. There is also consequently a need to better understand the dynamics of social movements and how NGOs and donors can engage with movements in the most beneficial ways towards shared visions of change on women's rights and gender justice (see Dütting and Sogge 2010).

\section{Social movements as a force for democracy and justice}

Citizen-based movements for democracy and political transformation peaked in countries in North Africa and the Middle East from late 2010, resulting in the overthrow of long-standing repressive political regimes in Tunisia, Egypt, Libya and Yemen. These events have revived discussion around the power and potential of mass-based citizen action to transform societies and create new forms of political participation and

8 Autonomous feminist activism refers to feminist activism independent of or outside formal organisational control or direction.

9 Occupy is an international movement that protests against the current economic structures that distribute wealth unevenly. It began in the USA in 2011 with protests in the financial centre of Wall Street in New York City (Sahasranaman 2013). 
political voice, including in the domain of governance, and in ways that foreign policy or development interventions have not yet been able to do (Sholkamy 2012). The complex gender dynamics of these movements are evident in two ways. On the one hand, women have been active participants and playing a leadership role in mobilising protests and articulating inclusive visions of democracy, in particular among progressive supporters of these changes. On the other hand, women revolutionaries have faced critique and harassment by family members and in the public arena, as well as gender-based violence in the streets by fellow protesters and State actors (Sholkamy 2013; Tadros 2013). In all contexts the revolutionary visions inclusive of women's rights have been undermined in postuprising governments as political parties framed with conservative Islamic views on gender roles and women's rights have taken power, and the involvement of women in protests has not been matched by the active inclusion of women in the newly elected or interim governments (Kandiyoti 2012). This trend echoes across history, and deserves interrogation.

\section{The need to build popular progressivism}

Despite important progress, there is still a mixed 'big picture' for progressive agendas. Formal 'wins' around gender justice are constantly challenged by the realities of persistent gender inequality in social, economic and political domains alongside remarkably high rates of violence against women and girls (United Nations 2010). Women's marginalisation is exacerbated by the realities of a crisis in mainstream models and visions of development, ${ }^{10}$ economic growth, governance and human rights, on which, in the past decade, the majority of global resources have been focused. Northern economies have been grappling with financial crises, and Southern countries experiencing shifting geopolitical power, including the rise of Brazil, Russia, India, China and South Africa, with varied impacts on governance, economic autonomy, trade and inequalities.

The varied picture for progressive victories is set against a rise in mass-based religious fundamentalist movements and the growth of 'popular conservatism'11 across the world, which in some cases is directly attacking legal, policy and social gains already made and shifting norms against equality and inclusion in areas as diverse as migration and reproductive rights. In the global North religious fundamentalist and far-right ${ }^{12}$ movements are gaining ground in capturing the imagination at community level and gaining footholds in mainstream political power (Göle 2011; Joyce 2009). Contemporary fundamentalist movements in the global North and South tend to construct their agendas around a defence of traditional gender norms, maintaining patriarchal control over the family, sexuality and reproduction, and gendered social roles (ASTRA 2012; Balchin 2011; Bop 2008; Castells 2011; Kaoma 2009). Women themselves, in particular young women, are often mobilised and active in conservative and fundamentalist movements, including in actions that further undermine women's rights or assert retrogressive notions of culture and tradition that limit women's autonomy (Balchin 2011, Sumaktoyo and Rindiastuti 2010). This in turn raises the question of the state of 'popular progressivism' ${ }^{13}$ - massbased movements for equality, rights and inclusion and the strength of these to speak back at a popular level through votes, or resistance in community platforms and affirming progressive social norms.

10 Mainstream development refers to frameworks and practices around development as defined and advanced by governmental agencies and large donor institutions. It is commonly used in the context of critique, and to describe frameworks derived from, or predominantly developed in, the global North and that support neoliberal economic approaches and governance models in line with the current status quo.

11 Popular conservatism is mass-based support for social, political and economic ideas that support the preservation of, or a return to, the traditional status quo and power relations.

12 Far-right refers to a set of ideologies that espouse extreme social, political and economic conservatisms and rejection of social and cultural diversity, often linked to racist, sexist, xenophobic and homophobic views, including legitimising acts of violence against specific groups.

13 Popular progressivism is mass-based support for social, political and economic ideas that support justice, redistribution and the transformation of societies towards inclusion, equality and democracy. 


\subsection{Why are women's rights and gender justice critical for progressive social movements?}

\section{An integral component of progressive activism globally}

Feminists and women's rights activists and movements have historically been situated as part of progressive social theorisation and social action. Movements for women's rights and gender justice have been among the most visible of social movements globally, with broad-based membership and a range of successful actions to challenge injustice and discrimination and build more inclusive methods and frameworks for achieving equality in multiple areas.

\section{A 'ground up' demand for social transformation}

The call to fully engage with and advance women's rights and gender justice is a 'ground up' demand that came out of women's own mobilisations across the world and over centuries. As such it is firmly 'on the table' as an ethical and practical imperative for all those working on development, human rights and democratisation. The fact that there is still reticence to acknowledge and promote the full spectrum of women's rights and gender justice concerns in social movements and in institutions affiliated to them raises concerns regarding the accountability and political commitment of progressive movements to full equality. ${ }^{14}$ As women's rights activists commonly ask: 'How can a movement that is itself unequal produce equality?'

\section{A necessary component of full justice}

Engendering the analysis of the political and technical challenges we face as well as integrating gendered political goals into the solutions that we seek is necessary to fully achieve justice in all areas, including the economy, the environment, politics and social life. Today any cutting-edge intervention or forward-thinking initiative around rights, democracies and equalities ultimately needs to include women's rights and gender justice in its analysis of inequality and its visions and methodologies for change. Indeed, without this, interventions are unlikely to succeed in their goals of contributing to full equality and complete social transformation. As one e-discussion participant noted, 'Social change is not possible without changing power relations, and power relations don't change if you don't address gender and racial relations' (Atila Roque, BRIDGE e-discussion October 2011).

\section{An agreed policy priority and binding legal obligation}

Women's rights and gender equality are established in law and policy internationally and to varying extents in most countries in the world, although implementation is still inadequate (see UN Women 2011). As such they are already present as a binding obligation and ethical commitment by many governments in the form of ratified United Nations (UN) agreements such as the Convention on the Elimination of All Forms of Discrimination against Women (CEDAW) and the Beijing Platform for Action and national gender equality action plans. In their role as a force for political accountability, progressive social movements should at minimum uphold existing gains while pressing for more extensive protection and visions of justice in states.

14 An equal society is one in which everyone can flourish. The diverse needs, situations and goals of individuals are recognised, discrimination and prejudice are removed, and the economic, political, legal, social and physical barriers that limit what people can do and be are tackled (Burchardt and Vizard 2007). 
In the policy arena there is also an ongoing need to fully uphold movements' demands around women's rights and gender justice. Looking globally, the international 'standardsetting' era of the 1990s saw women's movements' claims for recognition of full rights to bodily integrity and choice in international frameworks 'negotiated down' to exclude, for example, explicit acknowledgment of the right to terminate pregnancy and rights regarding sexual diversity (Petchesky 2000). The Millennium Development Goal (MDG) framework has also been critiqued for the 'instrumentalisation'15 of gender equality in the interests of economic growth, and for its limited focus on women's political participation, girls' education and maternal mortality to the exclusion of the full spectrum of related women's rights concerns, including violence against women and girls (Goetz 2007).

\subsection{What questions does this report explore?}

- What are social movements, and why do they need to engage more deeply on a women's rights/gender justice agenda to achieve social justice goals?

- How have women's and feminist movements worked over time to affect social change, including through alliances with other social movements?

- How have feminists and gender justice advocates worked within social movements to bring about gender justice?

- How have different social movement formations engaged with and incorporated women's rights and gender justice into their own politics and practice?

- What are the challenges in fully integrating women's rights and gender justice into the visions and practices of social movements across a range of issues and locations?
- What are the preconditions for constructing gender-just social movements, across the full range of social justice concerns?

- What are effective routes to change in transforming social movement approaches, strategies and conceptual frameworks to fully integrate women's rights and gender justice?

- What are the routes for movements to challenge their own internal discriminatory values and practices?

- How can women's and feminist movements strengthen inclusion and intersectional approaches that take into account emerging constituencies demanding rights and justice?

- What are the emerging areas that future research and reflection should consider?

15 The term 'instrumentalism' is used to describe the strategic use of a particular community, group or political standpoint to advance a goal in ways that do not directly benefit the people or ideas being drawn on or align with their own goals. 


\subsection{What is meant by 'gender' in this report?}

\section{Key gender terms}

Gender

Gender is commonly defined as the socially constructed identities, behaviours and practices tied to being a girl/woman or boy/man. There is growing acknowledgment in theory, law and social practice that the binary definition of gender (i.e. only two genders) does not fully account for the diversity of gender identities that exist, including those of trans ${ }^{16}$ and intersex ${ }^{17}$ people.

Gender equality

Enshrined in law as a basic right, gender equality refers to measurable, equal representation and status between women and men. Gender equality does not imply that women and men are the same, but that they have equal value and should be afforded equal treatment (Just Associates 2012).

Gender justice

This refers to the ending of - and, if necessary, the provision of redress for - inequalities between women and men that result in women's subordination to men. These inequalities may be in the distribution of resources and opportunities that enable individuals to build human social economic and political capital. Or they may be in the conceptions of human dignity, personal autonomy and rights that deny women physical integrity and the capacity to make choices about how to live their lives (Goetz 2007). Gender justice encompasses but extends beyond formal equality to include transforming systems of gendered power in all domains.

Gender power relations

Hierarchical relations of power between women and men that tend to disadvantage women. These gender hierarchies are often accepted as 'natural' but are socially determined relations which are culturally grounded and subject to change over time. They can be seen in a range of gendered practices, such as the division of labour and resources, and gender ideologies, such as ideas of acceptable behaviour for women and men (Reeves and Baden 2000).

\section{Patriarchy}

Systemic and institutionalised male domination and the cultural, political, economic and social structures and ideologies that perpetuate gender inequality and women's subordination (Just Associates 2012).

Feminist movements

Movements that align themselves with feminism as a political ideology and seek to challenge inequalities and injustices between women and men, framing these as a challenge to patriarchy and patriarchal power relations. Feminist movements have historically been built and constituted by women, although men and trans individuals also align themselves with the politics of feminism.

16 The term trans includes those people who have a gender identity which is different from the gender assigned at birth and/or those people who feel they have to, prefer to or choose to - whether by clothing, accessories, cosmetics or body modification - present themselves differently from the expectations of the gender role assigned to them at birth. This includes, among many others, transsexual and transgender people, transvestites, travesti, cross dressers, no gender and genderqueer people (Global Alliance for Trans Equality).

17 The term intersex is used for a variety of conditions in which a person is born with a reproductive or sexual anatomy that does not seem to fit the typical definitions of female or male (Intersex Society of North America). 


\section{Women's movements}

Movements of women that are built and constituted by women and seek to challenge inequalities and injustice between women and men. Women's movements may have varying approaches to transforming gender power relations, from more conservative to more radical. Individuals and groups within women's movements may not always ally themselves with political identity of 'feminism'.

\section{Gender justice movements}

Movements that challenge gender inequalities and unjust power relations; often used in the context of mixed-gender or men's movements and LGBTII8 movements that challenge gender binaries.

\subsection{What is the Overview Report for?}

This report is intended for a broad audience interested and/or involved in work around social movements and on women's rights and gender justice. The primary audience is women's rights and gender justice advocates who are part of progressive social movement activism (in formal and informal platforms) and are seeking to build solidarity for gender justice politics and transformative approaches to gender in movements. Other audiences include social movement activists and those working in research, and in donor and civil society organisations that are supporting movement-building and social mobilisation for gender-just societies. The report is designed for an audience with varied exposure to women's rights and social movement theory and practice; it maps out key conceptual frameworks alongside examples, analysis and recommendations.

\subsection{Scope, structure and additional resources}

This Overview Report provides an in-depth exploration of theory, case studies and key learning and routes to change drawn from the BRIDGE Cutting Edge Programme on Gender and Social Movements. Chapter two outlines a framework for understanding social movements and highlights some of the debates, tensions and challenges faced by movements. Chapter three introduces women's and feminist movements, their vision and strategies, and the gains they have made over recent decades, before exploring the responses to women's rights and gender justice in broader social movements with different constituencies and political foci. Chapter four assesses common challenges in building gender-just social movements, and chapter five identifies the core elements of gender-just movements and sets out some practical routes to nurturing social movements that challenge unjust gender power relations in all domains. Finally, chapter six offers some broad reflections and points to areas for further research and exploration.

As part of the Cutting Edge programme, a website has been developed to house a range of further reading and multimedia materials on social movements, women's rights and gender justice. The website houses the following case studies, developed in collaboration with activists in the respective social movements, which inform this report.

18 The acronym LGBTI stands for lesbian, gay, bisexual, transgender and intersex. 
David Kelleher and Manjima Bhattacharjya (2013)

The Amnesty International Journey: Women and Human Rights

This case study looks at Amnesty International's efforts over the last 25 years to integrate women's rights into its work. The authors conducted a review of relevant literature and first-hand interviews with human rights activists, including those who have worked with Amnesty in the past, as well as some current staff. They map the trajectory of Amnesty's engagement with women's rights and consider which strategies worked and which did not, pulling out some useful insights for other organisations and movements that wish to strategically incorporate women's rights in their work.

Pamela Caro (2013)

Gender equality and women's rights in the CLOC-Via Campesina movement

In this exploration of the experiences and strategies of women leaders in the CLOC movement in seven Latin American countries, the author demonstrates the impact that strong women's leadership and advocacy within mixed-gender social movements can have. She sets out the achievements of the movement in progressing towards improved external and internal understandings on gender equality, and considers the challenges that still remain.

Manjima Bhattacharjya (2013)

A Tale of Two Movements: How women's rights became human rights

This case study gives an overview of the development of global human rights thinking and movements. The author emphasises the importance of women's movements consciously and continuously engaging with and challenging human rights movements. Based on a review of key documents and interviews with global and regional women's rights advocates, the study looks at the points of convergence of human rights movements and women's movements, and how they have informed and changed one another over the years.

Vinita Sahasranaman (2013)

Who is the 99\%? Feminist perspectives on Occupy

The Occupy movement brought economic justice back to the table and was seen by many activists as a platform for leveraging national and international attention to their demands. But despite its democratic and participatory approach, fault lines soon began to emerge. This case study looks at the tensions around Occupy and the arguments and needs of women and other groups such as people of colour and disabled people. It examines the potential of the movement to highlight these tensions and interrogate them positively.

Hania Sholkamy (2013)

Gender, activism and backlash: Women and social mobilisation in Egypt

Women were equal partners in the organisation and enactment of the 2011 revolution in Egypt, but the formal structures that have since emerged are much less balanced in terms of gender. In this case study, the author looks at how women were involved in the revolution, and the cracks that began to emerge. She assesses the state of women's rights in the post-revolution context and comments on the future for gender equality in social justice activism in Egypt. 
Sharon Bhagwan Rolls (2013)

Defining our Space: Gender mainstreaming strategies in the work of the Global Partnership for the Prevention of Armed Conflict

This study sets out the ways that the Global Partnership for the Prevention of Armed Conflict (GPPAC), a global civil society network, adopted a gender policy and mainstreaming strategy. It notes the influence of women's organisations and activists in bringing about this positive development, and highlights some challenges for GPPAC in the future implementation of its plans on gender equality.

Solome Nakaweesi-Kimbugwe with Hope Chigudu (2013)

The LGBTIQ and Sex Worker Movements in East Africa

In this case study the authors consider the background and development of the lesbian, gay, bisexual, transgender, intersex and queer (LGBTIQ) and sex worker movements in the East Africa region, looking at the connections between the two movements and their strategies, tactics and agendas. The links between the two movements and feminist individuals and organisations are also highlighted. The authors discuss the movements' key achievements and the challenges that remain, and ask what lessons can be learned from this example about inclusive movementbuilding for social justice and human rights.

All of these case studies are available at our gender and social movements website.

The In Brief bulletin that accompanies this report includes an overview summary of the report as well as versions of the case studies on CLOC-Via Campesina and the global human rights movement. 


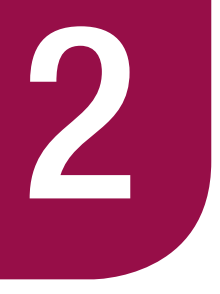

\section{Social Movements: Evolution, Definitions, Debates and Resources}

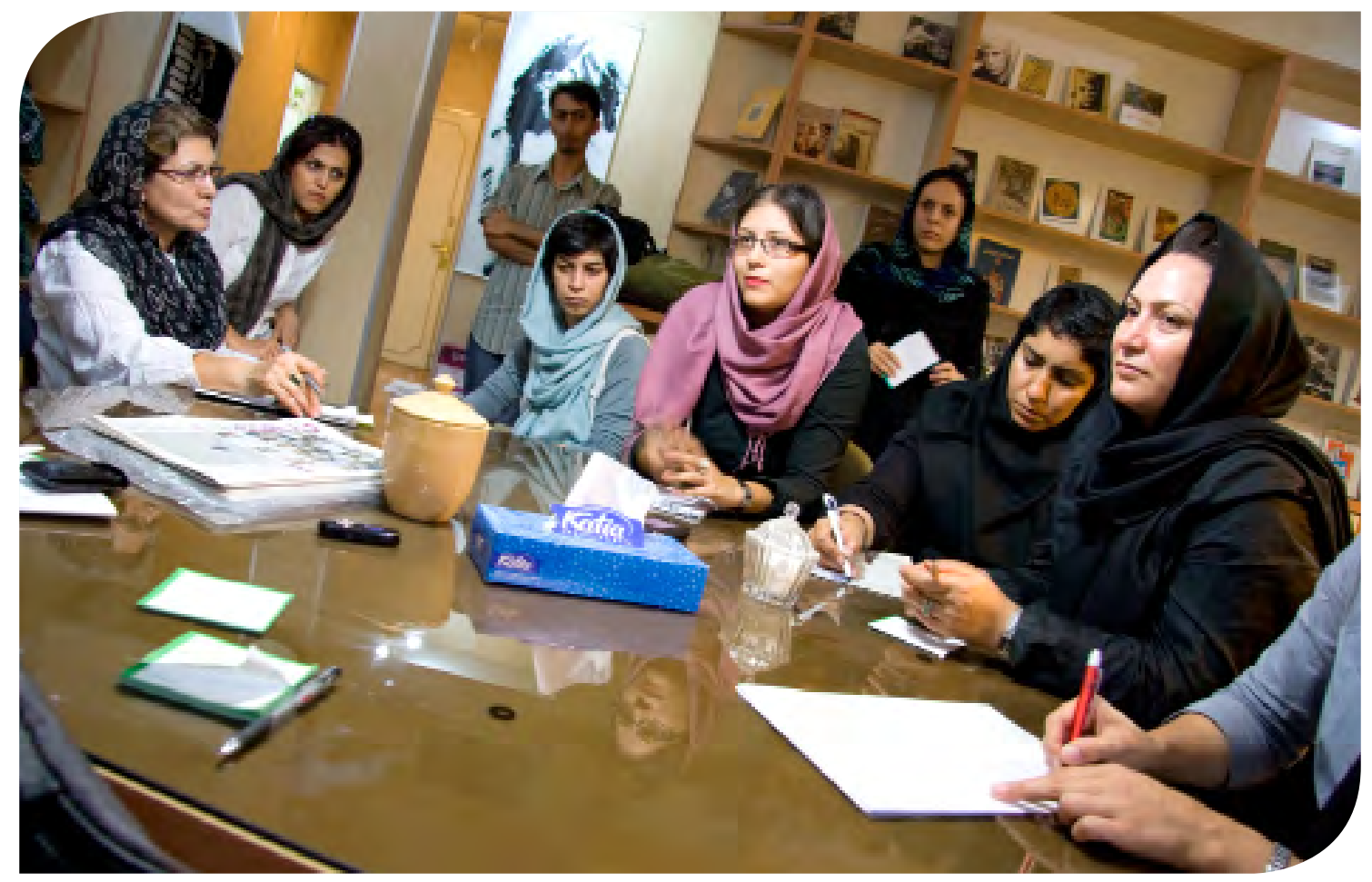

Journalists, lawyers and women's rights activists discuss Iran's polygamy laws.

Photographer: Raha Asgarizadeh

This chapter sets out the background for understanding social movements. It discusses the ways that movements emerge and develop and includes a brief map of social movement theory, including arguments relating to contemporary social movements in the global South. It expands upon the definition of social movements provided in chapter one, setting out some of the defining features of movements. It explores some fundamental conceptual concerns for social movements, including building common political agendas, issues of representation and leadership, and inclusion and marginalisation. It also considers the relationships between social movements and organisations and social movements and financial resources - relationships that are filled with tensions, opportunities and questions, particularly as social movements engage with institutional agendas and processes around gender equality, democracy and justice. The chapter is intended to provide a broad context, paving the way for chapter three, which focuses more specifically on the ways that progressive social movements have, and are, engaging with feminism, women's rights and gender justice. ${ }^{19}$

19 We would like to thank Wendy Harcourt for her work planning early versions of this chapter. 


\subsection{How and why do social movements emerge and grow?}

Social movements are forms of collective action that emerge in response to situations of inequality, oppression and / or unmet social, political, economic or cultural demands. They comprise 'an organised set of constituents pursuing a common political agenda of change over time' (Batliwala 2012:3). Social movements, including those integrating or focusing on gender power relations, have existed across history. Notable examples are the movement to end the transatlantic slave trade that had begun in the 16th century, movements of organised industrial workers beginning in the 19th century and movements to gain women's suffrage (the right to vote and run for office), emerging in the late 19th century (Naidoo 2006; Tripp 2006; Ghimire 2005).

The $20^{\text {th }}$ century was framed by movements for national liberation from European colonial rule in Asia, Africa, the Middle East and the Pacific and against dictatorships in Latin America, in which women played varied but significant roles. Other social movements, including those for feminism, peace and antimilitarism and the environment, those against race and ethnic discrimination and those around sexual orientation and gender identity also began to emerge or expand in the 20th century. This happened against a backdrop of political and economic crises, increasing urbanisation and international travel, the rise of mass media, rapid scientific changes and technological shifts, nuclear proliferation and the expansion of accessible communication technologies.

In understanding social movements it is vital to remember that they are dynamic, historical phenomena and as such 'are shaped by circumstance; they are contingent things, which grow or shrink in response to factors that enable or constrain them' (Dütting and Sogge 2010: 31). This includes contestation within them and significant changes in the external environment with impacts for social movement politics, membership and strategies. Hence, while generalisations can be made, it is also vital to consider movements in their historical context in order to fully understand their politics, choice of strategies, and the meaning and impact of their presence and actions. Put differently, 'social movements must be understood in their own terms: namely, they are what they say they are' (Castells 2010: 73).

Time is a critical factor in understanding social movements. Movements may envisage their change and commitment as taking place over a lifetime, or over generations, until the desired changes happen. Movement participation itself can develop over generations, as the children of movement activists and young people born into activist communities often go on to be active themselves in the same movements or in building new movements: 'There is involvement from children on up. For example, in the marches, the children go on people's backs, and grow up in that environment' (Interview with Sariah Acevedo; Ardón 2012). Movements may also be inspired by past social movement history, drawing on strategies, symbols, political visions and stories from the past as inspiration for contemporary activism.

As movements form they go through stages of growth and change, in some cases growing systematically in strength and impact over time and in others fluctuating in response to internal dynamics and external pressures. Movements can also cease to exist, most commonly when a movement's central cause has been addressed. Other reasons for movements to cease include systematic suppression by external forces that dissipate movement actors and make movement actions impossible. This can include targeted harassment and killing of key movement activists, and campaigns to discredit visible movement leaders. Movements may also end due to internal 
factors such as failure to adapt political agendas to changing contexts or concerns of movement members, or conflicts over politics and power among movement members, which leads to a lack of consensus or desire to continue movement actions.

The question of why movements form in the first place is an area of continued debate in social theory, and also a relevant consideration for movementbuilding and strengthening initiatives that seek to stimulate social movement action. Not all situations of injustice or inequality give rise to movements (see Batliwala 2002a; Mahmud 2010). Movements are thus 'built' in the sense that they are formed out of the active and deliberate investment of labour, thought and resources over time to develop movement consciousness, grow and retain membership and nourish movement structures, while also having external environments conducive enough to enable them to begin and develop.

Social movement theory has changed over time in response both to shifting theoretical perspectives among academics and to new social movements and new forms of social mobilisation. Theories lay emphasis on different factors including individual and group psychology, structural inequality, historical context and shifting institutional power, language and symbolism. The role of emotions has been considered in seeking to explain why and how people join movements, the development of movement politics and strategies, and visions of change.

\section{Key social movement theories in brief}

Theories of class conflict. Stemming from Marxist analysis of society and social change, these theories argue that social movements emerge primarily from the marginalisation of workers in industrial economies and resultant growing class consciousness and mobilisation among the proletariat to change this. Analysis explores how oppressed classes are mobilised, and impacts on transforming economic power and political decision-making towards the control of the majority.

Theories of collective behaviour. Considering the rise of fascism in Europe and urban unrest from the 1930s onwards, these theories frame social movements as spontaneous mass actions that challenge the social order and social norms of behaviour. Movements are largely framed as examples of the breakdown of social control, with movement theory exploring both the psychology of movement participation, particularly in mass public protest, and how movements emerge as responses to shifts in social structures.

Theories of resource mobilisation. Stemming from analysis of emerging social movements of the 1960s in the USA (student, feminist, anti-racist and lesbian and gay social movements), these theories argue that people are motivated to join movements by the potential rewards, incentives and costs of participation. The effectiveness of movements themselves is also assessed on the basis of their ability to generate resources (for example, financial, social networks, knowledge, legitimacy) and in turn use these to affect change.

Theories of political process, developed as a critique to resource mobilisation theories, consider the influence of shifting political contexts and the ways in which these create opportunities and affect the focus of social mobilisation. 
Theories of framing, developed from the 1970s and 1980s, engage elements of social psychology and culture of movements, arguing that social movements are born and grow around the construction of new frames for naming and understanding existing struggles and social concerns. In the process of reframing, social movements build a basis for people to connect with a cause while also identifying root causes and thus appropriate strategies to tackle them.

Theories of identity, prominent in European New Social Movement theory developed from the 1960s onwards, explore the idea that social movements emerge from a key concern to critique and construct new discourses of identity and belonging, generate new cultures and enact new forms of social relations including in the personal sphere and in lifestyle choices.

Theories of space and place highlight the relevance and role of geographic and spatial locations in inspiring and guiding social movements. They explore how movements develop around concepts such as the 'local' or 'global', are linked to spatial locations such as the body, physical environment or the economy, choose and form networks across geographies (e.g. South-South, regional and transnational networking) including through the use of communication technologies, and invest these actions across space and place with political meaning.

(Sources: Buechler 2011; Benhabib 1996, Castells 2010; Ghimire,2005; Leach and Scoones 2007; Harcourt and Escobar 2005)

\section{Movements in the global North and South}

Social movement theory based on the study of 'new social movements' that emerged in the 1960s and 1970s in the global North argues that contemporary social movements are framed by challenges to definitions of identity and belonging and, therefore, advance a politics of recognition. This is contrasted against social movements active before the Second World War, which tended to focus on structural inequalities such as social class, and advocated for a politics of redistribution (Fraser 1995; Castells 2010; Benhabib 1996).

In the global South, however, structural marginalisation has been an unavoidable element of social inequality, given histories of colonisation (Thompson and Tapscott 2010: 3). Many progressive social movements in the global South today are continuations of, or draw heritage from, the socialist and Marxist-inspired politics of national liberation and anti-imperialist struggle. They explicitly embrace a politics of redistribution alongside calls for the recognition of identities and meanings rendered invisible or suppressed by colonisation and its impacts. The result is a politics that acknowledges both structural and symbolic marginalisation and the need to act on both to achieve justice and ultimately 'liberation'. To use a historic activist slogan, progressive social movement struggles in the global South are typically 'not for bread or freedom, but bread and freedom'. 


\subsection{What are the defining features of social movements?}

In this section some of the key defining features of social movements are set out. In particular there is a focus on movement members or constituents and the actions and tools that social movements take and use.

\section{A social movement:}

1. Pursues a common political agenda or 'common cause'

2. Has a visible constituency or membership base

3. Involves members collectivised in either formal or informal organisations

4. Engages in collective actions and activities in pursuit of the movement's political goals

5. Uses a variety of actions and strategies

6. Engages clear internal or external targets in the change process

7. Retains some continuity over time (Adapted from Batliwala 2012: 3)

Social movement politics are formed from the premise that the world is socially constructed and that it is both possible and necessary to change it to achieve a movement's vision of a just society and of power relations within it. The justifications for what needs to change (political agenda) and why (political analysis), who should change them (leadership, membership and representation) and how (actions and strategies) are the core questions of movements and both define social movements and differentiate them from each other. The existence of social movements and the visions and actions that they present are inherently political in that they aim to challenge and change systems of power.

Social movements are not inherently progressive. Religious fundamentalisms, ${ }^{20}$ neo-Nazism and ethnic nationalism have all been rooted in and propagated by social movements and have also included the active participation and targeted mobilisation of women (see Balchin 2011; Bacchetta and Power 2013; Ferber 2004). This report considers the integration of women's rights and gender justice into progressive social movements that share the goals of inclusion, equal rights and equitable redistribution of power. In that vein, progressive movements can be defined as:

'Processes that build the collective power of an organised constituency of excluded, marginalised, oppressed or invisible people, around a change agenda that enables them to access the full body of human rights, challenge the distribution of wealth and control of resources, challenge dominant ideologies, and transform social power relations in their favour' (Batliwala 2010a).

Social movements have complex and varied relationships with organisations also involved in advancing social justice agendas, including non-governmental organisations (NGOs), civil society organisations, religious organisations, trade unions, political parties, academic centres and businesses. For a deeper and critical discussion of the relationship between social movements and NGOs, see section 2.4.

20 Religious fundamentalisms can be defined as 'the strategic use of religious discourse and institutions to forward views and actions that are absolutist and intolerant, anti-human rights and women's rights and at their root fundamentally patriarchal' (Horn 2012: 8). 


\section{Members of movements}

Movements are created and given meaning by their members. Without members, there would be no movement, although there is no standard rule regarding the minimum number of people required for an active constituency to be considered a movement rather than a collection of individuals. Social movement theory tends to focus on the question of who joins social movements and why, while social movement practice places more emphasis on defining who the legitimate or desired movement actors are and who should be targeted in outreach and constituency-building.

Movements are ultimately made up of individuals, although they may be affiliated or grouped in more or less cohesive ways to different movement ideas and structures (Batliwala 2012). Women's and feminist movements across the world have been instigated, populated and given direction and inspiration by individual actors including community activists, theorists and academics, artists, individual service providers and public figures. Individuals also play critical roles in carrying feminist and women's movement agendas and politics into other movement spaces and into formal organisational and decision-making processes (see Smyth and Turquet 2012). Recognising the role of individuals in movements is useful when considering strategies for integrating feminist and gender justice perspectives into progressive social movement practice (discussed in detail in chapter five).

\section{Movement actions, strategies and tools}

Social movements use a range of tactics as part of their activism. The theories of power generated within movements in turn inform what we can call theories of change - conceptual frameworks underpinning choices around movement membership, strategy and actions. In their practice, movements create activist and organising cultures, typically performing the emancipatory power relations and forms of relationship and expression that they seek to instigate in the broader world. Popular education, ${ }^{21}$ consciousnessraising ${ }^{22}$ groups, public art such as muralism and community theatre, protest marches, models of consensus-based decision-making, community-based fundraising and the creation of new languages and names are all examples of activist counter-cultures formed in and propagated by progressive social movements challenging gendered injustices.

Strategy can be both a dividing line and a connecting tool within movements.

Contemporary progressive social movements continue to diverge on the question of how much effort to invest in engaging the State and changing the terms of its relationships with its citizens, including laws, policies and the provision of basic needs considered as the 'enabling conditions' for rights. Women's movements globally have invested considerably in engaging and transforming state politics and practice (Antrobus 2004). However, women's and feminist movement actors also recognise the limitations of an exclusive focus on transforming state laws and policies. As expressed by a Zimbabwean feminist, 'Our battle is in fact not with the law per se, our struggle is with patriarchy' (in Essof 2005: 40).

Some argue that the principal indicator of change should not be changes in state policy but, rather, 'new possibilities for political action and engagement' (Khanna 2012: 164) that movement activism opens for the people engaged. Building 'power with' (collective strength) and 'power within' (sense of personal agency) (Just Associates 2006) are considered by feminist and other progressive movements as indicators of successful

21 Popular education is a community-based practice of learning and consciousness-raising where people (typically adults) analyse oppression from their own life experience, and use this reflection to develop conceptual and practical methods to challenge it.

22 Consciousness-raising is a group process that helps to explore personal experiences of violation and/or empowerment. See section 5.2.2 for a more detailed definition. 
transgression against unequal power structures and norms. Such approaches are able to bring change in dominant power relations at all levels and are not only tools for achieving change in the formal political arena.

Another example of divergent views on activist strategy is the use of armed resistance in progressive struggles. Feminist and women's movements have for the most part opted for the strategy of non-violence, including methods such as consciousness-raising, protest marches, litigation, civil disobedience and the creation of activist media. However, there is also a tradition of feminist and women's activists using armed resistance as a strategy for social transformation, most commonly in the context of armed liberation movements. Examples include the Zapatistas, where indigenous Mexican women in the state of Chiapas took up arms in self-defence and furtherance of their political project (Speed 2006), as well as national liberation and guerrilla movements such as Umkhonto we Sizwe, the armed wing of the African National Congress fighting apartheid in South Africa (Cock 2001).

However, there are also examples of situations where different movements have been brought closer together through the development of common strategies. In East Africa, for example, the emerging sex worker and LGBTI movements wanted to build support for their struggles by building a critical mass of supporters. They were both facing similar challenges around police raids, weak organisations and leadership crises. They have built their strength and resilience by engaging in joint influencing and awareness work and participating in coalitions and alliances - for example, to fight against repressive legislation on homosexuality (Nakaweesi-Kimbugwe with Chigudu 2013).

When thinking about the tools used by activists, information and communication technologies (ICTs) have long been used to disseminate movement information, facilitate solidarity across borders and social groups, and build movement membership and independent media platforms. Community radio has been a particularly successful tool for movements, with, in the area of women's rights activism, initiatives such as the Feminist International Radio Endeavour (FIRE) acting as beacons in demonstrating the ways that technology can connect and support activists and mobilisation. The growth of the digital 'network society' (Castells 2010), facilitated by the rapid advancement of the internet, personal computers and mobile phone technologies, has revolutionised and opened new opportunities around information flows and new media for social, political and economic connection.

What makes newer ICTs interesting in the context of social movements is the potential opened up to not only use communication tools for mobilising, but also for popular engagement in developing and/or appropriating new communication platforms for activist use. For women in particular, newer ICTs offer the ability to create social networks, receive and share information and participate in collective actions even when physical movement or public visibility is limited by social norms or political repression. ${ }^{23}$ However, it is important not to overplay the potential of new technologies as instigators of change. What makes technology subversive or not is the ways in which movements use, appropriate and also produce technologies as part of activist strategy and guided by movement politics, as the comment below illustrates. ${ }^{24}$

23 The HarassMap initiative in Egypt is an example of how activists have used online mapping technologies to document sexual harassment of women and develop an evidence base for activist intervention (see http://harassmap.org/en/). Queer feminist women in Lebanon have also made strategic use of online communications to build community and political consciousness, and form networks with queer Palestinian women living under Israeli occupation (see Moawad and Qiblaw 2011).

24 Free and Open Source Software (FOSS) is an example of technological innovation propelled by an explicit agenda to expand access to patent-free and cost-free software for all, democratise the technology develop process by enabling anyone with technological skill to engage with, create and share software, and in many cases also design software that meets the specific needs of progressive activists. 
'While technology is increasingly becoming a critical tool for social mobilisation, it is not an end by itself [...] While a majority of western media and cyber-utopians may call the Arab Spring a Twitter or Facebook revolution, the mere supposition is far from the truth. It takes courage, creativity faith, great risk, a belief in freedom and human dignity that pushes these groups to harness the power of these tools.' (Philip Thigo, BRIDGE e-discussion, October 2011)

Technologies are framed by power relations. As with all realms of social interaction, access to and use of technologies is gendered. While internet use is growing, 37 per cent of women are internet users compared to 40 per cent of men. The gender difference is more pronounced in the global South, where there are still 16 per cent fewer women than men online (International Telecommunication Union 2013). In addition, technology platforms such as social networking spaces tend to be owned or are easily co-opted by private business and corporations that may not always support activist agendas (Gurumurthy 2012). ICTs also pose new dilemmas around gendered social power and control, creating platforms for re-entrenching gender inequalities and enabling new forms of violence such as cyber-bullying and cyber sexual harassment. ${ }^{25}$

\subsection{Fundamental concepts for understanding social movements}

In this section some key concepts that help understand social movements are discussed. These include finding 'common cause' or a common vision; representation, leadership and voice; inclusion and intersectionality; and the 'deep structure' of movements - all important to consider in the context of integrating gender issues into social movement agendas and cultures.

\subsection{1 'Common cause' or common political agenda}

All movements have at their heart a 'politics', in the sense of a vision of society (or realm of interaction within society) that they seek to create, and sets of principles framing relationships in this world. This always includes theories of power and power relations, although they may not be explicitly named as such. All movements that seek feminist transformation, women's rights and/or gender equality name existing gender power relations as a principle axis of injustice and include transformed gender power relations as integral to their visions of liberation and freedom.

\section{Common cause}

The element of 'common cause' around a political agenda is central to movement politics and unites actors in movements who may have varying takes on strategy. In the case of women's movements the shared political agenda to end gender injustice brings actors together even though they may have different positions on the strategies to end it. Similarly a shared power analysis can play a bridging role in alliances between social movements. For example, the feminist analysis of how

25 Take Back the Tech, a campaign run by the Association for Progressive Communications Women's Networking and Support Programme, is an innovative initiative responding to this by inviting action by concerned activists across the world to name and address gendered cyber-violence. See https://www. takebackthetech.net/. 
patriarchal power relations reinforce heterosexuality and the heterosexual family as normative provides one starting point for solidarity between feminist movements and LGBTI movements working to end homophobia. Common adversaries can also provide a basis for solidarity in and between movements, uniting actors around a concern to challenge a particular power structure or movement. One example is the movement against neo-liberalism, which brings together a large range of social movements, including women's and feminist movements, which share a concern to challenge the power of institutions such as the World Trade Organization and multinational corporations but whose other political agendas or strategies may not necessarily overlap.

In developing such common political agendas, social movements are producers of knowledge in their thinking and practice. Some argue that in the process of contesting existing understandings of society and proposing alternative visions, movements in themselves create new forms of 'collective identity... through which new forms of self-knowledge and social knowledge are produced' (Jaschok, Milwertz and Hsiung 2001: 7; also Celiberti 2011). In this way, movements themselves can create in their practice the new ways of seeing, being and doing that they propose for broader society.

\subsubsection{Issues of representation - who can lead, who can speak for whom?}

\section{Who should lead the change?}

Leadership and representation within social movements is both defining of social movement politics and an arena of vibrant debate in social movement practice. Progressive social movements frame leadership in a variety of ways, including preferences for horizontal and 'leaderless' representation and consensus-based decision-making (recognising everyone's potential to lead and represent), and 'vanguardist' ${ }^{26}$ leadership and decision-making where a select group or organisation are seen as primarily agents in movement-building and advancing movement politics. Each model contains its own dilemmas around how to maximise participation while also ensuring effectiveness and coordination (Buechler 2011; Freeman 1972-3). Pragmatism may also frame the choice of how to manage movement leadership: '[W] here movements are made up of socially diverse participants, the roles and charisma of individual leaders in holding them together, or at least presenting a public face of a united movement, also become more significant' (Leach and Scoones 2007: 21). External factors such as political repression and violence can also shape how movement leadership emerges. An example is the contemporary women's movement in Iran, which is characterised by highly decentralised leadership and continues as a 'movement with a thousand and one thinking heads' (Hoodfar and Sadeghi 2009: 215) in light of a need to adapt and innovate in the face of constant opposition by the State.

\section{Recognising the agency of the most affected}

Movements addressing the needs of particular constituencies, including people with disabilities, people living with HIV and young people, all articulate variations on the principle 'nothing about us, without us', emphasising the agency of those most

26 Vanguardism is a political strategy that places a select group of people or an organisation at the forefront of a movement or change process, with the idea that they will ensure that movement politics remains consistent, and will also lead in building consciousness and membership, and guide movement actions. 
affected by injustice, and their legitimacy and authority as representatives of their own politics in external spaces.

Feminist and women's movements have historically affirmed the need to acknowledge women's agency in transforming gender power relations, as well as women's leadership and capacity to represent their own agendas within and outside women's movements. With that said, there is also considerable debate within women's movements themselves concerning which women's realities frame women's movement agendas, and whose voice and leadership is privileged and celebrated, notably concerning social class/caste, race/ethnicity, sexual orientation and other axes of difference between women. This points to the social reality that power circulates in all domains, including within social movements focused on creating inclusive, just forms of social relations. Consequently, some argue that a movement enacts the alternative power relations it envisions by challenging existing hierarchies in its practices, and that 'the transformative potential of a movement is only as present as the presence or strength or voice of the most marginalised' (Sahasranaman 2013: 4).

As part of challenging hegemonic ${ }^{27}$ power relations, social movements constituted by historically marginalised communities may also explicitly affirm a reconfiguration of the power to 'lead', as expressed by Sundaramma, a leader in a women's village collective in South India, saying to majority groups, 'In the beginning, you may walk in front of us. After a while, as we grow stronger, you must walk beside us. But finally, you must learn to walk behind us' (in Batliwala 2007).

\section{Who can speak for whom?}

The debate on who legitimately 'speaks for' and defines social movement concerns also arises in the interface between movement actors situated differently in mainstream power relations, notably between actors in the global North and South, and between more and less privileged actors within Southern contexts - all of whom may lay claim to being marginalised. On the question of who constitutes the 'ground', a useful approach is to consider that 'grassroots and non-grassroots should be differentiated in terms of the degree of vulnerability to global policy and economic shifts. In other words, grassroots can be a relative rather than static term, but should always refer to those who are most severely affected in terms of the material condition of their daily lives' (Batliwala 2002b: 396).

Contestation around who is chosen to speak 'on behalf of' movement agendas, as well as the language used to do so, also surfaces as autonomous social movements interact with more institution-based or mainstream activist spaces. Class and educational differences as well as grades of radicalism in movement politics come into play as movements negotiate how their demands are presented and who is supported as messenger:

'... the character of our development paradigm... perceives grassroots voices as raw, requiring translation into a high language that can be understood by those in power... creating hierarchies whether intended or implied. Our development narrative demands that everything must be produced, packaged, and presented in a certain form and [so] subsuming the very voices that we were meant to support' (Philip Thigo, BRIDGE e-discussion, March 2012).

27 Hegemony is the process through which the world view of dominant groups comes to be accepted as 'common sense' or the 'natural' order of things. [...] Hegemony can be expressed through language, culture, patriarchy, political and economic systems, and is designed to maintain the status quo in the interest of those in power (Just Associates 2012: 13). 
This tension around who speaks for whom plays out in the question of engaging men as leaders on women's rights and in feminist activism. Although there is growing consensus in policy circles that men as well as women need to be engaged in gender equality efforts, there is still divided opinion in women's movements around how to engage men as agents of change in these processes. The tension typically stems from three issues: first, a political position within feminism and women's activist traditions that women themselves must be recognised as agents of change in the face of their own oppression, and as such must be at the forefront of challenging patriarchy; second, a sense of the ongoing need for space for women and gendered minorities to raise consciousness and build collective power among themselves without having to negotiate space with those historically positioned as their 'oppressors'; third, experiences in movements of engaging men as allies who in turn are uncritical of their own gender-based power and occupy leadership positions, claim voice and / or and use resources originally dedicated to women.

Transformative activism by men to challenge patriarchy encourages active reflection on the part of men speaking up for women's rights and an impetus to engage in ways that do not simply entrench existing expectations of men's leadership, voice and agenda-setting abilities. The following experience from Zambia suggests the depth of transformation and reflection needed:

'When discussing gender equality issues within the social movements, suddenly the male comrades keep quiet. [..] I think that there is some perception that gender issues should be dealt with by women only. I sometimes also feel that the so called gender sensitive [male] comrades, just want to be seen to be politically correct. Otherwise deep down they are just who they have been socialised to be. To unlearn patriarchy would be a complete transformation for many of our comrades' (Emily Sikazwe, BRIDGE e-discussion, September 2012).

\subsubsection{Social movements, inclusion and intersectionality}

'Hegemony and power is always multidimensional. Strategies of change must address these multi-layered hierarchies. It is not a matter of choosing between gender and class, for instance, but to combine them in order to challenge how our own participation in the social processes sometime reinforces the status quo. Otherwise we will keep missing the point' (Atila Roque, BRIDGE e-discussion, October 2011).

Actors facing multiple marginalisations often find that their particular perspectives and political demands are not recognised fully in the movements of which they are part. Movements may, in both their external activism and their internal dynamics, fail to recognise and address the diversity of their members and those affected by the issue or problem they seek to address. In response, movement actors have developed further intersectional politics which speak to their particular economic, social or political positioning. In the early years of disabled women's activism, for example:

'Given the male domination of the disability movement, disabled women who were politically active often drew upon feminism to aid their analysis of the gendered character of disability oppression. However, this was not a two-way process. Within both theory and research, disabled women noted their exclusion' (Price 2011: 9). 
Some movements and related organisations are increasingly attempting to take an intersectional approach (see definition in the box below).

\section{Intersectionality}

Intersectionality is a conceptual framework that makes visible the multiple discriminations that people face, the ways in which systems of oppression (for example, those framing gender, race, class, sexuality, ability) interact with each other, and thus the activist imperative to name and challenge multiple inequalities as part of seeking justice for different constituencies of women. The concept first emerged in African-American feminist, disability and Marxist-feminist writings and has since become a common term in activist thinking and practice around both the nature of injustice and the forms of remedy needed for full justice. (See Crenshaw 1991; Brah and Phoenix 2004; Yuval-Davis 2006; Price 2011.)

Women leaders in the Coordinating Network for Latin American Rural Organisations (the Latin American branch of the global Via Campesina movement) have worked over the last 15 years to promote an intersectional approach to the issues of economic justice, food sovereignty and agricultural reform. They use the slogan 'Without feminism there is no socialism' and organise training schools for movement members to work on the strategy of linking gender equality with class equality (Caro 2013).

For social movements, committing to a holistic approach to inequality and recognising identities based on gender, ethnicity, caste, age, class, sexual orientation and (dis) ability is an important strategy, not least to avoid fragmentation and to allow strong alliances to be built, championing arguments and actions that respond to the human rights demands of everyone (Bhattacharjya et al. 2013). There is more detail in section 3.5 on the responses of different types of social movements to gender equality and women's rights.

\subsubsection{The 'deep structures' of movements}

Many of the factors discussed above - leadership, inclusion, agency and representation - are embedded into the 'deep structures' of social movements. Patriarchal gender norms, and other norms that entrench stereotypes and inequality, cannot be uprooted and eradicated without recognising and tackling them at this informal level, as well as through formal structures, policies and processes.

\section{Deep structure}

'Deep structure' is a term used to describe the hidden layers within societies, organisations and movements where a number of unconscious or even conscious but hidden processes occur. Within the deep structure lie assumptions taken for granted about gender roles and the place of women. These assumptions are below awareness level, and are therefore not talked about or challenged, but they determine how people think and act. Deep structures are the sites where all sorts of informal, invisible norms and rules operate, and from where formal processes are subverted. (Sources: Rao and Kelleher 2005; Srilatha Batliwala, BRIDGE e-discussion, March 2012) 
The deep structure of a movement can create profound challenges for the realisation of women's rights and gender justice as an external and internal priority. Deeply ingrained ideas on gender roles can lead to sexist and discriminatory behaviour towards women and minority groups.

\subsection{Relationships between social movements and organisations}

Relationships between movements and organisations are multifaceted: organisations may support movements and movement-building; movements may create organisations; and organisations may be allied with movements or may provide services to movements (Batliwala 2012). Organisations 'play critical roles in building movements and as organising structures within them' (Batliwala 2012: 14), but ultimately movements represent something larger and broader than organisations. This section considers relationships between movements and organisations, which can be sources of both support and tension.

\subsubsection{The interconnectedness of movements and organisations}

In the context of the 'contemporary global associational revolution' (Batliwala and Brown 2006), both formal and informal organisations have become critical players in social movement strategy, in their roles as participants in dialogue between the internal agendas of social movements and external objects of social movement engagement, including the media, the State and broader civil society (Batliwala 2012). The move from mobilising through more informal or non-state-registered organisation platforms to formal organisations, including NGOs, can, however, lead to confusion over definitions of what constitutes 'the movement', and the legitimacy of different actors in speaking for or receiving financial, political or solidarity support as representatives of a broader movement constituency.

\section{The formalisation of activism through NGOs}

Movements have made creative use of formal organisations to advance practical and strategic movement agendas. For example, women's NGOs have played, and continue to play, a pivotal role in changing normative legal and policy frameworks at the United Nations, given that participation in UN processes such as the Commission on the Status of Women requires accreditation only available to formally registered NGOs (see Antrobus 2004). Formal organisations continue to provide a base to organise movement activities, raise political consciousness and mobilise resources for collective action, as described through the example of the Greenbelt Movement in Kenya in the box on page 31. 


\section{The Greenbelt Movement - a movement-allied NGO}

The Greenbelt Movement (GBM) is a Kenyan NGO established by activist Wangaari Mathaai in 1977. The initial vision was to address rural women's needs around food, fuel and income, while tackling environmental degradation and deforestation. Although formally constituted as a national NGO, and resourced by global philanthropists and governmental donors, the GBM operated with the character of a social movement, mobilising mass action for tree planting through locally run tree planting clubs, supporting community-based political education on women's rights, politics, corruption and the environment, and engaging in pro-democracy activism. In 1989 the GBM led successful protests against the construction of a multi-storey car park in Uhuru Park, one of the only public parks in the Kenyan capital, Nairobi.

The GBM also showed solidarity with other struggles, notably the Release Political Prisoners movement, formed by mothers of political activists detained during the regime of President Daniel Arap Moi. These protests led to the creation of Speakers Corner in Uhuru Park, which has remained a gathering point for popular protest. The GBM became engaged in state politics, forming part of a coalition encouraging opposition groups to unite against President Moi in the catalytic 1992 national elections. Mathaai and other GBM members faced prison, police violence and political persecution for their activism during the Moi era, while the State attempted to shut down the GBM as an NGO. Mathaai herself entered formal politics later in life, becoming Assistant Minister, Ministry of the Environment (2005-2007). (Sources: Mathaai 2007, 2004)

The success of women's movement activism for state accountability in many parts of the world led to the rapid production of global and national policy frameworks and national gender machineries in the 1990s (Bhattacharjya 2013), alongside a growth in the number of women's and other NGOs engaging as policy advocates, representing civil society in governmental processes and implementing state-funded programming for women. The collapse of the Soviet Union and political transition in Eastern Europe and China from the 1990s also ushered in a shift as women's activism extended out of state-controlled women's platforms and into more independent academic centres and NGOs as well as non-state-registered women's groups (Posadskaya 1994; Hsiung et al. 2001).

These various turns towards 'NGO-isation', ${ }^{28}$ the creation of 'gender experts' and entry of many women's movement actors into government offices was met with criticism and reflection by community and movement constituents who questioned the legitimacy and accountability of NGOs and gender experts to full social movement demands (see Jad 2008 for the case of Palestine). In other contexts, individual feminists and movementallied women's rights activists working within more mainstream governmental organisations and NGOs have been important actors in pushing forward women's movements' agendas and policy and legal reforms (see Smyth and Turquet 2012) and providing a link between grassroots actors and policymakers. In the 2000 s there is a trend among women's NGOs, supported by some women's funds and progressive donors, to return to community-focused initiatives, movement-building and engaging in movement-created spaces as well as, or instead of, governmental forums (Alvarez 2009).

28 This is a term coined to describe the process by which social movement agendas and activities are taken up by formally constituted NGOs, which in turn become considered representative or leaders in voicing these agendas or implementing activities. Often used as a term of critique, pointing to the ways in which mainstream NGO approaches become valorised, resourced and promoted above more radical organisational approaches and independent activism and movement mobilisation (see Alvarez 2009: 176). 


\subsubsection{Tensions in the relationship between movements and organisations}

Tensions emerge in the inevitable complex power relations between movements and organisations, frequently underpinned by the presence of financial resources as well as questions of accountability and participation. There is concern in some contexts that the discussion of social movements has itself been narrowed down to NGO-based activism alone, a point explored in the following reflection on contemporary gender justice activism in South Africa:

'I would make a distinction between what constitutes a social movement and what constitutes an NGO sector... I am not sure in South Africa that we have so many social movements that have the coherence to warrant the name. We are very much part of the NGO sector, and in some ways part of a more activist NGO constituency... what makes us more activist is that we make demands on the State to fulfil their responsibilities and their obligations' (Interview with Dean Peacock; Nascimento 2012).

There are also ideological tensions in the engagement of progressive social movements with NGOs and other formal organisations and processes. There are many social movements with politics that actively oppose mainstream development models. These include movements that reject neo-liberal and enterprise-focused models of state-led development, questioning the ways in which mainstream development sidelines existing forms of cultural and technological knowledge (Sachs 2010), and critiques of ways in which development organisations engage and collaborate with repressive governments and state institutions. In the context of Egypt, for example, gender equality programmes operated by external donors have been critiqued for operating without questioning political inequalities:

'Quotas in a rigged election, access to high office in the absence of transparency and accountability, local council representation without good governance or voice without freedom do not deliver gender justice. The recommended recipes that are the agendas of development programmes fade when faced with a mass quest for dignity and choice' (Sholkamy 2012: 95).

Movements may support a politics that questions the validity of the nation-state itself (for example, movements with anarchist politics, and some indigenous and ethnic nationalist movements) or state-managed tools of public control such as the military and criminal justice and surveillance systems (for example, women's peace and antimilitarist movements). There is also an active critique of the concept of human rights as an organising tool in some left-wing and Southern political movements due to a rejection of the liberal individualist roots of human rights and their reinforcement through the model of the Western nation-state (for example, Shivji 1989; Sharma 2008). Each of these political positions influences the degree to which the respective social movements would consider engaging with mainstream policy or law processes or collaborating with actors that appeal to mainstream development or human rights discourse in the fight for justice. 


\subsection{Social movements and money}

Movements have complicated relationships with financial resources. Movements are not usually centrally resourced, and movement participation is often unpaid, although particular campaigns, strategies or organisations linked to social movements may be resourced or situated in organisations that are.

Movements can be self-resourcing, generating financial as well as other resources such as labour, physical space and donations of food, intellectual resources, media space and materials for gatherings, services and actions such as public protests from within their membership. Movements may also seek out financial resources from external sources, including institutional donors (private, governmental or public funds whose grantmaking activity is regulated by state authorities).

\section{Legal and policy frameworks impact on donor support to movements}

Although some institutional donors award grants to individuals or to collective initiatives which are not formally registered (including many women's funds), most donors require that the entities they consider funding are formally constituted and registered in accordance with the laws that bind their own grant-making. As a result, movement financing from institutional donors is typically received via the organisations that they are aligned with or have created as their institutional face. The introduction of external financial resources into movement activities inevitably impacts on relationships of power, decision-making and accountability within movements. Sections of movements may be required to be established as legal entities, constituted with particular formats such as governance boards and hierarchical staffing systems which may differ from how decision-making and power is distributed in the movement. Institutional funding can also place limitations on strategies used by organisations within social movements - for example, the use of civil disobedience and other strategies that defy the law, or association with certain constituencies or political viewpoints, which may not be deemed permissible under laws that regulate philanthropy ${ }^{29}$ (International Centre for Non-Profit Law 2010).

The policies of institutional donor funding can also impact on the ability of movements to voice their full political positions - a notable example being the limitations placed by the US government through the 'Global Gag Rule' and the first round of the President's Emergency Plan for AIDS Relief (PEPFAR) on HIV and AIDS funding for NGOs which prohibited organisations from providing information on or advocating for safe abortion or taking positions regarding the decriminalisation of sex work and rights of sex workers. Both of these provisions went against the politics of reproductive rights and sex worker rights movements and affected the resource base of service and advocacy organisations aligned to both of these movements (Centre for Reproductive Rights 2003; Centre for Health and Gender Equity 2008).

29 For up-to-date analysis of changing laws, see the quarterly review of Global Trends in NGO Law produced by the International Center for Non-Profit Law at http://www.icnl.org/research/trends/index.html 


\section{Tensions around donor funding}

Institutional donors continue to play a leading role in providing financial resources for women's and other progressive social movements. Movement actors considering the role of donors indicate the need for progressive donors to consider more generous and less bureaucratic support for initiatives advancing justice and equality, not least in light of flexible and ample funding available to advance conservative thinking and mobilisation (Rich 2005). Recent research shows that women's organisations working for rights and justice worldwide are significantly under-resourced, and points to a need to increase external donor resourcing of women's and feminist movements, alongside mechanisms to ensure that this funding is adequate, longer-term, and is directed to movement priorities (Clark, Sprenger and VeneKlassen 2006; Pittman et al. 2011). Women's funds - independent public funds established to support initiatives aligned to women's and feminist movement goals - are one strategy to leverage more resources for women's rights and direct these to women's rights initiatives and feminist movement-building (Adeleye-Fayemi 2007).

Relationships between donors and movements are nevertheless fraught with complexity. Timescales present a challenge, as social movements intersect with institutional programming or funding for change. Short-term donor timeframes tend to conflict with longer-term movement agendas and timescales - and, hence, resourcing needs. In addition, project-focused programming and funding alters the timeframe of movement actions, which can change the nature of movement strategy and methodology (Appadurai 2002; Rich 2005; Shivji 2007). Critics of institutional funding also point to the phenomenon of external donor funding quietening the more radical ideas and strategies, and shifting accountability within funded organisations from their community-based constituency to donors (Smith 2007; Mananzala and Spade 2008).

This chapter has given a broad overview of social movements; how they are defined, how they evolve and some of their strategies and activities. Some debates, challenges and tensions faced within movements have also been discussed. The next chapter moves to looking at the ways progressive social movements have engaged, and are engaging, with feminism, women's rights and gender justice. 


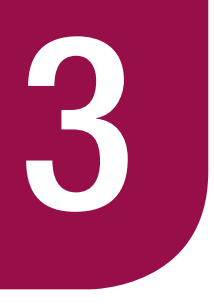

\section{Locating Women's Rights and Gender Justice in Social Movement Practice}

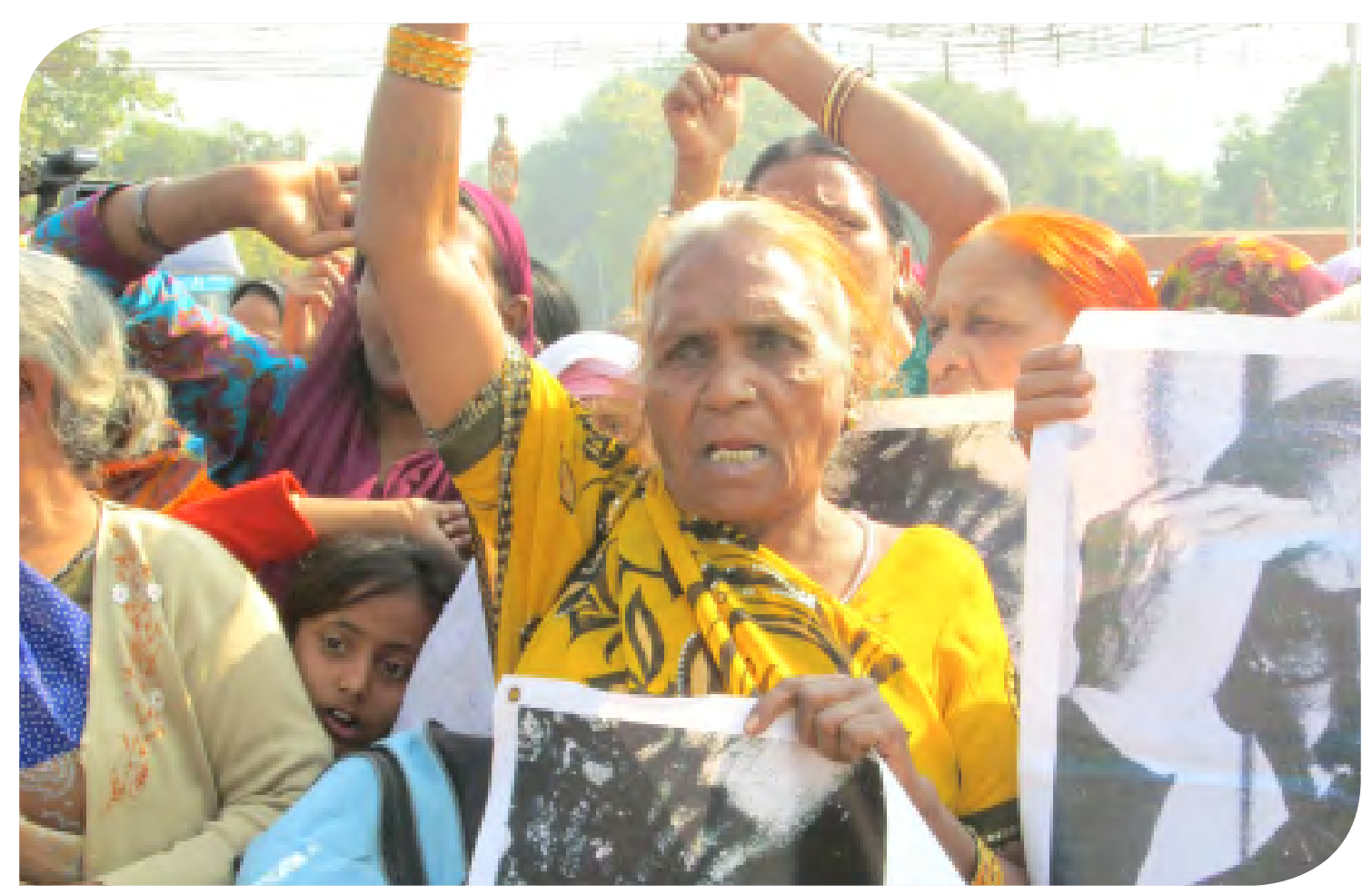

Bhopali activist Tulsa Bai, protesting against the Dow chemical company.

Photographer: Reena Shadaan

Leading on from the broad analysis of social movements in chapter two, this chapter begins to focus more specifically on mobilisation around women's rights and gender justice. It starts with a discussion of women's and feminist movements, the vision and concepts behind the different strands of activism within such movements, and the gains made by these movements over recent decades. The chapter then goes on to consider how women's rights and gender justice issues have been approached more broadly in movements with different gendered constituencies ${ }^{30}$ and political foci. It outlines the ways that different social movement formations have responded to women's rights and gender justice, looking at both the gender identity of the actors involved and the political agendas of the movements. The concepts of deep structure, intersectionality and questions of who can speak for whom introduced in chapter two are particularly pertinent to this analysis. 


\subsection{What are the defining features of women's and feminist movements?}

Progressive women's movements are united around a common cause of challenging gender inequalities and injustices in society with a view to ending patriarchal domination. ${ }^{31}$ They may focus on a particular issue (such as girls' education, housing, the vote, environment, peace, decolonisation), a particular constituency (for example, indigenous women, workers or young women) or frame their agendas more broadly as struggles against all forms of oppression on the basis of gender.

Not all women's movements or activists allied with movements for women's rights and ending patriarchy identify with the term 'feminism'. However, it is useful to consider that 'the consciousness of sexism and sexist oppression is the essence of feminist politics, and it is this politics that energises women's movements, whether or not the word "feminist" is used' (Antrobus 2004: 16). Feminism as a politics proposes that the systematic exclusion and marginalisation of women in society is not natural but, rather, is based on patriarchal gender power relations that systematically privilege the collective interests of men and boys over those of women and girls in all spheres of life. Different strands of feminism also analyse how other axes of power including capitalism, racism and ethnic privilege, heterosexism and ableism (privileging the able-bodied) interact with patriarchal power to marginalise different groups of women and also create hierarchies of privilege between women (for examples of these different strands and standpoints see Abu-Lughod 2001; Duatre 2012; Imam, Mama and Sow 1997; Mohanty 2003; Moraga and Anzaldúa 1981; Simmonds 2011; Price 2009; Wilson, Sengupta and Evans 2006; Shah 2011).

Feminist and women's movements have led the way in activism to address gender inequality across social, economic, political and cultural spheres, including engaging the body itself as a site of struggle, and seeking shifts in power around issues such as sexuality and reproduction at individual and collective levels through their engagement in social movements (Harcourt 2009; Harcourt and Escobar 2005). For example, activist campaigns such as Women in Black - allied to feminist and peace movements - have used the symbolism of occupying public space with their bodies to assert solidarity against the physical occupation of territory.

\section{Women in Black}

Women in Black was founded by a group of Israeli women in 1988 to protest against human rights abuses by Israeli soldiers in the Occupied Palestinian Territories. It has since become a transnational network of activists for peace and against violence against women, militarism and war. Women in Black groups protest by staging public vigils where protesters use their bodies and public presence as a tool of protest, dressing in black and carrying placards and leaflets expressing their political views. Some groups focus on transnational solidarity with ending conflict in Israel/Palestine, while others focus on conflict in their own communities and countries.

(Source: http://www.womeninblack.org/)

31 The term patriarchy describes systemic and institutionalised male domination and the cultural, political, economic and social structures and ideologies that perpetuate gender inequality and women's subordination (Just Associates 2012). 
Feminist movements are thus focused on the transformation of gender power relations in all domains of life, including cultural norms and practices, laws and policies, the structure of the family, media and representation, work and labour, religious institutions, the body and people's own perceptions of themselves as gendered beings.

\subsection{How have feminist and women's movements evolved?}

Feminism in its various forms has been a central political framework for many strands of women's mass mobilisation and demands for equality, rights and social change in all global regions. Although the origin of feminist political analysis tends to be placed in the writings and collective actions of women in Europe and North American, history shows that there is in fact a rich history of feminist critique and collective action across the world..$^{32}$ From the onset of feminist politics in the North itself, women of colour have also challenged what they saw as a limited discourse of white feminism in not engaging intersecting questions of race, class, heteronormativity ${ }^{33}$ and colonisation as axes of inequality between women as well as critical concerns for feminist action (Amos and Parmar 2001; Moraga, Anzaldúa and Bambara 1984).

In their politics, women's and feminist movements have approached the question of naming and confronting patriarchal power in many different ways, drawing on varied political traditions (such as liberalism, Marxism and anarchism). They situate themselves within political visions and movement commitments around challenging other axes of oppression such as race/ethnicity, class, religion and sexual orientation. There is in fact no monolithic 'women's movement'. Strategies and tactics in movement activism also vary, even within the same movements, as movements take on different approaches at different times in light of opportunities presented, in responses to spaces opened up within activism, and in assessing the efficacy of past strategies (Salo 2005).

Some women's movements originally started as part of mixed-gender movements, but the failure to redress their particular form of discrimination spurred them on to create their own social movement, as with this example of the Dalit women's movement:

'In the south Indian context during caste riots, the human rights movements and Dalit movements did not register the atrocities on Dalit women, and these were excluded in their fact finding reports. It was the Dalit women who stayed back and faced the violence by other castes but the issue of the rights violations of Dalit women and school-going children was absent in the documentation reports. That is why a separate Dalit women's movement was promoted. The Dalit women's movement condemned such ignorance and exposed the atrocities on Dalit women during caste riots' (Burnad Fatima Natesan, BRIDGE e-discussion, September 2012).

As mentioned above, there is still contention around the use of the label 'feminist' within women's movements, notably among constituencies that do not see their own realities reflected in Western feminist discourse (for example, some indigenous women and women of colour). Dividing lines also appear around the degree of

32 Examples include the Egyptian Feminist Union which was founded in 1923.

33 Heteronormativity is a term used to describe the assumption of universal heterosexuality. 
willingness to challenge patriarchal power in the private sphere, particularly around the construction of the family, sexuality and reproduction and related discourses of culture and tradition that shape these. In addition there are areas of disagreement and debate in relation to different positions on meta issues such as the economy and the State.

\subsection{Intersectionality and inclusion in women's movements}

Women's movements, as social phenomena, inevitably have to confront hierarchies and inequalities among movement members that stem from mainstream norms and social practices. Indeed discrimination within women's movements, by members representing social majorities, has itself spurred the creation of new movement politics from the perspective of different subjectivities and identity groups. Some of the key areas in this respect are discussed below.

\subsubsection{Sexual orientation, gender identity and evolving understandings of gendered power}

The debate around gender norms and gender power relations instigated by women's and feminist activism has raised questions around the underlying heteronormativity in both progressive politics and in law and policy around gender equality (see Cornwall, Correa and Jolly 2008). Feminist theory and activism has been central to naming and raising visibility around the ways in which lesbian and bisexual women face discrimination both due to their identity as women and their sexual orientation (CREA 2012; Rich 1980), pointing to a need to acknowledge different forms of gendered experience and hence different social, legal and service demands for different constituencies of women.

Transgender and intersex activists as well as queer theorists ${ }^{34}$ and activists have posed a challenge to those women's movements that still rest on a binary or biological understanding of gender. Requests by women-identified trans and intersex people for inclusion in women's activist spaces has pushed the discussion around gender as social rather than biological further, as the existence of more diverse gender expressions and identities, including transgender and placebased identities such as hijras ${ }^{35}$ is emphasised. These debates continue to provoke questions around who can claim the identity 'woman' and participate in and use 'women's spaces' and resources. ${ }^{36}$ Queer theory also raises questions around the utility of continuing to organise as 'women' when so many people do not see themselves as fitting neatly into 'male' or 'female' definitions or bodies - a debate that is ongoing in feminist and women's rights communities in both theory and practice (see Jolly 2000).

34 Queer refers to a theoretical framework and an identity that questions the norms of heterosexuality and the idea of binary gender (only two static forms of gender identity). It is increasingly used in addition to, or in the place of, the category 'Lesbian, Gay, Bisexual, Transgender and Intersex'.

35 Hijras are a long-standing community of people in the Indian sub-continent who adopt a female gender identity but are born physiologically male or intersex.

36 An example is the successful advocacy by transgender feminists to be included in the regional feminist movement forum the Latin American and Carribbean Feminist Encuentro. The statement presented to the Encuentro in 2005 is available at http://www.iglhrc.org/content/brazil-transgender-inclusionfeminist-encuentro. 


\subsubsection{Men, masculinities and challenging patriarchal power}

In the process of identifying gender as a social construction, feminism inevitably opened questions around the place of men's and boys' roles in patriarchal society. This includes interrogating the construction of ideas around masculinity, and the ways in which these both re-entrench gender inequality as well as limit men's own expression, social roles and identities and relationships to violence. Men engaging in transformative work on gendered power have raised questions around how heteronormativity affects both women's and men's activism for equality:

'I think a big challenge is the heteronormative binary view of what gender is. Many in the women's movement focus on women as mothers, carers and workers but essentially different from men, and many in the men's movement focus on men as fathers, lovers and partners but essentially different from women, all within a very prescriptive heteronormative framework of the monogamous nuclear family... we all have investments in that binary system whether we are aware of it or not' (Interview with Jerker Edstrom; Nascimento 2012).

There are now active movements of men, working in men-only contexts as well as with mixed-gender constituencies around masculinities and gender inequality (see Cornwall, Edström and Greig 2011; Shefer et al. 2007). Theorists such as Castells (2010) see the emergence of men's movements and the engagement around gender norms and discourses outside women's movements as evidence of the success of feminism in popularising new ways of thinking about gender identities and social roles. Feminist and women's movements have varied positions on this. Many support the engagement of men and boys in challenging accepted ideas and practices around masculinities and are keen for them to work in solidarity towards the goal of gender equality and women's rights. However, concerns are often raised that the political analysis, strategies and resources allocated to work on men and masculinities will benefit men and boys without resulting in a positive transformation in the lives of women.

\subsection{The impact of women's, feminist and gender justice movements}

While there is still a long way to go toward the transformation of unequal gender power relations, the growing presence of women's and gender justice movements and feminist activism across the world is testimony to the continued prevalence of patriarchal power and related struggles. Significantly, the analyses and demands of women's rights and feminist movements have gradually influenced the analysis, frameworks, programming and priority lists of institutions mandated to advance equality, development and/or rights. 
Looking historically, it is possible to trace the collective impact of women's and feminist movements' actions on dominant power relations. Although all social movement 'wins' are contingent and require vigilance in sustaining them against backlash, ${ }^{37}$ it is still possible to identify important changes in society towards a more just and gender-equal world to which women's movements have made a key contribution. These changes include shifting attitudes, beliefs and understandings around women's and men's roles, behaviour, treatment and opportunities; changing institutional practices; and changing definitions of equality, freedom and justice. ${ }^{38}$

While some activists have focused specifically on the experiences and needs of women and girls, and strategies to advance their rights, many have also been part of social movements that involve men, boys and trans people and have brought in analysis and created spaces to engage the specific concerns of women and girls within them. This includes movements around environment and climate change, sexual orientation and gender identity, race, caste and ethnic discrimination, labour rights, disability, peace and pro-democracy agendas. In fact women's activism has been instrumental in setting up new social movements, with broad social justice goals that hold gender justice at the core.

There is an increasingly diverse range of actors involved in demanding and defending women's rights and equality, including in social movements. In developing and articulating their political frameworks, women's and feminist movements have contributed a range of concepts to understandings of social, political and economic life, inequalities and gendered experience, many of which have been taken up by other social movements. This includes the development of important analytical concepts such as the public/private dichotomy, the 'triple burden' of productive, reproductive and care labour (see Moser 1993) and notions of patriarchy, bodily integrity and autonomy, gender identity and the framework of intersectionality (see Crenshaw 1991). These have been incorporated into the conceptual frameworks used by labour, disability, LGBTI, racial, ethnic and caste justice and other movements to generate a vision of social change and of justice. Similarly, feminist rallying cries of 'The personal is political' and 'Women's rights are human rights' have been taken up by other movements along with feminist practices, such as consciousness-raising and feminist leadership and movementbuilding approaches.

Significantly, feminist and women's movement activists have promoted the need for a gender-aware understanding of human rights, which has influenced the development of frameworks for law and policy worldwide (see the box on page 41).

37 Backlash refers to a strong negative response at a popular level or among an influential group to changes in society. Typically used to describe organised responses that seek to maintain unjust power relations or reverse positive gains made towards justice or equality.

38 Examples include legislation and policies around the world setting out women's right to equal and fair treatment in the workplace and public services, and accompanying shifts in attitudes and behaviours around gender equality and women's roles. 


\section{Shifts in human rights thinking on gender}

At the UN World Conference on Human Rights in Vienna in 1993, there was a Women's Tribunal on the theme of violence against women. Radical new ideas were put forth, emphasising the importance of the private sphere and non-state actors in human rights abuses for women. The slogan 'Women's Rights are Human Rights' resonated as women's testimonies moved the UN General Assembly to pass the Declaration to End Violence Against Women. Next stop was Cairo in 1994, where sexuality and reproductive rights were put onto the agenda, then Beijing in 1995, where the concerns of women's movements were cemented into a plan of action for governments to take back and translate into policy and legal reform. Continuing lobbying and advocacy by feminist activists meant that, as the 1990s drew to an end, an unmistakable feminist presence made its way into international human rights law. With evidence of mass sexual violence in conflicts, rape was recognised as a weapon of war. Women's rights advocates ensured the inclusion of gender-based crimes in the Rome Statute of 1998 that set up the International Criminal Court. Other successes included Security Council Resolution 1325 in 2000, which established women's rights as a matter of national and international security, and a re-defining of the 1998 UN Declaration on Human Rights Defenders to include the specific retaliation faced by 'women human rights defenders'. (Adapted from Bhattacharjya 2013)

\subsection{How are women's rights and gender justice included across the broader social movement spectrum?}

Even taking into account the considerable gains discussed above, for a complete transformation of patriarchal power to take place, alongside a dismantling of unequal power relations more broadly, activism on women's rights and gender justice cannot be limited to women's movements alone. The following section maps out the responses of different social movement formations to women's rights and gender justice. While categorising movements in this way facilitates comparison and analysis, it is critical to remember that social movements are porous and movement members or groups may see themselves as belonging to many movements simultaneously, particularly in the context of an intersectional analysis of their identities and politics.

\subsubsection{Women-led movements for broad social change agendas}

Women's movements may act as instigators for the birth of social movements not focused exclusively on confronting gender inequalities, or for generating popular support to tackle issues facing society. In these cases, women mobilise both as women and in the name of societal-level change on specific agendas. The political vision of equality for women is seen as being integral to the broader change being sought.

There are many historical and contemporary examples of women's activism instigating broad social and political action that has resulted in both increased rights and justice for women and societal or political change on a particular issue. For example, in 1917 Russian women workers gathered on International Women's Day in St. Petersburg to protest against bread shortages. The demonstrations grew as they rallied other workers to join, and were a contributing factor in the Russian 
Revolution and the fall of Tsar Nicholas II. The post-revolution provisional government granted women the right to vote (United Nations, 2008). The example of women's peace activism in the Liberian civil war below elaborates this point further.

\section{Women's leadership to end the Liberian civil war}

The Mass Action for Peace was a grassroots movement of women that contributed significantly to the ending of the second Liberian civil war (1999-2003). In the face of escalating violence against civilians, women began to mobilise through churches, mosques, links to the regional NGO Women in Peacebuilding Network (WIPNET), and using personal connections with one of the wives of the then President Charles Taylor. Dressed in white, the women used non-violent protest strategies including public demonstrations, silence and songs. Although women were not included in formal peace talks in Accra, Ghana, women from the Mass Action for Peace organised to travel so that they could stand in protest outside the building where the talks were taking place. During the peace talks, one of the movement founders, Leymah Gbowee, threatened to strip naked in front of men (a traditional form of women's protest which was understood by the West African men in the peace talks process). This strong cultural symbol of resistance was instrumental in persuading the rebels, the President and negotiators to come to an agreement. While the Mass Action for Peace's primary goal was to end the war, its activism also laid the ground for a historic step in women's rights. The first woman President in Africa, Ellen Johnson Sirleaf, was elected in post-war Liberia with support from the Liberian women who had mobilised for peace. She in turn committed to prioritising gender equality during her Presidency. (Source: Horn 2011)

The following example of women's activism against nuclear missiles from the 1980s onwards in the United Kingdom also demonstrates the broad and multifaceted impact that women-led activism can have.

\section{Greenham Common and the British peace movement}

In the 1980s the North Atlantic Treaty Organisation's (NATO) decision to deploy new intermediate-range nuclear missiles in Europe sparked the largest peace movement in the continent's modern history. Within it, the women's peace camp at Greenham Common in Berkshire, England, was one of the most significant mobilisations for peace and nuclear disarmament. In 1981 a Welsh peace group, Women for Life on Earth, embarked on a march from Cardiff, Wales, to Greenham Common to protest against plans to relocate American missiles to the US air base there. They eventually formed the Women's Peace Camp outside the base. Protesters identified as feminists and retained a strictly women-only camp, arguing that men were likely to become violent in the demonstrations. Over time they staged non-violent direct action campaigns, including chaining themselves to and/or cutting the fences of the base and blocking roads. Greenham women themselves became symbols of an alternative to accepted gender norms and roles, as they had relocated from their homes to the camp for long periods. Greenham women also became involved in a range of issues in a number of countries, including solidarity with workers around the UK miners' strike, anti-apartheid and the movement against pornography. The missiles were removed from Greenham Common in the early 1990s following the Intermediate Nuclear Forces (INF) Treaty between the US and USSR, however the camp remained until 2000.

(Sources: Harford and Hopkins 1984; McGuffin 2007) 


\subsubsection{Men's movements for women's rights and/or gender justice}

As feminists have raised questions around gendered social norms, activist men have also developed theoretical and practical approaches to interrogating how patriarchal power affects men and boys (see section 3.3.2). Male actors in movements allied to feminist and women's movements argue that:

'If we really want to make gender and women's rights an integral part of the agenda of everyone, not just women, we need to be prepared to empower other actors, particularly men, to speak with authority about women's issues' (Atila Roque, BRIDGE e-discussion, October 2011).

One strand of this activism focuses on men mobilising in solidarity with women and for women's rights agendas. Much of this solidarity and activism thus far has focused around ending violence against women, in initiatives such as the White Ribbon Campaign.

\section{Mobilising men against violence against women}

The White Ribbon Campaign, established in response to the Montreal Massacre of 1991, claims to be the world's largest movement of men and boys working to end violence against women, having spread to over 60 countries. It combines education, outreach and institutional support in an effort to engage and inspire men toward positive change. The wearing of a white ribbon symbolises a pledge to never commit, condone or remain silent about violence against women.

(Source: http://www.whiteribbon.ca)

Individual men play a role as allies, sometimes against the grain of other men in the movement, in redefining movement politics to be inclusive of gender justice, and pressing for change in social movement practices at all levels. Taking a generational view, younger men's exposure to activism by women in their communities may in turn generate new activism in support of women's rights, a point explained in the following example from the Canadian migrant care worker's movement:

'With respect to the migrant care workers' movement in Canada, it is interesting to witness how the sons of former care givers have become quite active in the movement. Their personal experiences with family separation have compelled them to seek changes on behalf of other migrant care workers and other migrant families. Thus, I think men who have directly witnessed the extent to which their mothers, wives, and sisters have struggled economically, socially, and politically are more likely to be involved' (Ethel Tungohan, BRIDGE e-discussion, October 2011).

Another strand of men's activism focuses on men themselves, looking in particular at how mainstream ideas of masculinity expose men themselves to harm and encourage male violence (see Barker et al. 2011). Similar to investments that women's groups have made in consciousness-raising, some men's groups are working on engaging individual men in processes of questioning and transforming learned patriarchal behaviour in all domains, as the example in the box on page 44 shows. 
The Study into Action project on challenging male supremacy, based in New York City, USA, brings together individual activist men in a nine-stage curriculum, 'exploring the workings of male supremacy as it interacts with other systems of oppression in the US context and looking at and practicing the ways in which men can be challenging male supremacy in their own relationships and friendships, as well as in their organisations and activist formations, and movement spaces more generally' (Alan Greig, BRIDGE e-discussion, October 2011; see also Jashnani, Maccani, and Greig 2011).

\subsubsection{Mixed-gender movements that do not have women's rights or gender justice as a foundational focus}

Historically, most progressive social movements have not embraced a commitment to consider gender inequality or challenge patriarchy from the outset. Often gender analysis and action begin in such movements when women activists start to question why they are being left out of movement visions or not acknowledged in movement leadership when they have risked their lives and / or worked just as actively for movement goals (for example, D'Atri and Escati 2008; Meer 2005). As such, many mixed-gender movements are in the process of transformation, albeit slow. In the Occupy $^{39}$ movement, despite a proclaimed focus on democracy and flat leadership structures, tensions quickly emerged over the movement's degree of inclusiveness and the diversity of its leadership. To highlight women's demands, feminists created new spaces within Occupy, such as feminist general assemblies and caucuses (Sahasranaman 2013).

\section{Feminist perspectives on Occupy}

'Now, feminists must take on the challenging task of placing women's demands at the centre of Occupy. Demands should not be restricted to issues of safety and prevention of inter-personal violence; they must be built by re-imagining the idea of economic justice from the perspective of women, as well as people who are otherwise excluded: the disabled, queer, homeless and those of colour. Only then can the movement claim to represent the 99\%.' (Sahasranaman 2013: 4)

In the case of Amnesty International, a key member-based organisation within the international human rights movement, the last 25 years have seen progress on 'takeup' of women's human rights. Critical to its progress on gender equality was the re-thinking of Amnesty's approach to human rights to include women's rights, as a result of internal pressure from members and staff and external pressure from feminist activists and colleagues from the broader human rights movement. The box on page 45 outlines the challenges and tensions of this process, the gains and the road yet to travel.

39 Occupy is an international movement that protests against the current economic structures that distribute wealth unevenly, with the vast majority of resources owned by 1 per cent of the world's population, leaving 99 per cent without an equal share. It began in the USA in 2011 with protests in the financial centre of Wall Street in New York City (Sahasranaman 2013). 


\section{Amnesty International - the road to women's human rights}

Amnesty International (Amnesty or Al) was founded in 1961 to promote and protect human rights. The organisation now has 3 million members and supporters in 75 national sections and structures and is a key actor in the global human rights movement. Amnesty's engagement with women's rights began in the period following the first UN Decade for Women (1975-1985) when advocates within Amnesty and outside began pushing Amnesty to work on women's rights and move beyond an exclusive focus on political prisoners. With the international recognition of women's rights as human rights in the 1990s, Amnesty's Secretary General took a leading role in stating Amnesty's support for women's rights.

However, active internal debates persist around the political and conceptual implications of women's rights, including the idea of advocating for a 'specific group' in the context of universal human rights; agreements on approaches to contentious issues such as abortion; and addressing rights violations by non-state actors in the name of religion and culture. Amnesty's Stop Violence Against Women Campaign (2004-2010), its adoption of a gender mainstreaming policy (2009) and the creation of staff positions focused on gender signify important steps in the process of embracing of women's rights. (Adapted from Kelleher and Bhattachariya 2013)

In calls for inclusion, women's rights and gender equality activists may bring an intersectional analysis to the struggle; for example, in anti-racist movements women have argued that race and gender cannot be considered separately and have pointed to the ways racism differently affects men and women, or climate change and environmental movements that highlight how environmental injustices have different gender impacts ${ }^{40}$ (Stein 2004; Zimmerman, Mial and Khan 2009). Women in indigenous people's movements have asserted the interconnectedness of gender relations, environmental justice, land rights and indigenous self-determination (Caro 2013). Equality activists in the human rights movement have argued that the concept of human rights must be flexible enough to address intersectional identities and the specific needs of different groups (Bhattacharjya 2013; Kelleher and Bhattacharjya 2013). By bringing women's rights into the picture, movement activists assert a vision of change in their own communities which is inclusive of their own lived realities of injustice and hence visions of positive transformation. A Roma woman activist expresses this point as follows:

'I'm convinced that always when I advocate for Romani women's rights, I advocate for the rights of Roma! We cannot achieve much in our struggle if we don't recognise that Romani women are victims of intersectional discrimination based on sex as well as ethnicity. Therefore, we have to overcome the existing misunderstanding between the Romani women's rights defenders and Romani men (and in some cases women) activists who think that Romani women's rights... do not need separate attention' (Memedova 2004: online). 


\subsubsection{Mixed-gender movements with women as active leaders and members but without a central focus on gender justice}

'The presence of women even in active roles does not necessarily imply that women in that movement have decision-making power or leading political status. I have noticed that in some meetings and events, there are many women doing the logistics, note-taking, interpretation and other support work. But on the plenaries, panels and other public representation, speaking and moderating slots are dominated by men from these movements. When I have insisted/asked for women to be on these panels or represent the movement, I am told "women in our movement do not have the capacity..." Subsequently, I have also tried to organise "capacity building" activities for women in these movements and met with a lot of resistance. The movement leaders say they don't have time and resources, other issues are more urgent, struggles have to be strengthened, deadlines have to be met, etc.' (Shalmali Guttal, BRIDGE e-discussion, September 2012)

There are many examples of progressive social movements where women play active roles by making up the majority of movement membership or acting as movement leaders, and yet they do not have an explicit gendered focus. This underscores the point that the presence of women in a movement does not guarantee that they or the movement will have an explicit focus on women's rights and gender justice. Gendered politics in a movement need to be built.

The pro-democracy movement in Libya is one example where women's activism was catalytic in igniting an uprising and making moral claims against the government of Muamaar Gaddafi but was not integrated into the vision of the movement or followed up in the immediate post-revolution period:

'It was women who ignited the Libyan revolution. Two days before it broke out a number of mothers of Libyan political prisoners held a demonstration outside Benghazi's main prison to protest the detention of their lawyer, Fathi Tuhail. The brutal response to this action brought Libyans into the street to demand the fall of Gaddafi. Female attendance at these initial protests varied between 10 and 20 per cent, and the women marched separately from the men... The most widely known symbol of the Libyan revolution was, however, Iman al-Abeidi, who had the extraordinary courage to enter a Tripolitan hotel packed with security agents and expose her rape by a group of Gaddafi cadres' (Al-Bizri 2011: online).

Some movements - commonly nationalist movements - may actively include women in roles that transgress accepted female roles, such as in armed combat. However, women are usually expected to revert to traditional gender norms once liberation has been achieved. ${ }^{41}$ Women who were once celebrated for non-gender-conforming roles in the battlefield and in public may find themselves ostracised in the post-liberation period when they continue to 'behave like men' in the way they dress and social roles (Connell 2001).

41 Examples include the Tamil Tigers in Sri Lanka (Basu 2005) and the Eritrean People's Liberation Front in Eritrea. 
Women who are active within movements do not themselves intrinsically adopt a gendered politics. This needs to be built or is instigated when it becomes unavoidable not to address gendered axes of power, either in the face of external challenges (such as targeting of women) or internal challenges (such as sexist statements or acts of violence against women by members). As such, movements with women as active members represent fertile ground for questions about where women's rights and gender equality stands. This may be sparked by consciousness-raising and exposure to feminist politics, by active outreach by feminist and women's rights movements to women within these movements, or experiences of gender discrimination which demonstrate the need to consider women's strategic concerns. It may also be instigated by women members within these movements who recognise a need to build up women's voice and gendered analysis, as in the case of Via Campesina's regional Coordinating Network for Latin American Rural Organisations (Coordinadora Latinoamericana de Organizaciones del Campo - CLOC).

\section{Integrating a feminist perspective into CLOC-Via Campesina}

Since the CLOC - the regional wing of the international peasant movement Via Campesina - was founded, women members have worked to fully integrate feminist and women's rights concerns into its visions and practices. The first Women's Assembly in 1997 secured a commitment to women's equal representation in the CLOC's decision-making processes. From there it built women's own political analysis and internal solidarity through training schools focused on gender and class equality, encouraged women's leadership in member organisations and formed an alliance between the CLOC and another global network, the World March of Women. To date these strategies have created visibility for the CLOC's Women's Network, including by increasing women's leadership in member organisations and delegations; a strong position against sexual harassment within; and successful campaigns 'From Seeds', 'Food Sovereignty' and 'Enough Violence', which were begun by women members but later taken up by the whole organisation. (Source: Caro 2013)

\subsubsection{Mixed-gender movements with gender justice as a foundational axis}

Progressive social movements that bring gender perspectives into broad-ranging social, political, economic and environment struggles and embrace women's rights and gender justice within their external- and internal-facing strategies and dynamics will be more effective, impactful and representative. Yet, as social movements emerge in the context of contemporary feminist and women's rights politics and widespread recognition of the need to tackle gender inequality, it is surprising how few movements actively incorporate gender justice as a foundational axis from the onset of their development.

There are, nevertheless, some examples of mixed-gender movements taking an intersectional approach to their politics, which includes analysis and action on gender inequalities as central. These tend to be movements that have taken up aspects of feminist-inspired analysis, notably movements focused on bodily integrity and autonomy, as well as on gender identities. In other cases, when women have been central actors and leaders in founding movements, they have framed the movement's 
agenda and strategies in gender equality terms without making explicit reference to a 'women's movement'. This is the case with the international movement of slum and shack dwellers.

Women's leadership in the international movement of slum and shack dwellers

'It is always women who dream of tree-lined streets, brick houses, and safe places for their children to play. And women are willing to save incrementally to turn this dream into a reality. Thus, women's savings and loan schemes are the foundation for all collective action.' (Shack/Slum Dwellers International: online)

Slum and Shack Dwellers International (SDI) is the organisational face of a transnational movement of the urban poor. It is made up of city-level federations of self-organised groups of urban poor living in slums, informal settlements and on the streets in Asia, Africa and Latin America. Women have played a central role from the onset of the movement, as active members of the local groups organising for land, housing and greater economic autonomy through savings schemes, as well as in the federation's leadership at local, national and international levels. Women active in local federations have helped organise poor urban women and men in other neighbourhoods, cities and countries, provided technical assistance to emerging groups in developing strategies around savings, negotiating with city authorities and learning about effective, affordable construction techniques. Women's leadership and participation are explicit pillars of SDI's strategy to both build inclusive cities and positively transform women's position in society. (Source: Patel, Burra and D'Cruz 2001)

In the few contexts where feminism has become an integral part of progressive politics, young women may see themselves not solely as part of a women's movement but rather as allied to social movements that are fully inclusive of a challenge to patriarchal power. As a young French feminist expresses: 'I don't only fight for women's rights, I feel myself in a fight against social norms which reinforce unequal power relationships' (Charlotte Soulary, BRIDGE e-discussion, May 2012). This represents a political step forward and needs to be sustained, including by listening to and being guided by the integrated analysis of newer generations of activists.

\subsubsection{Alliances between women's movements and other social justice movements}

Women's movements may form short- or long-term alliances with other social movements in the context of campaigns, uprisings and protests or as part of general solidarity and seeking common cause. These alliances may be based on intersectional politics - for example, alliances between women's movements and anti-racist or ethnic minority movements or movements of the urban poor - or they may occur when women's movements situate themselves as an integral part of other social movements for example, peace, environment, labour, housing or democracy movements.

There are several examples of positive and fruitful alliances between women's and other progressive social movements. In the East African region feminist, LGBTIQ and sex worker movements have joined forces to fight against conservative and regressive policies and laws affecting minority groups. Building relationships and links between movements has resulted in the concerns of sex workers and LGBTIQ people being included in the macro-level goals of feminist and other social justice movements: 
'There are plenty of people who do not identify as LGBTIQ or as sex workers but are interested in human rights, and are engaged with the movements. These people [...] do not want to see their friends, families, allies or co-workers discriminated against. They have realised the power of building on commonalities between movements' (Nakaweesi-Kimbugwe with Chigudu 2013: 5).

The acknowledgement of women's and feminist movements as full participants in other social movements, however, varies by context. Women's movements often face the challenge of reciprocal solidarity, whereby women's movement actors will stand 'side by side' with broader movements, but other social movement actors will not always step up in defence of women's movement agendas in return. This point is explored below:

'For years the Zambian civil society has been demanding for a people driven constitution. We have fought running battles with the politicians and the police on this issue. But when it comes to the content of the constitution that we desire, issues of women's rights, and social economic rights being enshrined in the constitution realising that the majority of the poor are women and as we say poverty has a woman's face, we are left alone in the ring. Our comrades would rather focus on corruption' (Emily Sikazwe, BRIDGE e-discussion, September 2012).

Women's movement activists engaged in recent pro-democracy movements in North Africa have faced similar experiences as women's rights demands are silenced during and after protests. In Tahrir Square in Cairo, Egyptian women activists point out that:

'[No others were]... told that their demands are unjustified, unnecessary, a threat to the gains of the revolution, out of time, out of place and/or the product of a foreign agenda! No other demonstrators were told to go back home and to the kitchen! No others were heckled for how they look and what they were wearing!' (Hania Sholkamy, BRIDGE e-discussion October, 2011).

Mutual solidarity is not automatic. Women's movement actors may find that they have to make the case for solidarity by 'proving their contribution' to the community first. In the case of a single women's group in a low-income area in Delhi, India, for example, 'the group gained a certain legitimacy in the [eyes of the] neighbourhood only after they started taking up community problems (water, corruption, electricity, demolitions) with the state that resulted in obvious changes in the community' (Manjima Bhattacharjya, BRIDGE e-discussion, March 2012).

In this chapter the focus has sharpened to look at women's, feminist and gender justice movements, and their history, politics and strategies, before moving on to consider the ways that different social movement formations have responded to gender equality issues. In chapter four, the discussion moves to some of the challenges and tensions experienced by women's rights and gender justice advocates when attempting to integrate a gender perspective into the internal and external work and dynamics of their movements. 


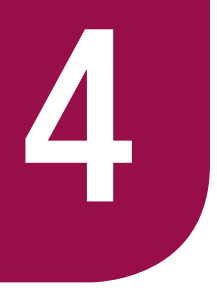

\section{Integrating Gender Justice into Social Movement Practice: Challenges and Tensions}

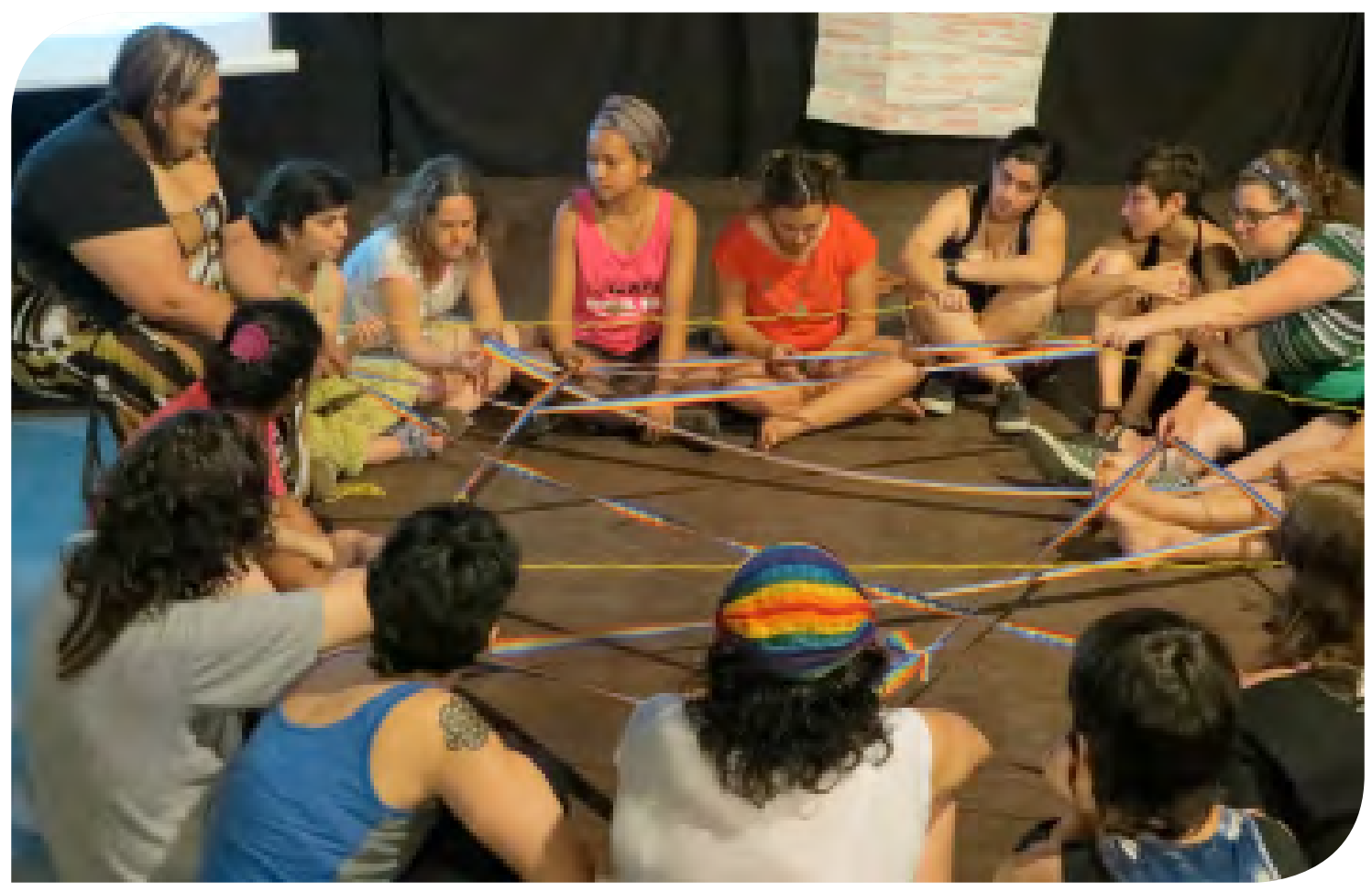

A workshop on abortion at the Encuentro LesBiTransInterFeminista Venir al Sur. A safe space of solidarity, respect and empathy.

Photographer: Tamara Pels-Idrobo Tapia

This chapter draws on experiences from within social movements to look at common challenges and tensions that obstruct or prevent the full integration of feminist perspectives and gender justice concerns into progressive social movement vision and practice. It draws on experience shared by social movement actors themselves as well as research and analysis around tensions and barriers that exist in different movements and geographic spaces. The similarity in experiences across locations in itself points to how pervasive accepted gender norms and power relations are in the deep structure of our societies and hence our movements, and the extent to which these norms are often defended even if they contradict movements' ethics around equality, equity and participation. Chapter five goes on to explore ways in which movements have responded to these challenges and tensions as part of advancing and sustaining an integrated feminist and/or gender justice focus. 


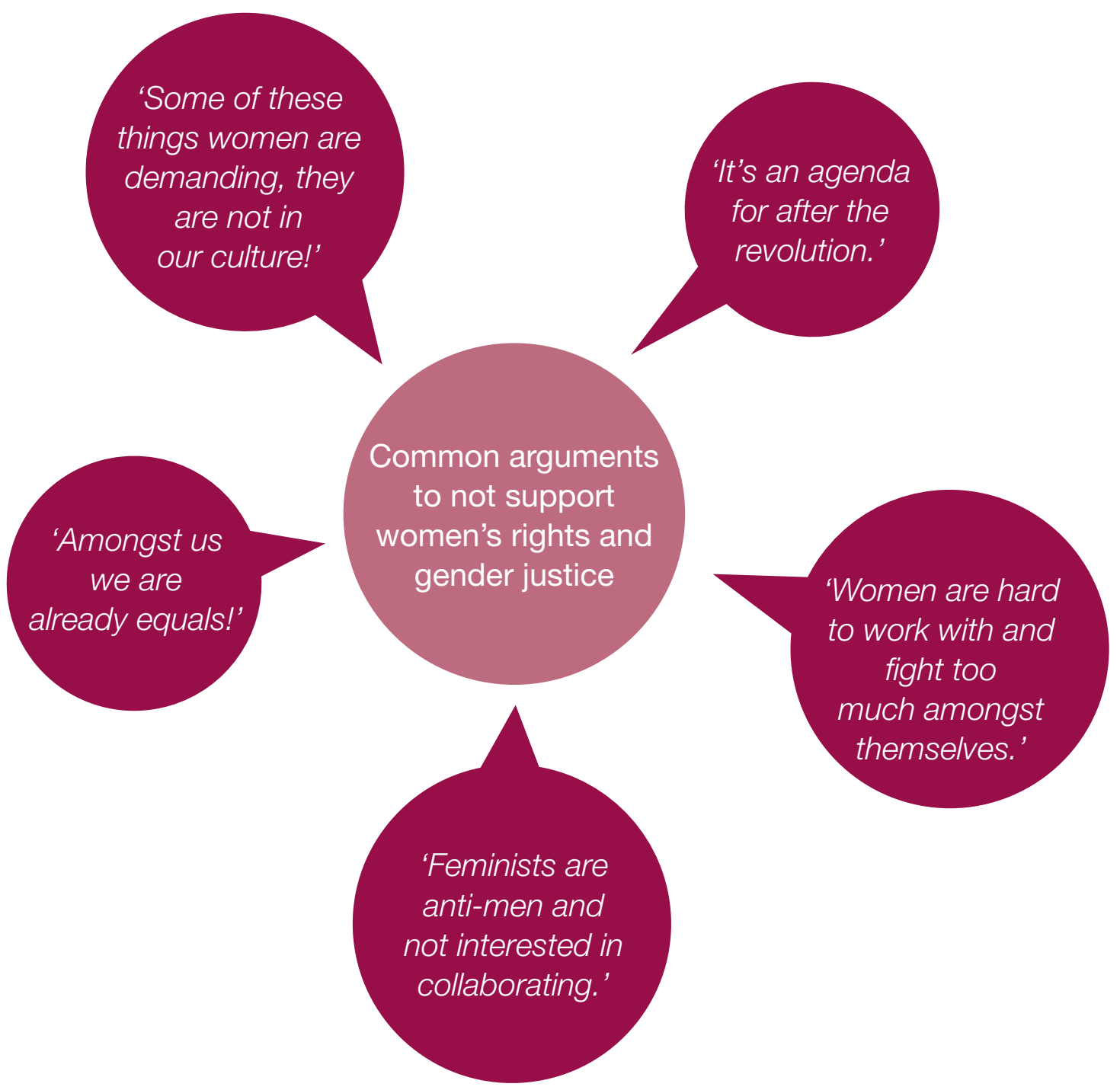

Although there is great diversity in social movement experience, there are still common recurring challenges that appear across different social movements and across cultural and geographic contexts. These challenges can be grouped into the following areas which are discussed below: recognition of gender equality as a key issue for movements; gendered attitudes and behaviours within the deep structure of movements; resistance to tackling gender power relations within the private sphere; de-prioritising of gender in movement agendas and allegiances; and the problems of sustaining gender-just changes in the longer term.

\subsection{Barriers around the recognition of gender equality and women's active roles as key issues within movements}

Resistance to integrating women's rights and gender justice as a key movement priority can often take the form of dismissing the significance of gender equality as a political objective. For example, it may be argued that women already actively participate in a movement, which in turn suggests that they are satisfied with the movement's focus, or gender justice may be positioned as a divisive topic that detracts attention away from other issues perceived as more important or fundamental to the movement. 


\subsubsection{Identifying inequalities among 'equals'}

Activists frequently come up against a challenge of making the case for gendered analysis and specific actions on women's rights and gender justice because the movements they are part of are ostensibly already about democracy or inclusion. Taking a historical perspective, women in liberation and decolonisation movements in the global South and anti-racist and civil rights movements in the global North faced numerous barriers in persuading others to acknowledge gender power differentials within revolutionary movements. In Latin America for example, 'most feminists - in the 1980s and before - belonged to left-wing political parties... [where people would argue that] we "are all equals, no racism, no sexism. Why do you include such a discussion in our parties?"' (Elsa Duhagon, BRIDGE e-discussion, October 2011). This trend continues to be present, even in movements emerging in contexts where the ideas of gender equality and women's rights are already widely accepted and supported. Indeed global progressive social movement spaces such as the Occupy movement, and the World Social Forum - a diverse movement space founded in 2001 - among others, have grappled with how to fully embrace women's rights and gender justice in their internal dynamics and public politics.

\section{World Social Forum - integrating feminism and women activists into} visions and practices of 'another world'

The World Social Forum (WSF) brings together activists and movement leaders from around the world who are fighting against neo-liberalism ${ }^{42}$ and for economic and social justice. It began in 2001 in Brazil, when the forum's phrase 'Another World is Possible' was born. It is 'a place of experimentation, learning and expression of global social movements' offering 'a new utopian vision - a vision that has almost disappeared in recent decades' (Vargas 2005: 107).

But women's rights and gender equality have not naturally emerged within this vision. At the first forum, although women made up 54 per cent of the participants, 85 per cent of those in the most important 'official' panels were men (Vargas 2005). The fifth forum in 2005 was the first time that gender featured within the forum's thematic axes, appearing as one of five cross-cutting axes (Navarro and Silva 2007). The idea of the WSF as an inclusive space was further undermined by incidents such as the sexual assault of young women in the youth camp of the fifth WSF in Brazil (Obando 2008), exposing the extent to which women's safety had not been considered in planning the Forum space.

The most recent WSF took place in Tunisia in March 2013. There were 11 thematic axes, one of which explicitly mentioned gender. The Forum itself commenced with a plenary on women's rights, which was full to capacity with delegates. There were also daily sessions on various women's rights themes including women's past and ongoing role in the revolutions in North Africa and Tunisian women's struggles. The marked change in the visibility of feminist voices and women's rights struggles was due to persistent advocacy by women in the forum planning process. As Gina Vargas, a member of the International Council commented, 'It was very impressive to see how the Tunisian women managed to put gender issues in the centre of this forum since the beginning' (Interview by author with Gina Vargas, 2013).

42 Neo-liberalism refers to a political movement that promotes economic liberalisation - for example, promoting the reduction of trade barriers, such as import tariffs, as a means to promote international trade and cooperation - as a means of promoting economic growth and securing political liberty (www.wiktionary.org/wiki/neoliberalism). 
Looking broadly, however, the WSF continues to grapple with how to fully integrate women's rights and women's voices and participation in shaping definitions of 'another world' and in building gender-inclusive practices in its own conceptual outlook and organising methods. (Source: Birchall and Horn 2013)

\subsubsection{Instrumentalising women's participation}

In some social movements, movement leaders have actively encouraged the participation of women for instrumentalist reasons such as increasing movement membership or creating a critical mass to shift the balance in key negotiations (see Meer 2005). Women may also be held up by movements as symbols of community or national integrity and part of the moral rationale for fighting oppression. Attacks against women by authorities or repressive social actors may in turn be seen as justification for movements to scale up or take action against violations. This symbolic embrace of women tends to be predicated on normative stereotypes of what are deemed 'good' or 'respectable' women (for example, mothers or 'innocent girls'). Solidarity is less likely in the context of, for instance, attacks against women sex workers or other women who transgress gender norms.

However, this active inclusion of women as members does not in itself signify a willingness to consider their specific strategic needs or to include women's collective concerns as part of the politics or agendas of the respective movements. On the contrary, in many cases there is ongoing resistance to recognising and taking action on women's rights as part of core movement politics.

\subsection{3 'Divide and rule' tactics around gender and sexuality}

External power dynamics around gender can influence if and how progressive movements take on and sustain a critique of gendered power internally. Given that norms and values around gender and related issues of sexuality lie at the core of how patriarchal societies are structured (see Ilkkaracan and Jolly 2006), they can also raise deep and complex questions and challenges. As discussed in section 1.2, conservative and fundamentalist forces continue to make strategic use of debates around gender and sexuality as entry points to rallying popular support for conservative agendas or as routes through which to implement laws and policies that impact on other progressive issues. Movement actors can find themselves facing new adversaries or unexpected challenges to their own legitimacy as members of their respective communities when they choose to show solidarity with particular minorities. This may lead to activists questioning the extent to which they support the full spectrum of gender justice agendas, particularly around women's bodily autonomy and on LGBTI rights.

\subsection{Gendered attitudes, behaviour and stereotypes ingrained within the 'deep structure' of a movement}

The ideas, norms and behaviours existing at informal level within a movement's deep structure can create profound challenges for the realisation of women's rights and gender justice as an external and internal priority. Within movements many women face the expectation of playing caring roles - for example, the assumption that women will organise food for events and gatherings, provide emotional support for movement 
members or take on the 'back office' administrative tasks. This can, in turn, frame limited roles for women's participation with women seen as 'tea makers rather than speech makers' (Meer 2005: 37). Deeply ingrained ideas on gender roles can lead to - and allow impunity for - sexist, discriminatory and even violent behaviour towards women and minority groups.

\subsubsection{Stereotypes about and backlash toward feminism}

As some of the common arguments not to support women's rights and gender justice illustrated at the beginning of this chapter show, there are a range of unhelpful stereotypes around feminism that serve to hinder the building of gender-just movements and alliances. Perhaps unsurprisingly then, there is, as mentioned in chapter three, ambivalence by some women's rights actors about using the term 'feminism' as part of their activism. As the examples below show, some feminists and gender equality advocates within movements report forms of backlash towards the concept, which block their ability to push forward on women's rights agendas.

'One thing I have noticed with the youth groups working on gender in the [UN climate change] processes is a strong pull towards seeing gender equality as simply equality of the sexes - that it should be mainstreamed - a sort of revolt against women in development which is to mainstream gender everywhere and not speak specifically about women. It's this knee-jerk reaction to say, well, this is about gender, not women, not feminism. And again, while I fully believe we need to understand all issues from an inter sectional lens - gender, race, class, socio-economic status, etc. - it is also important to find space to speak about women and equity - a balance which I think those who also have an understanding of feminist values can unpack a bit further' (BRIDGE e-discussion participant, May 2012).

'We/feminists are accused of dividing movements and struggles if we raise the issues of women's equality, equity, rights, etc. in mixed social movements. Part of the challenge here is that there is insufficient analytical work on how women in particular constituencies are differently affected by trends, laws, events, etc. But equally, there are patriarchal set-ups in the movements, and accepting a feminist analysis on issues will expose the contradictions within the movement itself' (Shalmali Guttal, BRIDGE e-discussion, September 2012).

\subsubsection{Sexual harassment and violence within social movements}

One of the most extreme manifestations of gender inequality within progressive social movements is sexual harassment and sexual and/or physical violence against women by their fellow movement members and others participating in movement spaces. It is a recurring phenomenon across many movement contexts (see page 55 for examples). Young women face particular challenges given both age and gender power differentials that make them 'easier' targets for harassment. In many cases women who speak up against violation are themselves sidelined within the movements or face impunity on the part of other movement members. 
Gender-based harassment and violation is political in its impact, with the effect of re-entrenching deeply held normative beliefs around gender roles, while impunity or lack of solidarity with women who are violated reinforces ideas of an 'appropriate' social order in which women do not challenge men's power. It also creates a dissonance between movement 'theory' and movement 'action', which can cause disillusionment or deep questioning within movements around the validity of a movements' politics.

\section{Sexual harassment and violence in progressive spaces}

'The [Youth Camp, World Social Forum, 2005] tried to create a socially progressive microcosm of political relationships and life in society. It was supposed to be the space where the values of the WSF were practised. In this, much like the WSF it failed to include women in this safe and progressive space. There were 90 reported cases of violence against young women in the camp. These included harassment, intimidation, sexual harassment in bathrooms including men masturbating, looking at or filming naked women, and rape.

The lack of a gender analysis for the living space on site created an unsafe living space for women. For example, participants who were not registered with the forum had free access to the camp; there were no women only spaces or campsites, and no women only showers. Moreover, that only one of the perpetrators was detained by the police showed the lack of commitment and procedure on the part of law enforcement. [...] And still, some young men claimed it was the women's responsibility to prevent attacks, and they should have known it was risky to share public bathrooms with men.' (Adapted from Obando 2008: online)

'In the Salvadoran case, feminists supported the Movimiento de Marchas Blancas (Movement of White Marches) - for health rights and against privatisation - but it never incorporated women's demands. At the same time, feminists were openly critical regarding cases of [alleged] rape committed by principal leaders of the Marchas Blancas movement; however, they did not receive support from the rest of the movement. [...] Feminism is still stigmatised in social movements that resist dealing with imbalances in power relations and topics linked to equality and non-discrimination.' (Interview with El Salvadorian activists Gilda Parducci, Yanira Argueta, Emely Flores and Margarita Fernández; Ardón 2012)

\subsection{Barriers posed by ideas around gender, culture, tradition and the private sphere}

Movement-based advocates for women's rights and gender justice face particular challenges around making gender inequality in the private sphere visible and a legitimate arena for movement intervention. Ideas about tradition, culture, religion and the sanctity of the 'private' sphere can be used to marginalise and silence those who speak up about gendered power in areas such as the family, making it extremely difficult for such areas to become accepted and common topics in movement agendas and discussions. 


\subsubsection{Resistance to challenging power relations in the private sphere}

Across social movements there is a recurring theme of resistance to tackling gender injustices in the private sphere. This resistance is often due to a reluctance to tackle issues such as relationships within families, gender-based violence and sexual and reproductive rights. In global human rights movements, the struggle to affirm women's rights as a valid or even priority movement concern has been directly linked to a willingness and ability to consider injustice in the private sphere, as the following box explains.

\section{Arguing the case for women's rights in global human rights movements}

With the adoption of the Universal Declaration of Human Rights (1948) human rights movements globally campaigned and litigated for an end to public violations by state actors, including torture and arbitrary detention. Although the Declaration denounced discrimination on the basis of 'sex', a deep enquiry into the status of the world's women came much later with the UN Decade of Women (1975-1985), with the ratification of the Convention for the Elimination of All Forms of Discrimination Against Women (CEDAW) and in the midst of rising numbers of feminist activists convening over three world conferences. Inspiring this initiative were radical new ideas put forth by feminist voices illustrating that: women in all cultures along their lifecycle experience abuse not only because of actions challenging the State, but simply because they are women; domestic violence was another form of torture; and that by ignoring the private sphere (the family or the market) or non-state actors, 'human rights' had been blind to violations of the rights of women. (Adapted from Bhattacharjya 2013)

\subsubsection{Using notions of culture, tradition and religion to silence gendered dissent}

Narratives of what constitutes accepted culture, tradition and/or religion are powerful in forging a sense of movement ethics and common identity but can also be deployed as reasons to maintain the status quo. Feminists and gender justice activists often face the argument that changes in the domestic sphere go against cultural, religious or traditional values or are being imposed by external oppressors or majority cultures. This is a particularly powerful challenge in identity-based movements where belonging and identification with a collective is central to movement membership and sense of solidarity. The quote below explores this tension in the context of indigenous people's activism in Guatemala:

'When we have to denounce our male colleagues we feel like traitors because the [belief is that the] only way to fight against racism and discrimination is by fighting together as Mayan people. However, some say that since there is complementarity in the Mayan worldview, there is no machismo. This isn't true. There is machismo and there is violence, but we are always thinking that when we say it out loud, the ladinos [mestizo] who look down on us take advantage of it to say that it is our culture to lie. Do you understand? It is very difficult to speak publicly about the internal problems we have among us (male and female) in the movement or in communities because we feel that the dominant culture takes advantage of it.' (Interview with Catalina, Mayan activist; Ardón 2012) 
Ageism can combine with gender bias in appeals around ideas of culture and tradition, and the notion of respecting elders. As newer members of movements, young people and in particular young women face the combined challenges of being women and being young and thus expected to 'listen and learn' rather than propose and lead. The following reflections from movement activists explore power relations around age in movements, and also how they intersect with other forms of privilege and exclusion:

'Young women are routinely denied opportunity and access to speak on behalf of their religion or religious community because they are women (within highly patriarchal religious structures in which the platform is primarily given to official, i.e. male, religious leaders) and young (in my experience, the women who are given a platform to speak are primarily older and, often, connected to a male religious leader - like the rabbi or imam's wife, or a woman who has proven herself after decades of volunteer work in her church, etc.)' (Sheherazade Jafari, BRIDGE e-discussion, May 2012).

'When we were working with the anti-displacement movement in India as 20-yearolds, it was very difficult to work through our own privileged positions as young urban middle class fluent in English activists to fight for what we believed was right. [However] we were also very disappointed by the patronising attitude of some of the older male activists towards young female activists in comparison to male activists, while we were "little girls", the young men were "adults"' (Devangana Kalita, BRIDGE e-discussion, May 2012).

Power relations around age are dynamic. As younger activists take on leadership roles themselves or are encouraged by movements to claim greater space, older activists may also feel that their knowledge and experience is no longer being drawn on, even to the extent of feeling excluded from movement spaces.

\subsection{Disparities and competition in movement priorities, allegiances and alliances}

Integrating women's rights and gender justice into movement agendas is made more difficult where gender equality is seen as a moveable priority - something that can be put aside in order to tackle a more immediate issue or 'traded off' to build alliances between movements on another area of focus.

\subsubsection{Hierarchies in movement priorities}

Across history, women who have participated in community struggles have faced the suggestion that women's rights are issues to be dealt with 'after the revolution', when the priority issue - for example, class, decolonisation or political reform - has been achieved. Women's rights and gender-specific concerns, as well as other intersecting identities, may consequently be framed as 'secondary' in movement politics in the face of identities such as class, ethnicity or race. In the Latin American left, for example:

"The end of the Cold War helped usher in the following discussion: "my first sense of self is as a union member, then as woman, then as indigenous." Many years passed after the end of the Cold War before [people] were able to say "we are women, indigenous and peasant." Still today there is no agreed consensus.' (Interview with Sariah Acevedo: Ardón 2012) 
Raising issues of inequality that shine a light on discriminatory attitudes held within social movements is a challenge for other social groups as well, as the following quote suggests:

'Gender is often regarded as divisive, but I don't think it's the only identity that comes under fire. Having worked for many years with indigenous people (mainly in Guatemala), I have observed that when they confront racism and internal colonialism, that also is countered as divisive (and those who denounce are often accused of "reverse racism"). When it's an issue of class, it's easy [for movements]: the State and the system are the villains, it's "them, out there". It is so much more difficult when the attitudes are in "us" as social movements' (Morna Macleod, BRIDGE e-discussion, September 2012).

Amnesty International's journey on women's rights illustrates many of these tensions. Early discussions were influenced and supported by women's rights activists outside Amnesty who provided important thinking, but at the same time there was mistrust by some staff and members. They worried that Amnesty's impartiality and objectivity would be suspect if the agenda were influenced by a particular group (in this case feminists), and feared that a focus on women's rights would dilute Amnesty's agenda. A landmark campaign on women's rights in 1994 was 'done with considerable opposition from more conservative members of the Amnesty International Secretariat who were concerned that women's rights activists were trying to hijack Amnesty's voice' (Kelleher and Bhattacharjya 2013: 3). At times, it is not just about hierarchies of priorities, but the clashing of fundamental, political positions, as in the example below.

\section{When political positions clash}

In 2009 there was a public confrontation between Amnesty senior management and a staff member who had led the gender unit for almost a decade. Amnesty made the decision to put on a public platform a survivor of torture at Guantanamo Bay who was also alleged to be affiliated with violent, fundamentalist groups. The question posed was: How could Amnesty associate itself with a person or group that was against the fundamental rights of women and sexual minorities? In response, women's rights activists drew up a global petition decrying the 'selling out' on women's rights and demanded accountability from Amnesty.

(Sources: Kelleher and Bhattacharjya 2013; Sawney and Daniel 2010)

All in all, this stance on deferring women's rights, or sidelining them as lesser priorities, represents a failure to fully engage an intersectional analysis around challenging inequalities, appreciating the ways in which different forms of oppression and injustice are connected and thus the necessity and utility of challenging multiple forms of injustice to achieve change for all. Deferring a challenge to patriarchal power also shows a failure to provide full justice as defined by the people experiencing oppression, and in turn calls very directly for an acknowledgement of how entrenched gendered power is in all systems of inequality. 


\subsubsection{Negotiating competing allegiances}

In practising solidarity and forming alliances, social movements may contend with managing competing allegiances, where solidarity with one constituency or political demand means unsettling social or political capital or solidarities with another constituency or demand. For women's rights and gender justice, this challenge tends to emerge where movements are called to stand in solidarity against prevailing cultural, traditional or religious norms and the institutions that perpetuate them. This is common in dealing with questions of rights and freedoms around sexuality, reproduction and the family as described in the following experience from the Philippines:

'In the Philippines, the Catholic Church has been a vocal and reliable ally of social movements on the issue of land, corruption, poverty, etc. But it is a consistent and vociferous enemy of reproductive health and rights and therefore of women's groups. As such, we are witness to the reality where some social movements will not take a stand on the issue of reproductive rights, not because they are against it (in fact, they are for it), but because they would not want to antagonise the Catholic Church. In this context, they argue that it is important not to hurt the broad alliance they have built with powerful groups like the Church, but others ask "at what cost to women's rights?" This is a very real and ongoing dilemma for many of us' (Marivic Raquiza, BRIDGE e-discussion, October 2011).

\subsubsection{Differences within and between women's movements}

While women's and feminist movements of various politics and constituencies share common ground in seeking transformation of gendered power, there are also disagreements and gaps between different women's movements, typically around axes of identity and around political vision and strategy. This can prevent the development of productive alliances. Approaches to sex work are one striking case in point, where there is complex and active disagreement in different schools of feminist political thought as well as between movements of women-identified sex workers and women's movements taking a variety of stances - from abolitionist advocacy for an end to sex work, to advocating for the recognition of sex workers' rights as workers (Shah 2011).

Another challenge emerges with progressive movements comprised solely or predominantly of women but which do not articulate a gendered vision or approach to their political agenda. Here solidarities between movements that have a gendered politics, and movements comprised of women need to be actively built, as has been the case in the domestic worker movement in India:

'The domestic workers movement in India on the whole did not have gender equality as one of its key principles or question the gendered and class division of labour; it is only in the last decade or so since feminist groups have been doing research on the issue and collaborating with domestic workers groups that there has been a sense of feminist articulation of issues. I wonder if this has something to do with who these 
organisations/individuals are and what is the ideological framework they are operating in is. The domestic workers movement is comprised largely of Christian missionary organisations and alliances (because many domestic workers are internal migrants from tribal areas with strong Christian missionary presence), and it would be interesting to look into what the implications of this have been [on the politics of women domestic worker activists]' (Manjima Bhattacharjya, BRIDGE e-discussion, October 2011).

\subsection{Difficulties maintaining change and achievements in the longer term}

Even as some social movements succeed in attracting women members, building women's leadership and encouraging thinking about what gender equality means in the context of their agendas, challenges arise in keeping up this work - in sustaining progress 'after the revolution' or building on initial achievements to ensure that women's rights and gender justice remain a constant area of focus.

\subsubsection{Sustaining an intersectional approach}

While the power of an intersectional approach in politics and practice has been demonstrated, movements nevertheless still grapple with building and acting in intersectional ways, particularly in movements made up of people with diverse identities and social positionings. At the level of political vision, a focus on single-issue politics and arguments regarding 'prioritising' struggles persists in many contexts. Issues faced by majorities, including 'majorities within minorities', tend to override those of the full movement constituency and membership, in particular those affected by multiple axes of discrimination, as the following quotes describe.

'Our lives as disabled women can grow as, stronger in ourselves, we look to strengthen coalitions with a diversity of others, groups that can open up new spaces - with those campaigning around climate change; those who address militarisation; those working to end violence against women; with those who struggle for sexual rights and sexual health. We need to acknowledge the impact of these and of much else upon the lives of women, already disabled and potentially disabled in the time to come' (Price 2011: 20).

'Many people are hopeful that a wider base of solidarity of people in the [Middle East and North Africa] region with the plight of domestic workers will become a reality in close association with the people's uprisings around the region. Yet in the elongated change process,... issues that are considered "the pressing priorities" the agenda for securing the rights of domestic workers may yet again be deferred. The intersectionality between gender, race, class, national origin create a dynamic of power hierarchies, and the migrant domestic workers' demand for rights keep staying at the bottom of that ordering in the region' (Simel Esim, BRIDGE e-discussion, October 2011). 
'Some feminists are still reticent on how to act on transgender persons. [This means that] the alliance between the queer movement and feminism is not happening. What a loss; we could strengthen each other's voice' (Leticia Zenevich, BRIDGE e-discussion, May 2012).

In terms of actions and strategies, movements may adopt forms of protest which have exclusionary impacts. For example, during activism in the Y'en a Marre ('We have had enough') movement against an unconstitutional third term in office for Senegalese President Adboulaye Wade in 2011 / 2012, disabled women questioned how street-based protest styles and police responses to this prohibited disabled people's participation, as they were not able to run from police attacks or move easily in streets filled with physical barriers:

'People with disabilities have lamented the fact that they can no longer move through the streets as protesters, despite the realities of their lives as vulnerable minorities who live primarily by begging on the streets of Dakar' (Cisse 2012: online).

\subsubsection{Sustaining gender transformation 'after the revolution"}

As discussed in section 3.5.4, in the process of movement creation and movementbuilding women may take on a broader range of roles and social identities than are supported in existing social norms. These acts of challenging gender norms and of creating new activist or 'revolutionary' identities may include increased public participation or public voice, new modes of dress, and roles in decision-making or action not previously deemed 'acceptable' for women. This is particularly so in the case of uprisings or targeted mobilisations against a specific adversary (for example, a dictatorial regime, colonial force or specific set of economic policies). However, a recurring theme across the diverse history of social movements is the difficulty of sustaining these new, broader 'ways of being' and gendered norms after the immediate change goal has been achieved. Indeed patriarchal gender norms tend to be the first normative practices to be re-asserted 'after the revolution'. The following examples describe these dynamics in the context of Nicaraguan revolutionary movements that led to the end of the Somoza dictatorship in 1979, and the popular uprisings beginning in 2011 against the regime of Egyptian President Hosni Mubarak, respectively. 


\section{Views on gender during and after the Nicaraguan revolution}

'[During the revolutionary decade], the roles women traditionally assumed began to be questioned. For the first time in Nicaragua women could be seen working successfully in the armed forces or in production, driving tractors, being leaders in their particular functions and specific tasks, some more effectively than some men. All of this amounted to a revolution in itself. But these changes didn't translate into public policies to strengthen them and make them more stable over time. So when the war wound down the roles reversed again and the tendency to send women back to the home prevailed. There was no profound reflection about what the changes had meant. There was no questioning of why women had new abilities added on, yet were still responsible for caring for children, the sick and the elderly and doing domestic chores alone.' (Source: Ana Criquillion; in Vergara 2012: online)

\section{From revolutionary solidarity to violence and exclusion in Egypt}

The millions who ended the 30-year rule of Hosni Mubarak were collections of individuals who had long waited for a chance to mobilise and effect real political change. Women were equal partners in the organisation and enactment of this social struggle. Public spaces were occupied by equal numbers of men and women. Public protests were instigated by women bloggers as well as by young women and men who had long been engaged in organising protests amongst workers, youth and victims of gross injustices and brutal transgressions. However, a few weeks after Mubarak left power, protesters who remained in Tahrir Square were attacked, and some of the women among them were subjected to 'virginity tests' by the army. The demonstrations by women in Tahrir Square commemorating International Women's Day on 8 March 2011 were attacked by passers-by and by other demonstrators. During further protests later that year security forces dragged and undressed a young woman who subsequently came to be known as the 'blue bra girl' by national and international media. The culmination of these transgressions against women happened on 25 January 2013 in Tahrir Square, when 19 separate incidents of sexual violence and harassment took place.

In terms of political reform, solidarity with women's rights in the still evolving new political landscape has been very mixed. Women voted in the parliamentary elections of November-December 2011 in record numbers, but the rate of female participation in the elected parliament was one of the lowest in the world, with women making up barely 2 per cent of parliamentarians. Only six of the 100 people selected to draw up a new constitution in the Constitutional Assembly were women, despite lists of women candidates provided by activist platforms. (Adapted from Sholkamy 2013) 


\subsubsection{Scaling up from initial change to movement-wide transformation}

Often a movement makes initial progress on women's rights and gender justice, for example, by developing a strategy on gender equality or developing training schools for women members. The difficulty comes, however, in translating strategic commitments into movement-wide actions or developing a culture where women trainees can go on to flourish or emerge as movement leaders. The examples below illustrate some challenges of this type.

Challenges to long-term progress at Amnesty International and CLOCVia Campesina

Amnesty International has a complex structure and multiple power centres involving country sections, members, and executive staff at the international headquarters. Internal change appears to have been uneven, despite a commitment to gender mainstreaming at strategic level. In some countries there has been considerable progress, while there has been less in other parts of the movement. There has been a gap between priority setting at governance level and implementation, and the difficult but necessary work of creating a culture of valuing women's rights and gender justice work has begun in many quarters but is far from accomplished. (Adapted from Kelleher and Bhattacharjya 2013; Bhattacharjya et al. 2013)

The women leaders of the CLOC-Via Campesina movement have made considerable gains; not least establishing gender parity in decision-making spaces. However, women continue to face difficulties, the most visible of which are in the mixed organisations. Masculine organisational models persist, and these limit advances made in achieving gender parity, and reproduce discriminatory practices towards women and expressions of explicit sexism. For example, there is still a difference in the way opinions are valued, and in mixed spaces it is very difficult for women to speak and put their problems on the table - men restrict women's dialogue. In other words, there are still practices that exclude. Gender parity ensures participation but not the role of women as protagonists or women's empowerment. Men's words continue to be worth more and women are seen as 'complementary'. (Adapted from Caro 2013; Bhattacharjya et al. 2013)

This chapter has looked at the common challenges faced in raising the question and mobilising for the inclusion of women's rights and gender justice concerns in social movements. Chapter five now moves to considering strategies to respond to these challenges, and mapping out some broad routes to shaping progressive social movements that advance the goal of gender justice and transformed gender power relations in their politics and practice. 


\section{Routes to Shaping Gender-Just Movements}

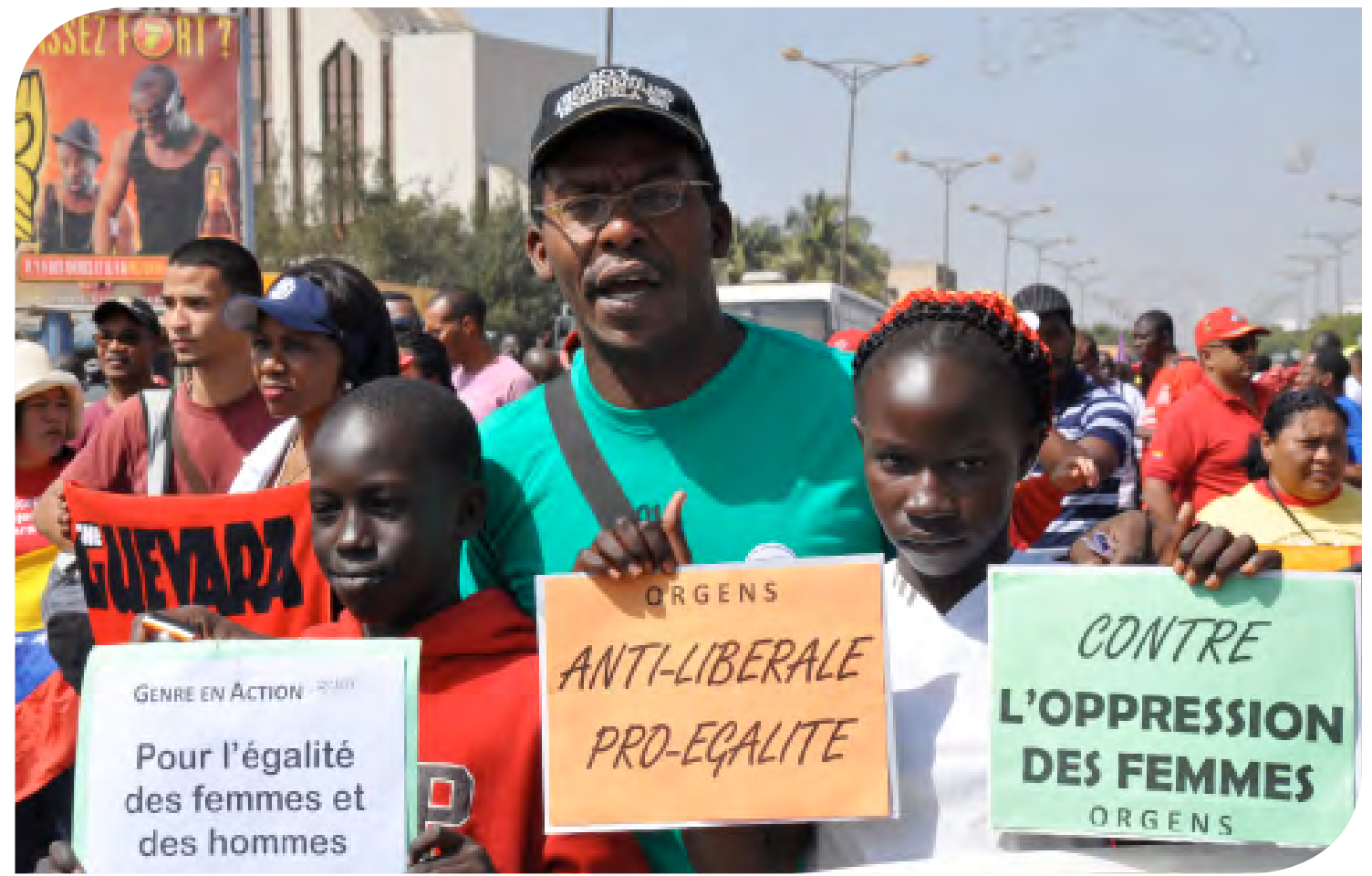

At the start of the march during the World Social Forum in Dakar, 2011,

families unite to demand equality.

Photographer: Marie Devers

'Change is not a linear process, for which there is a recipe'

(Susanna George, BRIDGE e-discussion, October 2011).

While there is tremendous diversity in social movement practice across contexts, and different constellations of power relations, there are also many common patterns in both the challenges (as explored in chapter four), and successful strategies around transforming gendered power in movements. This chapter draws on case studies and reflections by social movement actors to offer creative and practical ideas for fully integrating and sustaining gendered analysis and action into visions and agendas of progressive social movements. It begins by outlining core elements of gender-just movements, drawing on ground-up experience. It then explores practical ideas for initiating and expanding gendered transformation in movement political visions, actions, constituency and leadership, and addressing attitudes in deep structure that underpin these. As noted in chapter two, movements take on many forms, including in their structure and level of formal or centralised organisation and decision-making. The routes outlined here point to areas and ideas for action but would necessarily need to be adapted to respective movement structures and cultures. 


\subsection{What does a gender-just movement look like?}

While social movements vary in their outlook and methods across contexts, there are nevertheless many similarities in how movements respond to issues related to gender inequality and unequal power relations both within movements and in the external environment in which they are situated. The following box draws on past experience from diverse movements and movement actors to suggest possible components of feminist-allied and gender-just movements. These components function like enabling conditions, creating a supportive environment that allows for deep reflection, revision and action, and to sustain commitment to gender justice over time, including in the face of backlash. The routes to change outlined in the remainder of this chapter provide examples of how these elements can be acted on, including in light of the challenges explored in chapter four.

\section{A gender-just social movement:}

- Affirms the relevance and importance of integrating gendered inequality and challenging patriarchal power as an integral component of advancing justice for all, and naming this explicitly as a priority in movement politics, policies and strategies for action.

- Creates a positive, reflexive environment to support internal reflection and action around how gender operates in the deep structure of both individual and collective beliefs and actions.

- Provides active and formalised support for women's participation and leadership in all arenas of movement practice (including in movement policies if present and in movement-affiliated organisations), with attention to diversities among women and with adequate support for women in positions of leadership.

- Consistently tackles gender-based violence, establishing zero tolerance for the harassment of women, and creating mechanisms to prevent gender-based violence in movement spaces and to hold perpetrators to account.

- Assesses gendered bias in assigned movement roles and redistribution of labour and roles along more gender-just lines including in terms of public roles, movement outreach, internal administration and use of time.

- Enables full participation across gender by taking into account care work, reproductive roles and other gendered responsibilities which can affect movement participation.

- Appreciates the ways in which gender affects how activists are targeted by external opposition, and develops specific strategies to prevent and respond to gender-based backlash, repression and violence against women activists by external actors.

- Engages with norms and notions of gender including taking into account contextspecific gender identities, trans and intersex identity and shifting understandings of gender in social life and activism. 


\subsection{Recognise and transform culture, power dynamics and hierarchies within movements}

As chapters three and four showed, there are many barriers to building genderjust movements that cannot be easily tackled, because they lie within the informal structures and cultures of movements. It is, therefore, essential to engage with the personal - often invisible - power dynamics of movements to create lasting change.

\subsubsection{Engage with the deep structure}

Experience has shown that it is vital to engage with and work on transforming the deep structure of inequalities and biases within movements and among movement members in order for deeply ingrained social practices and attitudes around gender to shift. Indeed where efforts to work on the formal and visible aspects of gender justice such as introducing new equality policies - fail, it tends to be because the deeply held beliefs and informal practices that sustain patriarchal gender norms have not been named or interrogated.

Many practitioners believe that supportive organisational cultures are essential for sustained, well-resourced and exemplary work on women's rights and gender justice (Kelleher and Bhattacharjya 2013). Working on the deep structure of a movement or organisation requires active individual and collective reflection and questioning around learned gender hierarchies in who speaks, decides and leads, and supporting new ways of being, seeing and doing that enact egalitarian power relations in terms of gender and other social divisions.

It is vital to initiate focused discussions on how power is used and shared in movements and their organisations, in relation to the thematic issues movements address but also with regards to the internal dynamics, practices and willingness to take on women's and gendered concerns. The necessity of discussing power and not simply more neutral ideas of 'gender' or 'women's concerns' is voiced in the following reflection:

'In our experience, we are increasingly coming up against people who have picked up the "right" jargon - participation, gender, equality, empowerment etc. So, we have terribly biased men (and sometimes women) using all the right words but without any matching intentions. For movements to resist these forces we need to move beyond their stated words. This requires more time and engagement, and pushing our analysis deeper and deeper' (Roshni Kishore Nuggehalli, BRIDGE e-discussion, May 2012).

An element of political will is required to open up to self-critique and rethinking in the name of advancing more inclusive, just politics and practices. The methodology of self-critique, while powerful, can also involve very difficult processes of facing past discrimination and of interrogating people's own acts of discrimination or violence against others. It requires patience as well as support as people work with and reconstruct their belief systems and political worldviews. 


\subsubsection{Politicise the personal}

'Gender transformation usually needs a personal commitment to be successful, which also helps to avoid the problem of people just "talking the talk". The work to do a gender and intersectional power analysis in one's personal relationship, and linking it to social movement politics, is likely more successful if done in a way that is non-threatening, such as among peers. Engaging movement members at the personal level and/or with people in their personal lives are ways that l've seen successful changes come about' (Nadine Jubb, BRIDGE e-discussion, March 2013).

Feminist and women's movements have created sophisticated practices to interrogate how societal power impacts on people's personal lives, including in relation to selfperceptions, internalised oppression and learned hierarchies used to engage others. The notion of 'the personal is political' frames this work to question individual and collective understandings of gender and other axes of social power, and places emphasis on an ethics of 'walking the talk' in activist practice. As a Nicaraguan feminist activist reflects, 'We go along in the fights against violence but do not check how much violence there is in our personal relationships. We ourselves do not recognise the power we have' (Interview with Nicaraguan activists; Ardón 2012).

Consciousness-raising groups (see the box below) and other techniques of selfreflection are also used in mobilising traditions such as popular education, where people analyse oppression from their own life experience and use this reflection to develop conceptual and practical methods to challenge it. This process of reflection can become an ongoing collective engagement within movements about harmonising theory and action.

\section{Consciousness-raising}

Consciousness-raising is a movement-building strategy common in feminist movements. It involves creating group processes to explore personal experiences of violation and/or empowerment and develop a critical understanding of the root causes of oppression, deepen knowledge of history (including activist and alternative perspectives on mainstream history) and build solidarity and a shared political commitment to changing the status quo. Consciousness-raising is commonly facilitated in non-hierarchical ways, with the experiences and knowledge of all participants considered valuable and relevant for learning and reflection.

The move to encourage individual self-reflection within movements stems from a political embrace of personal experience as a legitimate, relevant domain of movement politics and action. Support for this idea cannot be assumed, particularly in movements with a more collective vision of activism, and as such needs to be cultivated. This point is explored in the following reflection from the South Africa context:

"It seems to me that creating the "right" balance here is like walking a tightrope. In our recent work in labour unions in South Africa, our very attempt to politicise the personal, to value "individuals" and "whole beings" as well as and as part of "collective" action has been severely criticised - the "movement" valorisation of the collective to the exclusion of the personal I think is a structural condition that many of our movements unconsciously perpetuate' (Michel Friedman, BRIDGE e-discussion, March 2013). 
As the experience below from the Admas network in eastern Ethiopia shows, the process of personal critique and reflection can also support organisational platforms to become more activist in their approach to women's rights and gender equality.

Changing attitudes on gender through consciousness-raising in eastern Ethiopia

Admas is an umbrella network of seven community-based organisations, each of which has its own members in Dire Dawa (eastern Ethiopia). At the time, it was a woman-dominated association with around 3000 members. Its core business involves income-generation activities, which provide saving and credit services to non-members who are organised into cooperatives. The organisation decided to launch a process addressing issues of violence, poverty and HIV among women in their communities. At the first peer-learning event, Admas began with the idea to promote 'gender equality' but decided on the goal to create core change agents and a critical mass of people who believe in the education provided by the association. It explored the root causes of gender inequality, analysing proverbs, stories, progressive interpretations of religious texts and personal experience.

The process trained 140 change agents who were then supported through regular meetings and dialogue. Change team members transformed their understanding of themselves, their context and how gender relations work in their context and their capacities. Their change strategy reflects an understanding of gender that is not only about women but also expanded commitment from men and the involvement of key religious leaders in debate. In its approach, the Admas change team also shifted from the idea of providing access to paralegal services such as access to courts, law and justice to developing a critical mass of change agents who, through discussing and educating members and their families about underlying misconceptions, would address the issue on a different level, through individual consciousness-raising and collective action. Organisationally, the relationship between the Admas board and its members in the various civil society organisations has been changed by the role of the change agents. Having given the change agents freedom to facilitate how they wanted to, the agents have in turn become much more responsible network members. (Adapted from Kelleher and Friedman 2009: 11-17)

\subsubsection{Acknowledge that change is emotional, and provide space to name, heal and change}

In as much as everyone in the world is gendered, everyone has also, therefore, had experience of living with gendered power relations, and the privileges and/or marginalisations that come with it. People often become activists out of a desire to confront and stop further violations against them or their communities. As part of their activism, people may subsequently have to face tremendous loss and deep personal compromises, including the death of or acts of violence against movement members or their kin and friends as they challenge power. In the change process people thus engage a full range of emotions from fear and anger to happiness and courage, all of which also affect the interpersonal relationships within and the overall experience of movement participation. 
Acknowledging that social change is emotional means providing space to anticipate and positively recognise and deal with these varied emotions, including through structured support and space to explore the emotional side of activism - for example, through artistic expression, and building a 'politics of compassion' (Doetsch-Kidder 2012; Goodwin, Jasper and Polletta 2001). In practical terms, there is growing recognition in women's movements, in particular around the importance of creating spaces and providing tools and resources for emotional health about the centrality of well-being and for self-care as a form of activist practice in itself (see CREA 2008; Barry and Djordjevic 2008). Both in principle and in practice, well-being strategies affirm the importance of helping to support activists and address burnout and the human impacts of marginalisation and repression, shape organising strategies that enable reflection and organisational sustainability, and model the holistic, balanced relationships that social justice movements aim to create in society.

\section{Practical tools to support activist well-being}

Capacitar emergency response kits: A set of simple hands-on techniques that can be used to address stress and trauma. Available in multiple languages at: http://www.capacitar.org/emergency_kits.html.

Integrated security manual: Practical tools and strategies for the safety and security of women human rights defenders. Available at:

http://www.integratedsecuritymanual.org.

Out of the spiritual closet - organisers transforming the practice of social justice: A framework and practical activities for holistic activism and integrating reflection towards individual, group and societal transformation (Zimmerman et al. 2010).

Self-care and self-defence manual for feminist activists: A workbook for personal and collective reflection and training (CREA, Artemisa and Elige 2008).

Spirit in motion sustainability toolkit: Guide and workshop exercises to support personal and reflection for social justice activists. Available at: http://movementbuilding.movementstrategy.org/media/docs/5857_SIMtoolkit.pdf.

\subsubsection{Rethink masculinities}

As discussed in section 3.5.2, progressive men's movements have taken on board feminist critique around the patriarchal behaviours most men learn from an early age, and have committed to transforming norms held by men activists around masculinities, including around men's expected leadership, public bravery, heteronormativity and reliance on women as care workers in the family. The quote below reflects on this kind of exploration:

'[Part of my activism is] being clear about how I see my own patriarchal privileges in my life which I certainly have enjoyed but which have not always been good for me. [For example]... relying on my former wife to take care of the children while I charged ahead and developed a career including in gender equality and HIV. I am now much more aware [of the ironies inherent in that] and try to challenge others to be clear about what investments we have in this system and how that colours what we do' (Interview with Jerker Edstrom; Nascimento 2012). 
Reflecting on internalised notions of masculinity - and hence of femininity - is a critical component of interrogating the deep structure of movements and organisations, since subtle, unquestioned expressions of these, often oppressive to women, are often manifested there, and thus cannot be inspected or addressed without examining the deep structure. The gendered division of labour, described below, is one such manifestation.

\subsubsection{Interrogate the gendered division of labour in movement practices}

Social relations within movements tend to replicate those existing in society as a whole unless they are actively questioned and transformed. As in the wider world, women bear greater responsibility for unpaid care than men (Esplen 2009; Budlender and Moussie 2013, Chopra et al. 2013), and the importance of care work as an economic support structure goes unrecognised (Razavi 2007). In mixed-gender movements it is important to analyse the gendered division of labour both in formal and informal understandings of what roles women and men play, including in leadership, decision-making, administration and care work between movement members. Experimenting with gender role reversals, putting in place formal policies around gender-just representation, and tackling barriers to movement participation posed by roles that women and men play outside movements, such as domestic work and child care, are all ways to address this.

\subsection{Support internal activism for change}

The most powerful accountability mechanism in any movement is its own constituency. It is thus vital to consider and support initiatives by movement members themselves that call for the respective movements to address their politics and practices around women's rights and gender justice. Here are some examples.

\subsubsection{Build collective power among women}

In contexts where women have not had opportunities to build leadership, political and technical experience, it is important to invest in building women's own skills and capacities. At the outset this may require space for women to interrogate past injustices both in their lives and in the context of movement work, and through this to build a sense of solidarity among women around feminist and gender justice politics and demands on their respective movements, and to build confidence to engage with broader movement constituents. Different constituencies of women - for example, young women, women with disabilities, women of colour and HIV-positive women - may see the need to form their own caucuses or groups to be able to explore their specific experiences and develop their politics. In the CLOC-Via Campesina movement, women leaders have worked hard to empower women in their movement so that they can challenge traditional gender norms:

One successful strategy has been to organise training schools where women are encouraged to recognise each other as owners of rights. They make themselves more visible, empower themselves, and their fears and mistrust lessen. In mixed groups, emblematic women leaders go on to act as role models for other women's empowerment, and they train others in how to confront discrimination or abuse and how to do public speaking. In this sense, the movement is an ongoing training school, producing "teachers" as it goes. (Adapted from Caro 2013) 
As noted in section 5.2.5, this process of building collective power is emotional as well as technical. Cultivating a greater sense of agency and voice among women may be a necessary precondition for women to be able to engage effectively with everyone in their movements, given that it can be very difficult for groups who have been previously excluded, marginalised or violated to be more practically inclusive of the "oppressor" groups without some prior process of emotional healing having taken place' (Michel Friedman, BRIDGE e-discussion, March 2012).

\subsubsection{Build and support feminist leadership}

Feminist leadership can challenge both visible and invisible power and construct new forms of power that are more democratic, legitimate and accountable (Batliwala 2011). It can, therefore, play an important role in the development of gender-just movements. CREA, an Indian feminist human rights organisation that has played a leading role work to build and understand feminist leadership, has developed the following definition:

'[CREA's] leadership programme works on the assumption that leadership is not a fixed state of being but a process through which women assert their rights by continually evaluating relevant experiences, questioning their roles in society, challenging power structures and effectively catalysing social change' (Batliwala 2011: 27).

In a social movement context, the women leaders of CLOC-Via Campesina are doing this; they are working together to build a new generation of leaders who can embody the principles of feminist leadership they have developed. For them, leading their movement towards a stronger understanding of the 'popular rural feminism' they seek to promote 'implies accepting oneself as a woman, being proud of it, desiring equality, preventing abuse, taking the opportunity to think differently, valuing oneself and demanding respect' (Caro 2013: 4). For others within the movement, the CLOC's women leaders are seen as 'as hardworking, creative, bold and brimming with ideas and proposals for dealing with crises' (Caro 2013: 2).

\subsubsection{Develop women's platforms and caucuses}

Women's rights advocates have used the strategy of building women's platforms within mixed-gender movements not yet actively committed to women's rights or feminist visions, as a way to both focus in and develop analysis, skills and a sense of personal and collective power, as well as a stronger lobby for gendered demands to the broader membership and movement leadership where relevant. For example, at Occupy Wall Street, a series of feminist general assemblies were organised that addressed not only women's role in economic justice movements but also took up issues of patriarchy, heterosexism and transphobia. ${ }^{43}$ Occupy caucuses were set up for women, as well as for people of colour and queer people, and groups such as Occupy Patriarchy and Women Occupying Wall Street emerged to highlight the particular demands of women from the Occupy movement (Sahasranaman 2013).

43 Transphobia is intolerance towards and discrimination against people who are trans. 
As the example from the Anti-Privatisation Forum in South Africa below shows, forums built by and for women in movements can help to shift gender power relations within social movements:

\section{Remmoho: a women's space in South Africa's Anti-Privatisation Forum}

'As women we were part of the Anti-Privatisation Forum (APF) [in South Africa]. This organisation struggled for basic services, especially water, housing, proper sanitation and electricity for poor people in the community. As women in this organisation we had no voice and were oppressed as our leadership was male dominated. They expected us as women to listen and agree with them at all times without questioning or challenging any issue. We sat down and discussed the problem of being voiceless and concluded that we will have a woman structure - Remmoho - in order for us to have a voice, a safe space and a say in how the organisation is run. We knew that Remmoho would be able to speak for all women collectively and also challenge some of the decisions taken on behalf of women. In this space we will be able to share, dialogue and discuss problems we face as women in our homes, at work and in the public space. This is one of the reasons why we formed Remmoho. We wanted to engage without any anger as previously you needed to fight before you can be heard in the APF' (Phillips 2012: 32).

The impact of women's platforms on broader movement membership is contingent on a number of factors, including the internal strength of the platform. There is also the possibility for women's platforms to become marginalised within broader movement spaces, resources and decision-making processes if they are not fully acknowledged by the rest of the movement membership or not given explicit roles in contributing to shaping movement agendas and practices. The following perspective on the anti-dam movement in India points to the potential for women's wings or platforms to become isolated from general movement politics and hence responsibility:

\section{Limited power for the women's wing of a farmers' movement}

'A large farmers' movement, begun by Krishak Mukti Sangram Samiti in Assam, India, was started in 2001. [They began] to take up women's issues but it is not yet part of their core agenda. A separate women's wing has been set up within the movement to take up these issues. It is often seen that only women talk about women issues. Even in their decision making body, out of a hundred only three are women. In Northeast India there are 168 mega dams proposed to generate 80,000 megawatts of electricity. This involves huge investment in the region, so the antidam movement is considered to be involved in "anti-national activities". Being a conflict zone, this region is heavily militarised... So, more women are going to be victim of sexual violence, human trafficking, and displacement as a consequence of the presence of more military forces. But these issues are not considered as core issues and also are not discussed widely in the movement. Women's participation is considerably high in activities like demonstrations, mobilisations and other similar activities, [yet] their representation in decision-making bodies is as low as [to be almost] invisible. The women's rights agenda is either sidelined or discussed by women only' (Bondita Acharya, BRIDGE e-discussion, October 2011). 


\subsubsection{Work on movement politics, not just representation of women}

Representation of women (and historically marginalised women within them) in movement leadership, public voice and decision-making is one critical component of mixed-gender movements. However, as discussed in chapters three and four, representation in itself is insufficient without a complementary focus on redistributing gendered power and, through this, fundamentally changing the gendered power relations that sustain inequality within movement spaces. In the CLOC-Via Campesina movement, which has a significant proportion of women members and a policy on gender parity in decision-making spaces but still experiences gender inequalities within its deep structure, women leaders have developed a plan of action to transform movement politics:

'Since patriarchy is a long-standing problem, the CLOC women's network aims to raise awareness that will enable people to see the inequality that is naturalised at present in cultural constructions of the family, in organisations and in society at large. This means denouncing injustice and transforming daily behaviour such as unbridled male sexuality, expressed in crude comments and other forms of sexual harassment. It also means addressing the sexual division of the word and hence questioning the non-democratic use of speech in meetings; since men generally speak first, they often mark out the conditions for debate [...] It means training men, incorporating them in debates with women and young people so that they manage to understand that women only want access to the same choices.' (Caro 2013: 6)

Within the Occupy movement, a disparity between representation and movement politics was also observed:

As Occupy attracted more women activists, the personal safety of women within the movement became a serious issue. Women occupiers faced harassment while participating in protests. Safe spaces committees were set up in Occupy Wall Street as well as in other Occupy encampments. Safety was also brought up in General Assembly meetings. However, along with the issue of building safe spaces within a movement that, at its centre, was about space and who can claim it, women also raised key questions about the role and relation of women in Occupy. Could they remain limited to issues of sexual harassment and safety? What about their demand for economic justice, knowing they were paid less, that poverty affected them in unique, distressing ways; that women of colour are acutely affected by foreclosures, and that queer/gender non-conforming people do not find jobs easily? (Adapted from Sahasranaman 2013)

\subsubsection{Support and learn from individual change-makers}

In some movement contexts, individuals with influence have broken ground in opening up debate and initiating changes in politics and practice on gender. This may include changing their own practices as well as questioning movement politics and practices that perpetuate gender power dynamics, as the example of the Batang Berjuntai Credit Cooperative below illustrates. 
Leadership for change in the Batang Berjuntai Credit Cooperative

'The Batang Berjuntai Credit Cooperative was begun by a few inspired and inspiring young leaders (both men and women) who were all from a rural Indian-Malaysian plantation community. While they were always focused on ending poverty and social justice, somewhere along the line one of their leaders, Paul Sinnapan, went for a clearly powerful gender sensitisation course run by the Asian Women in Cooperative Development Forum (AWCF) - and came back a transformed man. The first thing he did when he came back from this training was to call a meeting of the cooperative and share his experience, and get an agreement from the board and its members that the credit cooperative and its board was immediately going to become $50 \%$ women. They did this by changing the policy on membership. Men could only belong to the credit cooperative if one member of their family (whether mother, wife, daughter or sister) were a part of the credit union as well. Their board also has more than 50\% women, and they also have policies regarding making sure that the board is inter-generational. To work on the deep structure of their culture, they tapped into the writings of an old Tamil [philosopher and social reformer] who wrote a lot about right conduct in the family and in relationships... interpreting gender equality, social justice and human integrity as intrinsically rooted in their Tamil/Hindu heritage.

Over time, and through dialogue within the cooperative and in different smaller units around which the cooperative is organised, they developed concepts of gender equality and redistribution of power in the family. One example I recall is having family budget meetings where everyone in the family, children included, were a part of the discussion of how household income and expenditure were decided. Sharing of reproductive work including childcare is a centre piece of these discussions (though this has been a harder area to bring about change in). Sinnapan himself changed his own routines as the leader to incorporate reproductive work... and the cooperative itself changed the meeting times in their office - no meeting would start until after 10a.m. to give both women and men time to see their children off to school, clean their houses, do laundry and cook before coming into work' (Susanna George, BRIDGE e-discussion, October 2011).

\subsubsection{Anticipate and respond to backlash}

While individuals can help break ground in questioning internal discriminations and injustices and putting women's rights and gender justice on movement agendas, they may also face backlash and criticism for doing so. Indeed people who step outside movement norms to question the internal status quo are not always welcomed from the outset, and can face experiences of being sidelined, harassed or discredited as invalid spokespeople for the movement. ${ }^{44}$ These forms of silencing tend to take gendered forms, with attempts to discredit women by framing them as outside 'appropriate' gender norms, in particular questioning women's actual or alleged sexual or reproductive choices. Men who stand against patriarchal gender norms may also face ridicule and / or questions regarding their identities as 'men'. People who act as forerunners can experience isolation or a lack of public support for their positions, even though some who fear retribution by taking a public stance may express solidarity in private (Tamale 2003).

In supporting change it is, therefore, important to express solidarity with individuals and minority voices within movements who do speak out, including ways to show both public and private support and redistribute the burden of backlash that they

44 For a personal exploration of this in the context of anti-apartheid activism in South Africa, see Govender (2007). 
face. Support may also need to include anticipating and taking action around genderspecific forms of marginalisation and silencing such as gender-based ridicule and harassment which can come from inside or outside the respective movements (see Rothschild 2005). The Women Human Rights Defenders International Coalition is an example of a targeted initiative around the protection of activists facing repression and violence for their work challenging gendered injustice (see the box below).

\section{The Women Human Rights Defenders International Coalition}

The Women Human Rights Defenders International Coalition began as a campaign in 2005 to document the particular violations faced by women human rights defenders and LGBTI defenders, and to advocate for gender-sensitive protection and prevention mechanisms. The coalition advocates for support for individuals as well as groups, including through mechanisms to respond to individual women's human rights defenders at risk, proactive measures for activists' safety and personal selfcare, and greater donor funding for self-care and safety for activists, organisations and movements. (Source: http://www.defendingwomen-defendingrights.org/)

\subsubsection{Acknowledge women's agency and avoid a 'victim" approach}

Although the realities of violence and systematic marginalisation of women and girls make a compelling case for promoting gender justice, it is important to not end the analysis of gender inequalities or the case for alliance-building there. Solidarity with gender justice entails acknowledging women's agency and leadership in naming and taking action against gendered oppression and inequality, and the subsequent need for movements to listen and respond. This point is expressed in the following quote:

'The specific demands of women are part of social [demands]. Perhaps the invisibility comes from their not having been named as subjects of change or as social actors with full rights. They did not appear on the list... Now we see that naming female and male actors means that we are highlighting that the fight against domestic violence is a social problem... To make visible one of the components also shows its specific condition... that which makes it an agent of change.' (Interview with Domingo Hernández Ixcoy, Maya-K’iche leader; Ardón 2012)

\subsection{Draw the line on impunity for gender-based violence}

Holding movement members and leadership to account for ethical conduct around gender relations - be it in public or private - is essential to challenging hidden and invisible power dynamics that make movement participation uncomfortable or unbearable for women and gender minorities and undermine the lived politics of a movement. This includes issues such as domestic violence or sexual harassment by movement members, either to others in their movements or in their personal lives. It also includes challenging impunity and the failure of movement leadership to take a stand against discrimination or violence within movements.

In practice, individuals or groups within movements may decide to take action within their movements or at community level which in turn instigates a broader response and action for changed behaviour, as the following example from India suggests. 
Holding our own to account - women in the Mumbai pavement dweller movement

'I remember the pavement dweller women in Mumbai that I helped organise in the Eighties came up with an ingenious tactic for dealing with men who beat their wives: the moment a beating started, the woman at the receiving end would yell out to her neighbours, and each household would send their children, armed with slippers and sandals, to the hut with the offending man. The children would surround and clamber on top of him and "garland" him with footwear - this is a traditional form of public humiliation in the Indian subcontinent, to garland a wrongdoer with footwear. To have this done by children, than whom you as an adult should be wiser, was even worse humiliation' (Srilatha Batliwala, BRIDGE e-discussion, October 2011).

Women in the Piquetero Movement of unemployed workers which emerged in Argentina during the financial crisis of the 1990s have led similar community-based activism against domestic violence:

\section{Internal activism against domestic violence in the Argentinian}

Piquetero movement

'In the Piquetero Movement, people don't go to the police in these cases; instead, "persuasive actions" are taken towards the aggressor. Several women go to the home of the man who has engaged in violence against his companion to talk to him about what this means, about why he shouldn't continue to act this way, about the way his companion suffers, etc. The first goal is to let him know that his violent attitudes are a public matter, well-known in the neighbourhood, and to insist that he seek out a self-help group or other type of therapy. In some cases, when these measures haven't produced favourable results, the women remove the aggressors from their homes by force.' (Source: D'Atri and Escati 2008: 6)

In addition to activism by members, it is important for movements to take explicit stands against gender-based harassment and violence in any spaces where the respective movements lay out ethical and political principles, such as in organisational or physical spaces created by movements, and in their publically articulated political visions and codes of conduct where these exist. Standing up against internal discrimination is important in principle and may also help open space for frank discussions and change in movement practices. This can include interventions to ensure women's physical safety in collective spaces, and solidarity with people who are violated, while also challenging impunity in bringing perpetrators to account or in silencing claims made by people targeted.

\subsection{Develop the politics and make the arguments on gender and movements}

Developing and continually reflecting on a political approach regarding patriarchal power lies at the heart of fully engaging women's rights and gender justice within movements. Political visions are what make a movement, and as such taking a position on gendered injustice and oppression is a necessary component of building genderjust movements. This also includes developing clear notions of how gendered power manifests, including with regards to gender identity (including trans and intersex 
identities), and the ways in which gender identities are compounded by other forms of oppression. While separate spaces for women or other marginalised groups within movements can create an important arena for these discussions to take place, it has also proved necessary for issues of women's rights and gender justice to be debated and explored in broader, mixed spaces, so that gender is not siloed into a small range of 'women's issues' (Bhattacharjya et al. 2013).

\subsubsection{Make women's rights and gender justice visible in movement agendas}

As this report has argued, gender justice is not a separate issue that movements should 'add on' to their agendas; gender inequality is central to all issues tackled by social movements -therefore, no issue can be fully addressed without taking into account these gender dimensions. Making this visible to movement members in the context of movement politics is the first step to fully establishing why it is necessary to integrate gender analysis and action as part of activism. Awareness can be created through many means including public mobilisations, position papers on gender in relation to the movement's core issues, internal dialogues, questions and demands for specific actions, leading by example, developing gender analyses on movement issues and politics and encouraging members to reflect on the gender dynamics of movements' cultural practices. As in the experience of the Korean Women's Trade Union (see the box below), taking the step to do what is being asked of the broader movement and organise women around movement agendas is also a means of having women's concerns heard and inviting solidarity to take the issues on.

Making women workers' rights visible in the Korean trade union movement

The Korean Women's Trade Union (KWTU) was founded in 1999 to meet the organising needs of women workers - typically working in smaller un-unionised companies and in short-term, temporary and contracted labour which fell outside the scope of traditional labour unions. The KWTU has led by example in organising women temporary workers for better working conditions, including as golf caddies, and cleaners in universities. Their successful strikes in turn encouraged existing unions, until then only supporting full-time workers, to open their membership to women workers on temporary contracts. (Source: Park 2009)

\subsubsection{Openly discuss what women's rights and gender justice means for the movement}

To improve the chances of success and overcome resistance, one strategy is for a movement or movement-related organisation to work on discovering and building its own understanding of women's rights and gender justice. Movements need knowledge, pedagogical methods and concrete tools that can translate gender-responsive approaches from theory into practice that works in different contexts and among different movement actors. Movements and their related organisations cannot simply 'import' gender equality strategies from outside; they need room to digest ideas about women's rights and gender justice and translate them into terms and approaches that fit with their context and ways of working (Bhattacharjya et al. 2013; Caro 2013). 
These ongoing discussions and negotiations may be difficult at times. For example, at Amnesty International, this involved translating thinking from one movement (feminist/women's) into the language and understanding of another (the Amnesty movement). Debates were shaped by the legalistic nature of human rights movements - for example, debating whether domestic violence could be classed as torture. 'An important step was this dialogue of insiders and outsiders shaping the issue of women's rights into a form that Amnesty could incorporate into its ways of working as well as pressure from inside and outside' (Kelleher and Bhattacharjya 2013: 3).

\subsubsection{Agree movement-wide political positions and/or policies on gender}

Another strategy is to develop specific policies and analysis on women's rights and gender justice and incorporate these in key movement frameworks or guidelines. This can only occur in movements that have a degree of centralised leadership and policy or agenda-setting mechanisms. Once established, these statements or policies have both symbolic and practical value, and can be used by movement members in other contexts - for example, in their more localised organising, to reinforce the political legitimacy of a women's rights agenda or to hold actors to account in areas such as women's representation or meaningful participation. The strategy of establishing gender policies has been used by the Global Partnership for the Prevention of Armed Conflict (GPPAC), a global civil society network of organisations, and an important organisational ally for women's peace movements in the South Pacific. Its founding document in 2005 recognised the importance of including a gender perspective in conflict prevention, followed by a comprehensive gender policy, the result of pressure from women's networks within GPPAC.

Introducing and sustaining a gender-aware approach to conflict prevention

The Global Partnership for the Prevention of Armed Conflict (GPPAC) is a global civil society network of organisations working on conflict prevention and peace-building that calls for a fundamental change in dealing with violent conflict. GPPAC's Global Action Agenda, the founding document developed for the network's launch in 2005, recognised the importance of including a gender perspective in conflict prevention. However, women's groups within the network pressed for a comprehensive gender policy. FemLINKPACIFIC, a network of Pacific women's peace groups, proposed a model for enabling spaces for country and regional gender focal points within the network with key roles and responsibilities to ensure accountability of the network to women's rights treaties and conventions, including UN Security Council Resolution 1325. While a lack of resources delayed the implementation of the commitments and proposals set out in the framework, commitment remains high, given the political commitment of the GPPAC Executive Director, and a targeted gender coordinator. The members of the International Board of GPPAC including the Chairperson also continue to be strong champions of the policy as well as gender equality in their own work and actions. (Source: Bhagwan Rolls 2013) 


\subsection{Build inclusive alliances, shared analysis and common cause}

The important process of building alliances and finding common cause between feminist and other social movement politics involves openness to critique and a desire to listen and to change. Put differently, 'inclusion works in two ways - the struggle to be included and the willingness to include' (David Kelleher, BRIDGE e-discussion, March 2012). Some strategies to help this process are discussed below.

\subsubsection{Create spaces for dialogue to build understanding between movements and activists}

Common cause can be built through dialogue and constructing a shared analysis as the following experience suggests:

'I remember a meeting that a group of feminists convened with peasant and indigenous leaders to speak about our commonalities... I think that trying to look at how we agree, instead of disagree, always works better. In that moment... some leaders discovered that feminism could be a good thing, something positive, even though it would be difficult for them to admit it.' (Interview with Catalina, Mayan activist; Ardón 2012)

In East Africa, the sex worker and LGBTI rights movements both emerged with significant support from feminist individuals and organisations in the region as well as supportive donors. Bringing members of these movements into frequent contact with each other in leadership training and strategy meetings helped form activist relationships and solidarities, including for people who identified with two or more of the movements.

Negotiating solidarities: Building support for LGBTIQ and sex worker rights in East Africa

In the early 1990s, individual lesbian and gay community members and activists in East Africa stepped into rough waters to claim their right to be human, to engage on issues deeply passionate to themselves. Later in the 1990s, the sex worker movement in East Africa grew from small regional organising to more joined-up activism which was strengthened by ongoing capacity-building and leadership training to encourage sex workers to engage in policy processes and influence decisions. The LGBTIQ and sex work movements began to collaborate in light of a need to grow movement numbers, out of external encouragement from donors, and in the face of common forms of repression including police raids and retrogressive legal reform.

Feminist organisations, individual feminists and activists, and feminist movements ${ }^{45}$ in the region contributed greatly to creating space for dialogue and engagement within the women's movement on the issues being raised by the sex worker and LGBTIQ movements. They supported and spearheaded the birth of the coalition of civil society organisations that campaigned against the homophobic bill in Uganda, and rallied to petition the government of Uganda against the closure of leadership training workshops for sex workers.

45 Key among these are the Uganda Feminist Forum and the Africa Feminist Forum. 
'This led to issues of identity politics being seen by other movements as human rights concerns. Other social justice movements and actors, especially feminists, realised what they had in common with the LGBTIQ and sex work movements; all are trying to change the status quo'. (Nakaweesi-Kimbugwe with Chigudu 2013: 5).

\subsubsection{Use intersectional analysis to find areas of common struggle}

Intersectional analysis is a useful tool for identifying how different axes of power intersect and, through this, defining areas of common struggle between social movements. For example, individuals and groups that embrace an intersectional approach can also act as bridges between movements, using relationships and experiences across movements as a way to call for unified action and to help build social capital between movements. This has been the case with the human rights movement, as gender equality advocates from both women's movements and within the human rights movement itself have worked over a number of years to bring an intersectional approach to rights, arguing that 'women's rights are human rights'. The result has been that 'when the politics of feminism are combined with the tools of the human rights framework, great progress can be made. And when both sets of movements work in tandem, each others' voices can be amplified' (Bhattacharjya 2013: 5).

In Brazil, Afro-Brazilian feminists have engaged in intersectional activism around gender, race and class inequality, gaining social capital and organising experience through national gender equality platforms and transnational feminist organising with black and Afro-descendant women from across the Americas. The experience of mobilising around governmental forums on gender equality also provided women activists with leadership and technical skills that they then used in engaging governmental process around race, organising alongside Afro-Brazilian men activists in spaces such as the 2001 United Nations World Conference Against Racism in Durban (Franklin 2011).

Alliances may also emerge around a need to unite against common adversaries. This is common in campaigns or in the face of sudden shifts in political power or political repression, where there is a very focused change objective, and the need to create a base of allies around it may supersede existing antagonisms between movements concerned. In the course of confronting a common adversary movement actors often get to know each other and form relationships which may carry on after the particular campaign or goal has been achieved.

\subsubsection{Highlight the history of women's activism in forging alliances}

Too often the past activism of feminists and women's movement activists is written out of the history of social movements. Women are not recognised as agents of progressive change, which can hinder building alliances and solidarity with other movements and activists. 'The tragedy is that the role of women [is often] silenced by the narrators of history. How can we ensure that history recognises/acknowledges the role of individual women and gender justice movements as part of our collective narrative and not a footnote in the margins?' (Philip Thigo, BRIDGE e-discussion, October 2012; see also Abbas 2012). 
The very act of women being visible in solidarity actions can challenge such stereotypes and help to build common cause and new or stronger relationships with allies:

'[During] the coup d'état in Honduras in 2009... an incredible number of women took to the streets in protest, and men in mixed organisations realised that this was due to years of feminist organising. This broke down negative stereotypes of feminism (as "bourgeois" elites only interested in individualistic personal issues), and the "Feminists in Resistance" gained a lot of respect for their perseverance and commitment in their fight for democracy in Honduras despite repression and reprisals specifically against women' (Morna Mcleod, BRIDGE e-discussion, October 2011).

It is clearly essential to weave women's stories back into histories of activism. With this in mind, feminists and women's movement activists continue to engage in a retelling of activist histories, researching and making visible the hitherto undocumented or uncelebrated histories of women and gendered minorities in community and national struggles. They have also documented and reconstructed the history of social movements to better reflect the role of women, such as the rich history of Muslim women's activism (see the box below).

\section{Re-telling the story of Muslim women activists}

The training and information kit Great Ancestors: Women asserting rights in Muslim contexts documents stories of Muslim women activists in Asia, Africa and the Middle East from the 8th to the 20th centuries, making visible a rich and diverse history of activism in personal, community, political and religious domains. The tool was produced by the global network of Women Living Under Muslim Laws and the Pakistani women's rights organisation Shirkat Gah Women's Resource Centre (see Shaheed and Shaheed 2005).

Knowledge of activist history in itself is a resource in coalition-building. Demonstrating a history of connection between social movements and political struggles can help make the case for contemporary solidarity and the need to build on past progress. The following quote explores this idea:

'In my efforts to advance feminism within anti-racism movements and vice versa in the UK, I have found it useful to be able to demonstrate how feminism has always been a part of the historical anti-racism struggle in the country. This has been key because of how racism operates in the UK, which can make some people of colour/ ethnic minorities/black people resist ideas that appear to come from the dominant white majority, especially when it comes to how "our" women should be... [M]any people have been surprised and then pleased to learn that the movement for women's votes in the UK was born out of the fact that women were barred from participating in the anti-slavery conferences of the time. It was in trying to be part of the anti-racism movement of the time that women became aware of their rights as women' (zohra moosa, BRIDGE e-discussion, September 2012). 


\subsection{Expand inclusion within women's movements}

'Women and women's movements are not immune to social hierarchies within them. This brought the discussion back to the processes of building common cause - for example, healing past oppressions and operating from a place of reflexivity, self- awareness, and introspection - the 'qualities of relationship' (Alia Khan, summary of BRIDGE e-discussion, March 2012).

Women's movements themselves are not static; they emerge, grow and change in response to internal factors (such as new constituencies demanding recognition, inter-generational change and new directions in theory) and external factors (such as political clampdowns and new technologies). As the quote above suggests, challenging inequalities and the exercise of discriminatory power within women's movements remains ongoing as movements self-critique and work towards increasingly inclusive politics of transformation. This in turn strengthens solidarities with other movements of which women's movement members are part, and contributes to moving progressive politics forward. The Latin American and Caribbean Feminist Encuentros explored in the box below provide a snapshot of this dynamic of internal critique and inclusion.

The Latin American and Caribbean Feminist Encuentros: Engaging political and identity-based difference

'The meetings have helped pluralise feminisms' (Virginia Vargas, AWID, 2011: online).

The Feminist Encuentros in Latin America and the Caribbean were founded in 1981 as gatherings for feminists from across the region to debate their politics, develop and reflect on strategies and form solidarities across different feminist constituencies. Disagreements and transformations around how the Encuentros are organised, who participates and what is discussed have mirrored broader challenges in feminist movements around intersectionality, in particular concerning race and ethnicity, social class, sexual orientation and gender identity. As growing numbers of poor and workingclass women from mass women's movements joined, participants questioned where class fits in the feminist visions of the space and how much money was spent on venue costs given the economic status of many participants. Black/Afro-descendant and indigenous women called for greater visibility and consistent integration of their agendas in the programme, including issues of racism among feminists.

Black/Afro-descendant women mobilised within the Encuentro and created a separate regional platform to build a stronger regional black feminist movement. Lesbian women faced both homophobia and solidarity, forming a lesbian feminist network in response. Indigenous women were under-represented in early Encuentros, with indigenous women's mobilising gathering pace primarily outside regional feminist spaces and instead as part of the broader Latin American indigenous movement. In more recent years debates over the inclusion of transgender and intersex feminists have surfaced. In response to experiences of transphobia, a platform of lesbian, transgender and intersex feminist and allies organised a separate meeting in 2012, Encuentro LesBiTransInter Feminista 'Venir al Sur'. The Feminist Encuentros themselves continue to take place, adapting and expanding their political analysis in light of the needs and emerging movements of diverse Latin American and Caribbean feminists. (Adapted from Alvarez et al. 2003) 


\subsection{Operationalise gender justice in movements and movement-linked organisations}

Evidence from the detailed case studies developed for this report points to the role that a movement's central body or support organisation can play in whether and how women's rights and gender justice are embraced. Where there is an organisational base or platform relevant to or influential in guiding movement thinking and practice, it may be useful to consider how organisational change strategies and auditing and evaluation approaches can be adapted to support this process (Bhattacharjya et al. 2013). Below are some ways this has been done in practice.

\subsubsection{Harness and adapt organisational change strategies and techniques}

Work on changing internal politics needs to be coupled with a range of change strategies, to transform movement culture and staff or member consciousness. While not sufficient on its own, senior-level commitment is a key driver of change: whether in terms of forging action to create gender parity in decision-making or membership, ensuring gender justice goals are at the heart of strategic plans and campaigns, allocating resources to staff with a gender-specific remit, or setting up accountability mechanisms (Bhattacharjya et al. 2013). In the case of GPPAC discussed earlier, pressure from gender advocates within the movement for 'gender mainstreaming' and a comprehensive gender policy, coupled with supportive leadership, has heightened political commitment to work on gender justice (Bhagwan Rolls 2013). It became clear that 'simply having a policy is not enough. It is vital to effectively demonstrate the "how to integrate" or operationalise the policy" (Bhagwan Rolls 2013: 3). This is supported by a pool of active gender 'focal points' (both women and men), part of GPPAC's gender mainstreaming ${ }^{46}$ strategy.

Neither leadership nor policy insures against weak or inconsistent implementation. This is where feminist tools relating to consciousness-raising can be harnessed, enabling a shift in culture so that gender justice issues can be integrated across all levels of organisational culture and, through this, into operational planning, staff management, resources and accountability structures.

\subsubsection{Measure and track movements' records on women's rights and gender justice}

In order to plan effective action for integrating women's rights and gender justice into a movement or movement-related organisation, some kind of audit of the 'current state of play' on gender issues is useful, drawing on well-established gender auditing tools. ${ }^{47}$ Such audits and ongoing evaluations can inspire reflection, learning and further action by identifying failures and recording progress, both on 'internal' mechanisms and outwardfacing policy and activism. Amnesty International introduced its Stop Violence Against Women (SVAW) Campaign in 2004, which was to last six years. This campaign was a real departure for Amnesty; it was a new subject and a long and global campaign, involving

46 GPPAC's two-pronged approach to gender mainstreaming consists of an internal strategy of integrating a gender perspective into GPPAC's work at all levels, alongside an external strategy that focuses on strengthening GPPAC's advocacy and outreach work on priority topics related to gender justice (Bhagwan Rolls 2013). 
working partnerships with other organisations. It was also intended to change Amnesty's approach to women's rights (Kelleher and Bhattacharjya 2013). The subsequent evaluation exercise was, therefore, an important learning event; it concluded that while the campaign mobilised large amounts of energy on women's rights, it did not change the movement or normal organisational functioning and did not make women's rights part of Amnesty's 'DNA' (Wallace and Banos Smith 2010).

\subsection{Remain attentive to power relations between movements and organisations}

Today many organisations, including NGOs, formally registered community-based organisations, trade unions, political parties and donors are major actors with concerns and priorities that intersect with social movements' demands for women's rights and gender justice. It remains critical to be alert to the tremendous opportunities as well as tensions involved in these interactions. Organisations explicitly dedicated to movement-building and movement support need to remain aware of their own positions of power when working with movements, and recognise the importance of tackling new forms of oppression and emerging constituencies. They should also engage with movements' critiques of mainstream models including mainstream organisational forms and political processes.

\subsubsection{Better align donor practice with movement methods and needs}

Donors investing in social change around gender equality and women's rights should continue to explore ways to support movement-building ${ }^{48}$ and longer-term investments in base-building, cultivating popular political consciousness around challenging patriarchal power, and more clearly focused processes for building genderjust movement cultures. A number of donors are considering ways to democratise the donor-grantee relationship around grants decision-making and better align with activist agendas through participatory grant-making models, as profiled below.

\section{Participatory grant-making to support movement agendas}

There is growing interest among social justice and human rights donors to consider grant-making models that allow for funding allocations and strategic direction to be set more directly by organisations and activists in social movements. The Nicaraguabased Central American Women's Fund (http://www.fcmujeres.org), founded in 2003, has pioneered a model of participatory grant-making where applicants make the decisions around who receives funding. The fund supports feminist and women's rights activism with a focus on young women and minorities. This model has since inspired activist donor initiatives in other regions including UHAI - the East African Sexual Health and Rights Fund (http://www.uhai-eashri.org/) supporting LGBTI and sex worker activism in East Africa, and FRIDA, the Young Feminist Fund supporting young feminist activism globally (Pittman 2011).

48 See McGarvey and Mackinnon (2008) for a funders' guide to supporting community organising. 
In addition to changing grant decision-making processes, donors funding movementbuilding for women's rights and gender justice should continue to consider funding strategies that support movements to develop and reflect on gender justice and feminist politics, strategies and actions relevant to their respective contexts, and longterm tools to trace success in moving agendas forward. Multi-year and core funding are essential for movement-building as a means to enable continual investment in gender justice goals including among new movement members. This more flexible resourcing also enables movements to invest in ongoing work on deep structure, internal reflection and action around gender norms, and support for healing and emotional transformation. In both their funding and convening capacity, donors can support inter-movement dialogues both between and within women's / gender justice and other social movements to facilitate learning and building common cause.

\subsubsection{Consider how organisational resources can contribute to movement-building}

Organisations working on issues that intersect with movement agendas around gender justice and challenging patriarchal power can consider how to use their resources to advance movement-building. There remains a need to support spaces (physical and virtual) to develop and share movements' political visions, a process that can be supported by collaboration with movement actors, convening and creating spaces that may not already exist for different movements and members of movements in different geographical locations to meet and explore common political concerns and build analytical and leadership skills. Looking strategically, organisations have acted, and can continue to act, as intermediaries for movement actors to access formal discussion and decision-making spaces around women's rights and related intersectional concerns, including in governmental forums within other social movements. The example below looks at how CREA, a feminist NGO, supports movement-building to advance the rights of women and girls and the sexual and reproductive freedoms of all people.

CREA: movement-building through training, knowledge production and creating inter-movement spaces

CREA, a feminist human rights organisation based in New Delhi, India, contributes to movement-building in India, South Asia and globally through its Building Feminist Leadership and Movements initiative. CREA uses leadership training, hosting dialogues across movements and generating knowledge and analysis on contentious issues between and within movements which each provide conceptual resources and practical knowledge for movement actors. The annual Feminist Leadership, Movement Building and Rights Institutes (FLaMBRI), aimed at younger activists, builds analytical skills and reviews past organising strategies and how they can be applied to contemporary agendas. CREA also hosts global dialogues that facilitate inter-movement alliances by opening space for rigorous debate on contentious issues. In 'Ain't I a Woman: A Global Dialogue' activists from the sex workers' rights and the stop violence against women movements explored disagreements and ways to build common cause around sex workers' rights to freedom from violence. The Count Me In Conference, held in 2011, was historic in providing a platform for South Asian activists from a spectrum of movements - many of whom had not previously interacted - to learn about and strategise on ways to end violence against sex workers, disabled women, lesbian women and trans people. 


\subsection{Stay with it, and support change over time}

Time is an important factor in the development and success of social movements (see section 2.1) Although individual campaigns or instances of uprising for change may be limited to particular points in time (typically ending once successful, or if diffused), the broader struggle for women's rights and gender justice remains ongoing. Movements can help open space in society for new discussions and new voices, which in turn means that new constituencies begin to demand their rights - for example, the LGBTI and disability activist communities in the past half-century have been calling for action on their respective concerns and are highlighting how these intersect with gender inequality issues. As noted earlier, success can also bring backlash, as individuals, constituencies or institutions that benefited from the unjust status quo attempt to reclaim their power or role - a situation which in turn requires a response and sometimes different activist strategies. Movement politics must remain flexible to remain relevant as power relations shift, new constituencies emerge and new demands surface. Thus while shifts in how movements engage gender - for example, in acts of solidarity with women and gendered minorities, or welcoming new leadership - are important, the actual test is sustaining this respect and working on the full integration of women's rights and gender justice over time.

The process of changing perceptions and politics in itself is long-term in its scope and requires what Brazilian activists call 'revolutionary patience' (Obando 2008), and continual engagement. This idea is explored by activists in the reflections below:

'One of the major difficulties that we have found in our work is that movements and organisations need to "digest" what gender means to them. They have to be able to think about it in their own terms, integrate it into their ways of thinking and negotiate a place for it in their own cultural realities. This takes a long time, and it's not done in a gender training workshop' (David Kelleher, BRIDGE e-discussion, September 2012).

'Another challenge is the often unstated, but pervasive, focus on the ends or goals, and not the means or process. In campaigns and strategy meetings, there is a tendency to look at the tangible results at the cost of ignoring and devaluing the process. It is a constant struggle to raise issues of process and recognising how change is incremental' (Roshni Kishore Nuggehalli, BRIDGE e-discussion, May 2012).

'These are very complicated discussions even between two individuals to integrate what gender equality means in your marriage, in your family... Integrating gender equality has to be part of daily practice between our cultures, between our different economies... These discussions do not have easy answers. We have to talk about it constantly, and in that talking we find our solutions' (Interview with Mirijam Van Reisen, Social Watch Philippines, 2011). 


\section{Sustain the gains with new activist generations}

As part of building on past movement gains, it is vital to support new activist generations to continue to advance feminist and gender justice politics, actively sharing activist histories, knowledge and analysis while also making space for young people's leadership and new analysis of gender and other intersecting justice concerns. This requires confronting ageism in movement spaces (see chapter 4.3.2.), as well as building on the potential of younger generations to advance gender justice within social movements' agendas. It means actively considering support, where asked for or appropriate, for emerging younger movement actors, as voiced in the following quote:

'I suppose the hardest deep structure is the hierarchies within hierarchies that make activism difficult. The spark of activism is so often being faced by difficulties because of some aspect of discrimination. To address the structures, one may really need to find a way to educate youth about injustices and find a way to get them to realise that everyone needs to work towards equality and fairness for a better society. Good mentors [are needed], as well as adequate leadership, especially within the youth activist movement' (Sian Rolls, BRIDGE e-discussion, May 2012).

This chapter has outlined a range of enabling conditions needed to create a supportive environment for thinking about and acting on unjust gender power relations in social movements. It has identified key routes to change emerging across social movement practice, profiling examples of how these have been conceptualised and enacted in different movement contexts. The concluding section points to insights emerging from the process of writing this report around areas for further exploration, documentation and analysis. 


\section{Reflections and Areas for Further Exploration}

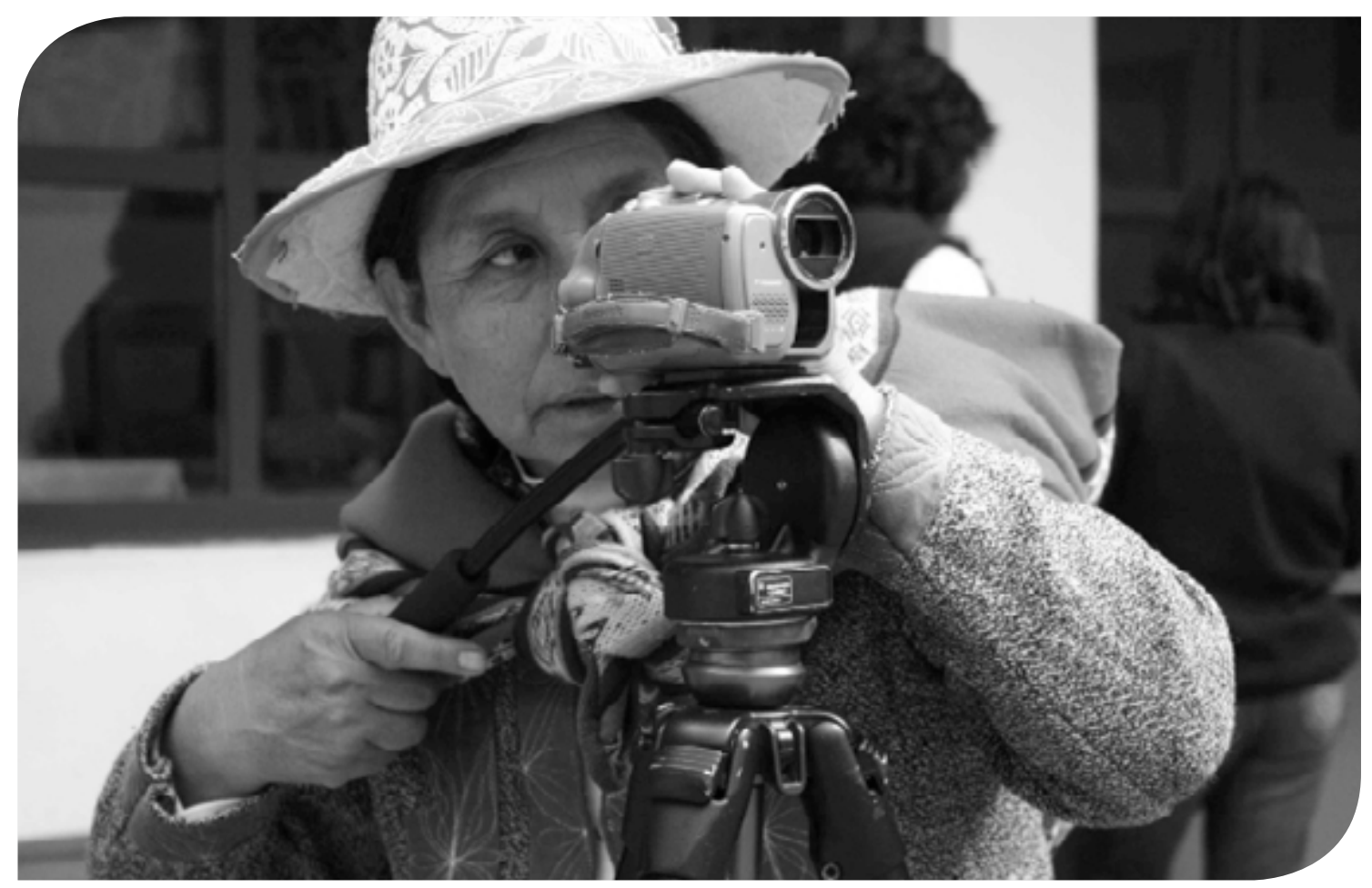

Guadalupe Cuba, a community defender from Cusco, Peru.

Photographer: Annie Thériault

This report makes the case for progressive social movements to fully integrate women's rights, gender justice and challenging patriarchal power into their politics and change visions and strategies. Social movement activism continues to play a pivotal role in defining, demanding and instigating change in all arenas of social, political, economic and cultural life. Movement-based demands to end violations of women's rights and transform gender power relations towards justice are now firmly on the table. However, through evidence drawn from a diversity of social movement experiences, this report has also shown that achieving full support for women's rights and gender justice remains an incomplete task and a point of struggle. A commitment to transforming gendered power is still for the most part inadequately prioritised, or at times even contested, in the politics and practice of progressive social movements. 


\subsection{Reflections}

In as much as women's rights and gender justice are understood as necessary conditions for justice and equality for all, this report calls for progressive social movements to think more actively about and implement ways to catalyse gendered transformation. It has presented a range of 'routes to change' for movements to consider in their journey toward the ideal gender-just movement set out in section 5.1. What final reflections can be drawn from the arguments, evidence and strategies presented in the preceding chapters?

\section{Building solidarity and inclusive alliances is key}

In the light of enormous external challenges - including rising fundamentalisms, militarism, accelerating climate change and financial crises - it is more important than ever to build inclusive alliances between women's movements and other progressive social justice movements to help build popular progressivism and leverage social transformation for all. Recognising the value of solidarity is the first step forward. It is equally important to acknowledge that disagreement is a natural part of building alliances, and that paying attention to the factors that might divide groups and confronting these with respect and honesty is essential.

History has shown that it is those most affected by discrimination and injustice that are likely to lead in raising questions and calling for inclusion or a change in a movement's visions and methods. Change agents raising questions about the invisibility of women's concerns, questioning the use of culture or tradition to reinforce oppressive gender norms, or calling for roles within movements to be subjected to a critical gender lens may themselves face backlash and need support and solidarity as they mobilise and lead change processes.

Constant attention to the intersections of gender and other axes of marginalisation and inequality are also important in building movements representative of the diverse realities people experience in their daily lives, and also provides a rich basis for building common cause with other excluded interests and voices, towards the achievement of justice for all.

\section{Transformation requires unblocking deep patriarchal structures}

Sustained change will only take place once actors in movements - especially movement leaders - name and begin to engage with the deep structure of patriarchal gender norms and the ways that these manifest in movement imaginations, power dynamics and roles. As this report has shown, 'there are patriarchal set-ups in the movements, and accepting a feminist analysis on issues will expose the contradictions within the movement itself' (Shalmali Guttal, BRIDGE e-discussion, September 2012). Moves to transform deep structure may be instigated by crises such as cases of gender-based violence committed by movement members, through mobilisation from within, or by external actors raising questions, offering or asking for solidarity, or through training and consciousness-raising. As feminist movements have affirmed, the process of questioning gender power relations in our personal lives and practices is a valid component of activism. It requires methods that not only build individual and collective critical consciousness but also engage people's emotions and provide space to reflect and heal personally and collectively. 


\section{It is essential to remain reflexive and rethink political visions}

Movements are defined by their political visions - propositions for new ways of ordering our world. Given this, a commitment to women's rights and gender justice ultimately needs to move beyond questions of representation or gender-focused policies to re-imagining movement politics in ways that acknowledge gendered demands and visions of justice. Furthermore, all social movements, including women's movements, benefit from holistic approaches to equality and justice, taking an intersectional approach and championing arguments and actions that respond to the human rights of all people. This process of re-envisioning needs to remain active as political demands change in terms of definitions of gender, in particular with the emergence of queer, transgender and intersex movements, new activist constituencies and shifting external power dynamics.

\section{Investment in gender-just movements and feminist movement-building is vital if sustainable change is to be made}

The upsurge of interest among development and human rights NGOs and donors to engage with social movements and invest in movement-building after pro-democracy revolutions marks an important opportunity to grow support for social movements. Where organisations or donors play a movement-building role, they also need to consider their responsibility in ensuring that questions of transforming gendered power and advancing women's rights and gender justice are central.

There is tremendous potential, alongside challenges, in harnessing the power of organisations linked to movements, and donors funding movement agendas and movement-building, for promoting transformative change. While acknowledging critiques of the role of NGO-isation on women's and gender justice activism, it is nevertheless evident that women's movements and feminist agendas remain comparatively under-resourced and poorly supported in institutional domains, especially in comparison to other meta-justice issues. As such, exploring ways to increase resources and organisational support for movement activism for women's rights and gender justice, alongside ways to increase organisations' accountability to movements, remains a priority.

\subsection{Areas for further exploration}

While this report has begun a process of discussion on routes for gender-just change in social movements, it is clear that going forward further work in a number of areas would be extremely useful. These are discussed below.

\section{Methods and practices for transforming deep structures in social movement contexts}

There is as yet little guidance, training material or theorisation around the complex area of tackling gendered deep structures in social movements. This report has begun to explore this area, but further work is needed to document existing, and develop new, practical strategies for movements to adapt and try. These strategies might include techniques drawn from feminist organising and movement-building, such as smallscale consciousness-raising and reflective learning approaches, and from organisational change methods such as gender audits and policy reviews. 


\section{Possible roles for formalising accountability mechanisms on gender justice}

Many feminist and women's rights activists express frustration that despite vibrant women's movements and widespread formal acknowledgement of the importance of making the fight for justice more gender-aware, there is still a limited sense of accountability to these agendas within progressive movements. This sparks the question of whether there is use in having more formalised methods and structures of accountability, in particular in contexts where movements organise and engage in formal ways with each other - for example, in shared physical spaces such as conferences, in inter-movement networks or where movements engage through organisational platforms. One key question to ask is: 'Should women's movements and activists play a "watching" role, monitoring and speaking out about what is happening in social movements and reflecting back [when] they are replicating the same power imbalances that occur in the very structures we are challenging, or sometimes negotiating away core parts of the agenda, which too often includes women's rights?' (Joanne Sandler, BRIDGE e-discussion, October 2011). In terms of accountability tools, there are existing methodologies such as gender audits used in organisations ${ }^{49}$ which could be adapted to respective movement contexts, as well as existing initiatives to track global resourcing for women's rights. ${ }^{50}$

\section{Mapping what works for building effective and equitable alliances}

This report and related materials have started to build an evidence base of what works in integrating concerns of gender justice into social movements, including in building strategic alliances. What do we know from practice is needed to build an effective alliance?

'Too often we seek to forge alliances without having first articulated the differences - building upon commonalities, without doing the deeper structure work. This works fine if the alliance is a quick fiery public action to protest something [...] but the work of building consensus and longer-term working together will take a lot more work peeling away at the layers of centres and peripheries and power dynamics' (Susanna George, BRIDGE e-discussion, March 2012).

For feminists and women's rights advocates, there are recurring challenges around building alliances with social movements that do not yet have a gendered politics, notably when it comes to a willingness to take progressive approaches to questions of culture and tradition, bodily integrity and sexual and reproductive choice. In that light, '[i]t would be great to know more about how to join in an effective way. And how to avoid ending up negotiating competing interests, rather than converging and complementary interests that propel long-term change' (Joanne Sandler, BRIDGE e-discussion, October 2011).

Within women's and feminist movements themselves, more work is needed on how to move beyond the current dilemmas about 'when to cooperate and when to resist' (Islah Jad, BRIDGE e-discussion, March 2012), and how to build intersectional approaches that take into account the diversity and related political claims of all women.

49 Examples of gender audit tools include Moser (2005) and International Labour Organization (2007).

50 The 'Where is the Money' initiative of the Association for Women's Rights in Development has led the way in producing new research and analysis that tracks funding patterns and needs of women's rights organisations globally. See http://www.awid.org/Our-Initiatives/Where-is-the-Money-for-Women-s-Rights. 


\section{Building and investing in gender-just social movements}

In order for both established movements to transform their external agendas and internal dynamics, and new movements to develop with gender justice at their core, it is essential to invest in gender-just movement-building and to support movements in ways that allow long-term planning and sustainability. Doing this will maximise the potential for social transformation that is representative of actual social demands, inspiring a new generation of activists and bringing long-term benefits for everyone.

Movement-building investments for gender justice can include creating safe spaces for movement activists or leaders to come together with time for dialogue, reflection, learning, and the building of trust. It may also include supporting the development of feminist leadership, and new knowledge and analysis on women's rights and gender justice that is specific and appropriate in particular movement contexts. It is also essential to ensure that resources are available to sustain activist well-being and support women human rights defenders. If feminists and gender equality advocates are to lead the transformation of social movements, building energy, security, self-care and peer support is critical.

\section{Further research, documentation and analysis}

There is still a documentation and research gap around the history of women's and feminists' activist involvement in progressive social movements across the world, and the challenges and successful strategies used to advance gender justice in movements. Much of this information is anecdotal or profiled in internal reports that do not have wide circulation. The following are some of the key questions that further research could address:

- How do we engage and transform the gendered deep structure of movements? Are there lessons to be learned from transforming other deep structure dynamics in movements that can be drawn on and developed?

- What are existing models and experiences of alternative gender roles and divisions of labour within mixed-gender social movements? How can these be sustained?

- What are existing models of intersectional approaches that fully integrate gender dimensions in current or emerging social movements?

- What accountability mechanisms have been developed and used by movements committed to women's rights and gender justice, including ways of addressing violence against women within movements?

- What happens in mixed-gender movements where women have taken on new roles in movement membership and leadership to effect external change? Do these altered power dynamics continue after change has been achieved, or is there pressure to return to traditional gender norms?

- What are the perspectives and strategies on feminism, women's rights and gender justice among new generations of movement activists and emerging social movements?

This report has begun a process of exploration on these issues. It is hoped that this process can continue and grow, and that more gender-just movements can be built, supported and experienced, ultimately contributing to changing our societies towards full justice and equality. 


\section{Bibliography}

Abbas, H. (2012) Are Women Occupying New Movements?, http:/ / thefeministwire.com 2012/ 06 / are-women-occupying-new-movements / (accessed 15 May 2013)

Abu-Lughod, L. (2001) Remaking Women: Feminism and Modernity in the Middle East, Princeton, NJ: Princeton University Press

Adeleye-Fayemi, B. (2007) 'Financing for Gender Equality and the Empowerment of Women: The Critical Role of Autonomous Women's Funds in Strengthening Women's Movements', presentation at the Expert Group Meeting for Financing for Gender Equality and the Empowerment of Women, New York, NY: United Nations Division for the Advancement of Women

Al-Bizri, D. (2011) Women in the Arab Spring: New and Distinct Forms of Political Participation, Berlin: Heinrich Boll Foundation

Alvarez, S. (2009) 'Beyond NGO-ization? Reflections from Latin America', Development 52.2: $175-184$

Alvarez, S.; Friedman, E. J., Beckman, E., Blackwell, M., Stoltz Chincilla, N., Lebon, N., et al. (2003) 'Encountering Latin American and Caribbean Feminisms', Signs: Journal of Women in Culture and Society 28.2: 537-581

Amos, V. and Parmar, P. (2001) ‘Challenging Imperial Feminisms', in K. Bhavania (ed.), Feminism and Race, Oxford: Oxford University Press

Antrobus, P. (2004) The Global Women's Movement: Origins, Issues and Strategies, London: Zed Books

Appadurai, A. (2002) ‘Deep Democracy: Urban Governmentality and the Horizon of Politics', Public Culture 14.1: 21-47

Ardón, P. (2012) Personal interviews with Latin American movement leaders. Unpublished

ASTRA (2012) Reclaiming and Redefining the Rights. ICPD+20: Status of Sexual and Reproductive Rights and Health in Central and Eastern Europe, http: / / www.astra.org.pl/ pdf/publications/ICPD_20.pdf (accessed 9 July 2013)

AWID (2011) The Relevance of the Feminist Encuentro for Latin American Feminist Movements, www.awid.org/News-Analysis / Friday-Files/ The-Relevance-of-the-Feminist-Encuentrofor-Latin-American-Feminist-Movements (accessed 19 February 2013) 
Bacchetta, P. and Power, M. (2013) Right-wing Women: From Conservatives to Extremists around the World, London: Routledge

Balchin, C. (2011) Towards a future without fundamentalisms: Analysing religious fundamentalist starategies and feminist responses, Toronto: Association for Women's Rights in Development (AWID)

Barker, G.; Nascimento, M., Ricardo, C., Olinger, M. and Segundo, M. (2011) 'Masculinities, Social Exclusion and Prospects for Change: Reflections from Promundo's work in Rio de Janeiro, Brazil', in A. Cornwall, J. Edstöm and A. Greig, Men and Development: Politicizing Masculinities, London: Zed Books

Barry, J. and Djordjevic, J. (2008) What's the Point of a Revolution if We Can't Dance, Boulder, CO: Urgent Action Fund For Women's Human Rights

Basu, A. (2005) Women, Political Parties and Social Movements in South Asia, Geneva: UNRISD

Batliwala, S. (2012) Changing their World: Concepts and Practices of Women's Movements, 2nd Edition, Toronto: AWID

Batliwala, S. (2010a) 'All About Movements', presentation at the CREA South Asia Movement Building and Human Rights Institute, Kathmandu, Nepal

Batliwala, S. (2010b) Feminist leadership for social transformation: Clearing the conceptual cloud, New Delhi, New York: CREA

Batliwala, S. (2008) Changing Their World: Concepts and Practices of Women's Movements, Toronto: AWID

Batliwala, S. (2007) 'Walk Beside Us', speech given at the High Level Thematic Debate on Gender Equality and Women's Empowerment held by the United Nations General Assembly, New York, 6 March, http: / / www.genderatwork.org/article/ walk-beside-us (accessed 19 February 2013)

Batliwala, S. (2002a) 'The Missing Transnational Social Movement: The Case of the European Roma', Paper presented at the Workshop on 'Transnational Dynamics' organized by the Kennedy School of Government, Harvard University, Cambridge, MA

Batliwala, S. (2002b) ‘Grassroots Movements as Transnational Actors: Implications for Global Civil Society', Voluntas: International Journal of Voluntary and NonProfit Organizations 3.4: 393-410

Batliwala, S. and Brown, L.D. (2006) 'Shaping the Global Human Project: The Nature and Impact of Transnational Civil Activism' in S. Batliwala and L.D. Brown (eds), Transnational Civil Society: An Introduction, Bloomfield, CT: Kumarian Press

Benhabib, S. (1996) Democracy and Difference: Contesting the Boundaries of the Political, Princeton, NJ: Princeton University Press

Benhabib, S. (1996) 'Introduction: The Democratic Movement and the Problem of Difference' in Benhabib, S (ed.) (1996) Democracy and Difference: Contesting the Boundaries of the Political, Princeton, NJ: Princeton University Press 
Bhagwan Rolls, S. (2013) Defining our Space: Gender mainstreaming strategies in the work of GPPAC - the Global Partnership for the Prevention of Armed Conflict, Brighton: BRIDGE, IDS

Bhattacharjya, M. (2013) A Tale of Two Movements: How human rights became women's rights, Brighton: BRIDGE, IDS

Bhattacharjya, M.; Birchall, J., Caro, P., Kelleher, D. and Saharasman, V. (2013) ‘Why gender matters in activism: feminism and social justice movements', Gender $\mathcal{E}$ Development 21.2, London: Routledge

Birchall, J. and Horn, J. (2013) World Social Forum: Integrating feminism and women activists into visions and practices of "another world", Brighton: BRIDGE, IDS

Bop, C. (2008) Senegal: Homophobia and Islamic Political Manipulation, Sexuality Policy Watch Working Paper, Rio de Janeiro: Sexuality Policy Watch

Budlender, D. and Moussie, R. (2013) Women's unpaid care work in Nepal, Nigeria, Uganda and Kenya, Johannesburg: ActionAid International

Buechler, S.M. (2011) Understanding Social Movements: Theories from the Classical era to the Present, Boulder, CO, London: Paradigm Publishers

Burchardt, T. and Vizard, P. (2007) Definition of equality and framework formeasurement: Final Recommendations of the Equalities Review Steering Group on Measurement. London: OPSI

Brah, A. and Phoenix, A. (2004) 'Ain't I A Woman? Revisiting Intersectionality', Journal of International Women's Studies 5.3: 75-86

Caro, P. (2013) Gender equality and women's rights in the CLOC-Via Campesina movement, Brighton: BRIDGE, IDS

Castells, M. (2011) The Power of Identity, 2nd edition, Chichester: Wiley-Blackwell

Castells, M. (2010) The Rise of the Network Society, 2nd Edition, Chichester: WileyBlackwell

Celiberti, L. (2011) Imaginaries in Dispute, Lima: Programa Democracia y Transformación Global

Center for Health and Gender Equity (2008) Implications of U.S. Policy Restrictions for HIV Programs Aimed at Commercial Sex Workers, Washington, DC: Center for Health and Gender Equity, www.genderhealth.org/files/uploads/change/ publications / aplobrief. pdf (accessed 20 February 2013)

Center for Reproductive Rights (2003) Breaking the Silence: The Global Gag Rule's Impact on Unsafe Abortion, New York, NY: Center for Reproductive Rights

Chopra, D. with Kelbert, A. and Iyer, P. (2013) A Feminist Political Economy Analysis of Public Policies Related to Care: A Thematic Review, Brighton: IDS 
Cisse, A. (2012) M23: In the Name of the Senegalese People, http: / www.

opendemocracy.net / 5050 / aissatou-ciss\%C3\%A9/m23-in-name-of-senegalese-people (accessed 1 December 2012)

Clark, C.; Sprenger, E. and VeneKlassen, L. (2006) Where is the Money for Women's Rights? Assessing Resources and the Role of Donors in the Promotion of Women's Rights and the Support of Women's Organisations, Toronto: Association for Women's Rights in Development

Cock, J. (2001) Colonels and Cadres: War and Gender in South Africa, Cape Town, New York: Oxford University Press

Connell, D. (2001) Rethinking Revolution New Strategies for Democracy and Social Justice, Trenton, NJ: The Red Sea Press

Cornwall, A.; Edström, J. and Greig, A. (2011) Men and Development: Politicising Masculinities, London: Zed Books

CREA (2012) Count Me In: Research Report, Violence against Disabled, Lesbian and Sexworking Women in Bangladesh, India and Nepal, New Delhi: CREA

CREA, Artemisa and Elige (2008) Self-defence and Self-care manual for Feminist Activists, New Delhi, New York: CREA, Artemisa and Elige

Crenshaw, K. (1991) 'Mapping the Margins: Intersectionality, Identity Politics and Violence Against Women of Color', Stanford Law Review 43.6: 1241-1299

Critical Resistance; INCITE! (2001) Critical Resistance and INCITE! Statement: Gender Violence and the Prison Industrial Complex, Redmond, WA: INCITE!, www.incitenational.org/media/docs/5848_incite-cr-statement.pdf (accessed 19 February 2013)

Duatre, A.I. (2012) 'From the Margins of Latin American Feminism: Indigenous and Lesbian Feminisms', Signs 38.1: 153-178

Dütting, G. and Sogge, D.S. (2010) Moving Targets: Notes on Social Movements, The Hague: HIVOS.

D'Atri, A. and Escati, C. (2008) The Piqueteralo Movement of Argentina, Toronto: AWID

Doetsch-Kidder, S. (2012) Social Change and Intersectional Activism: The Spirit of Social Movement, New York, NY: Palgrave Macmillan

Ekine, S. (2010) SMS Uprising: Mobile Phone Activism in Africa, Cape Town, Dakar, Nairobi, Oxford: Pambazuka Press

Esplen, E. (2009) Gender and Care: BRIDGE Cutting Edge Pack overview report, Brighton: BRIDGE, IDS

Essof, S. (2005) ‘She-murenga: Challenges, Opportunities and Setbacks for the Women's Movement in Zimbabwe', Feminist Africa 4: 29-45 
Falk, R. (1993) 'The Making of Global Citizenship', in J. Brecher, J. Brown Childs and J. Cutler (eds.), Global Visions: Beyond the New World Order, Boston, MA: South End Press

Ferber, A.L. (2004) Home-grown Hate: Gender and Organised Racism, London: Routledge

Feree, M.M. and Tripp, A.M. (2006) Global Feminism: Transnational Women's Activism, Organising and Human Rights, New York, NY: New York University Press

Franklin, J. (2011) ‘Race, Gender, and Human Rights: A Glimpse into the Transnational Feminist Organization of Afro-Brazilian Women', in C.Romeán-Odio (ed.), Transnational Borderlands in Women's Global Networks: The Making of Cultural Resistance, New York, NY: Palgrave Macmillan

Fraser, N. (1995) 'From redistribution to recognition? Dilemmas of justice in a "postsocialist” age', New Left Review 212: 63-98

Freeman, J. (1972-3) 'The Tryanny of Structurelessness', Berkeley Journal of Sociology 17: $151-164$

Ghimire, K. (2005) The Contemporary Global Social Movements: Emergent Proposals, Connectivity and Development Implications, Geneva: UNRISD

Global Alliance for Trans Equality, http:/ / transactivists.org/trans/ (accessed 12 July 2013)

Goetz, A.M. (2007) ‘Gender Justice, Citizenship and Entitlements: Core Concepts, Central Debates and New Directions for Research', in M. Mukhopadhyay and N. Singh (eds.), Gender Justice, Citizenship and Development, Ottawa, New Delhi: IDRC

Göle, N. (2011) The New Faces of the European far-right, http: / / blogs.ssrc.org/ tif/2011/05/11/the-european-far-right/ (accessed 14 May 2013)

Goodwin, J.J.; Jasper, M. and Polletta, F. (2001) Passionate Politics: Emotions and Social Movements, Chicago, IL: University of Chicago Press

Govender, P. (2007) Love and Courage: A Story of Insubordination, Johannesburg: Jacana Media.

Gurumurthy, A. (2012) The Big Deal About the Network Age: Political Economy Conversations from the CITIGEN Network, Bengaluru: IT For Change

Harcourt, W. (2009) Body Politics in Development, London: Zed Books

Harcourt, W. and Escobar, A. (2005) Women and the Politics of Place, Bloomfield, CT: Kumarian Press

Harford, B. and Hopkins, S. (eds.) (1984) Greenham Common: Women at the Wire, London: Women's Press

Heywood, M. (2009) 'South Africa's Treatment Action Campaign: Combining Law and Social Mobilization to Realize the Right to Health', Journal of Human Rights Practice 1.1: 14-36 
Hoodfar, H. and Sadeghi, F. (2009) 'Against All Odds: The Women's Movement in the Islamic Republic of Iran', Development 52.2: 215-223

Horn, J. (2011) 'Case Study of the Women's Peace Movement in Liberia', Curriculum of Movement Building Bootcamp for Queer African Activists, Nairobi: Fahamu

Horn, J. (2011) 'Introductory Notes: Theories of Power and Change', Movement Building Bootcamp for Queer African Activists, Nairobi: Fahamu, http: / fahamu.org/ $\mathrm{mbbc} /$ ?page_id=716 (accessed 10 November 2012)

Horn, J. (2009) Christian Fundamentalisms and Women's Rights in African Contexts: Mapping the Terrain, Toronto: AWID

Hsiung, P.C.; Jaschok, M., Milwertz, C. and Chan, R. (2001) Chinese Women Organizing: Cadres, Feminists, Muslims, Queers, Oxford: Berg.

Htun, M. and Weldon, S.L. (2012) 'The Civic Origins of Progressive Policy Change: Combatting Violence Against Women in Global Perspective, 1975-2005', American Political Science Review 106.3: 548-569

Ilkkaracan, P. and Jolly, S. (2006) Gender and Sexuality: BRIDGE Cutting Edge Pack overview report, Brighton: BRIDGE, IDS

Imam, A.; Mama, A. and Sow, F. (1997) Engendering African Social Sciences, Dakar: CODESRIA

Intersex Society of North America http: / / www.isna.org/ faq/what_is_intersex (accessed 12 July 2013)

International Center for Non-Profit Law (2010) Legal Frameworks for Global Philanthropy: Barriers and Opportunities, Arlington, VA: Council of Foundations

International Labour Organization (2007) A Manual for Gender Audit Facilitators: The ILO's Participatory Gender Aduit Methodology, Geneva: ILO

International Telecommunication Union (2013) ICT Facts and Figures: The World in 2013, Geneva: ITU

Jad, I. (2008) The Demobilisation of Women's Movements: The Case of Palestine, Toronto, Mexico City, Cape Town: AWID

Jaschok, M.; Milwertz, C. and Hsiung, P.C. (2001) 'Introduction', in P.C. Hsiung, M. Jaschok, C. Milwertz and R. Chan (eds), Chinese Women Organizing: Cadres, Feminists, Muslims, Queers, Oxford: Berg

Jashnani, G.; Maccani, R. and Greig A. (2011) ‘What Does it Feel Like When Change Finally Comes? Male Supremacy, Accountability and Transformative Justice', in C. Chen, J. Dulani and L. Piepzna-Samarasinha (eds), The Revolution Starts at Home: Confronting Intimate Violence within Activist Communities, Boston, MA: South End Press

Jolly, S. (2000) “"Queering” Development: Exploring the Links between Same-Sex Sexualities, Gender, and Development', Gender \& Development 8.1: 78-88 
Joyce, K. (2009) Quiverfull: Inside the Christian Patriarchy Movement, Boston, MA: Beacon Press

Just Associates (2012) Feminist Movement Builders Dictionary, Washington, DC: Just Associates

Just Associates (2006) Making Change Happen: Power, Washington DC: Just Associates

Kandiyoti, D. (2012) Disquiet and Despair: The Gender Sub-texts of the 'Arab Spring', http:/ / www.opendemocracy.net /5050/ deniz-kandiyoti / disquiet-and-despair-gender-sub-textsof-arab-spring (accessed 20 November 2012)

Kaoma, K. (2009) Globalizing the 'Culture Wars': U.S. Conservatives, African Churches and Homophobia, Sommerville: Political Research Associates

Kelleher, D. and Friedman, M. (2009) In Their Own Idiom: Reflections on a Gender Action Learning Program in the Horn of Africa, Toronto: Gender at Work

Kelleher, D. and Bhattacharjya, M. (2013) The Amnesty International Journey: Women and Human Rights, Brighton: BRIDGE, IDS

Khanna, A. (2012) ‘Seeing Citizen Action through an “Unruly” Lens', Development 55.2: 162-172

Leach, M. and Scoones, I. (2007) Mobilising Citizens: Social Movements and the Politics of Knowledge, Brighton: IDS

Mahmud, S. (2010) 'Why do garment workers in Bangladesh fail to mobilize?', in L. Thompson and C. Tapscott (eds), Citizenship and Social Movements: Perspectives from the Global South, London: Zed Books

Mananzala, R. and Spade, D. (2008) 'The Non-profit Industrial Complex and Trans Resistance', Sexuality Research and Social Policy 5.1: 53-71

Mansbridge, J. (1996) ‘Using Power/Fighting Power: The Polity', in S.Benhabib (ed.), Democracy and Difference: Contesting the Boundaries of the Political, Princeton, NJ: Princeton University Press

Mathaai, W.M. (2007) Unbowed, London: William Heinemann

Mathaai, W. (2004) The Greenbelt Movement: Sharing the Approach and the Experience, New York, NY: Lantern Books

McGarvey, C. and Mackinnon, A. (2008) Funding Community Organising: Social Change Through Civic Participation, New York, NY: Grantcraft

McGuffin, P. (2007) 'A new generation of CND goes on the march', Telegraph \& Argus UK

Meer, S. (2005) 'Freedom for Women: Mainstreaming Gender in the South African Liberation Struggle and Beyond', Gender \& Development 13.2: 36-45 
Memedova, A. (2004) Romani Men and Romani Women Roma Human Rights Movement: A Missing Element, www.errc.org/ cikk.php?cikk=1850\&archiv=1 (accessed 25 June 2013)

Moawad, N. and Qiblaw, T. (2011) 'Who is afraid of the big bad internet?', in J.S. Kee (ed.), EROTICS: Sex, Rights and the Internet, Melville: Association for Progressive Communications

Mohanty, C.T. (2003) ‘Under Western Eyes Revisited: Feminist Solidarity through Anticapitalist Struggles', Signs 28.2: 499-535

Moraga, C. and Anzaldúa, G. (1981) This Bridge Called My Back: Writings by Radical Women of Color, Watertown, MA: Persephone Press

Moraga, C.; Anzaldúa, G. and Bambara, T.C. (1984) This Bridge Called My Back: Writings by Radical Women of Colour, New York, NY: Women of Color Press

Moser, C. (2005) An Introduction to Gender Audit Methodology: Its Design and Implementation in DFID Malawi, London: Overseas Development Institute

Moser, C. (1993) Gender Planning and Development: Theory, Practice, Training, London, New York: Routledge

Motta, S.C. and Nilsen, A.G. (2011a) Social Movements in the Global South: Dispossession, Development and Resistance, Basingstoke: Palgrave Macmillan

Motta, S.C., and Nilsen, A.G. (2011b) 'Social movements and / in the Post-colonial: Disposession, Development and Resistance', in S.C. Motta and A.G. Nilsen (eds), Social Movements in the Global South: Dispossesion, Development and Resistance, Basingstoke: Palgrave Macmillan

Naidoo, K. (2006) ‘Claiming Global Power: Transnational Civil Society and Global Governance', in S. Batliwala and L. Brown (eds), Transnational Civil Society: An Introduction, Bloomfield, CT: Kumarian Press

Nakaweesi-Kimbugwe, S. with Chigudu, H. (2013) The LGBTIQ and sex worker movements in East Africa, Brighton: BRIDGE, IDS

Nakaweesi-Kimbugwe, S. and Mugisha, F. (2009) ‘Bahati’s Bill: A Convenient Distraction for Uganda's Government', Pambazuka News 453

Nascimento, M. (2012) Interviews with men working for gender equality, www.youtube. com/user/BRIDGEsocialmovement or http:/ / vimeo.com/bridgesocialmovements (accessed 9 July 2013)

Navarro, Z. and Silva, M. (2007) Diversity and Social Opposition in the 21st Century: The Trajectory of the World Social Forum (2001-2005), IDS Working Paper 275, Brighton: IDS

Obando, A.E. (2008) Sexism in the World Social Forum: Is Another World Possible?, http:/ / awid.org/Library/Sexism-In-The-World-SocialForum-Is-Another-World-Possible (accessed 18 November 2012) 
Oommen, T. (2010) Social Movements: Issues of Identity (Vol. 1), New Delhi: Oxford University Press

Park, N. (2009) ‘The Korean Women's Trade Union: Mobilising Women Workers', Development 52.2: 246-250

Patel, S.; Burra, S. and D'Cruz, C. (2001) 'Slum/Shack Dwellers International: Foundations to Treetops', Environment and Urbanisation 13.2: 45-59

Petchesky, R. (2000) ‘Sexual Rights: Inventing a Concept, Mapping an International Practice', in R.G. Parker, R.M. Barbosa and P. Aggleton (eds), Framing the Sexual Subject: The Politics of Gender, Sexuality and Power, Berkeley, CA: University of California Press

Phillips, M. (2012) 'I feel 120\%', Transforming Power: A Knotted Rope: 32-33, Canada: Gender at Work

Pittman, A. (2011) Emerging Models of Participatory Philanthropy: FRIDA I The Young Feminist Fund, http: / / hausercenter.org/iha/2011/12/05/emerging-models-ofparticipatory-philanthropy-frida-the-young-feminist-fund/ (accessed 24 June 2013)

Pittman, A.; Arutyunova, A., Vidal Degiorgis, V. and Shaw, A. (2011) 2011 AWID Global Survey 'Where is the Money for Women's Rights?', Preliminary Research Results, Toronto: AWID

Posadskaya, A. (1994) Women in Russia: A New Era in Russian Feminism, London: Verso

Price, J. (2011) The Seeds of a Movement: Disabled Women and their Struggle to Organize, Toronto: AWID

Price, J. (2009) Disabled, Queer: Queering Embodiment, Brussels: International Lesbian and Gay Association

Rao, A. and Kelleher, D. (2005) 'Is there life after gender mainstreaming?', Gender $\mathcal{E}$ Development 13.2: 57-69, London: Routledge

Razavi, S. (2007) The Political and Social Economy of Care in a Development Context: Conceptual issues, research questions and policy options, Geneva: UNRISD

Reeves, H. and Baden, S. (2000) Gender and Development: Concepts and Defintions, BRIDGE Report No. 55, Brighton: IDS

Rich, A. (2005) 'War of Ideas: Why Mainstream and Liberal Foundations and the Think Tanks they Support are Losing in the War of Ideas in American Politics', Stanford Social Innovation Review: 18-25

Rich, A. (1980) ‘Compulsory Heterosexuality and Lesbian Existence', Signs: Journal of Women in Culture and Society 5: 631-660

Rothschild, C. (2005) Written Out: How Sexuality is Used to Attack Women's Organizing, New York, NY: International Gay and Lesbian Human Rights Commission, Center for Women's Global Leadership 
Sachs, W. (2010 [1992]) The Development Dictionary: A Guide to Knowledge as Power, London: Zed Books

Sahasranaman, V. (2013) Who is the 99\%? Feminist Perspectives on Occupy, Brighton: BRIDGE, IDS

Salo, E. (2005). 'Multiple Targets, Mixing Strategies: Complicating Feminist Analysis of Contemporary South African Women's Movements', Feminist Africa 4

Sawney, M. and Daniel, R. (2010) Amnesty International working with others: an independent review, London: Amnesty International

Shack/Slum Dwellers International, Women: The Engines of Development, http: / www. sdinet.org/method-women/ (accessed 24 June 2013)

Shah, S.P. (2011) Sex Work and Women's Movements, New Delhi: CREA

Shaheed, F. and Shaheed, A. (2005) Great Ancestors: Women Asserting Rights in Muslim Contexts, London: WLUML

Sharma, J. (2008) 'The language of rights', in A. Cornwall (ed.), Development with a Body: Sexuality, Human Rights and Development, London: Zed Press

Sharp, G. (2012) Sharp's Dictionary of Power and Struggle: Language of Civil Resistance in Conflicts, New York, NY: Oxford University Press

Shefer, T.; Talele, K., Strebel, A., Shabalala, N. and Buikema, R. (2007) From Boys to Men: Social Constructions of Masculinity in Contemporary Society, Cape Town: University of Cape Town Press

Shivji, I. (2007) Silences in NGO Discourse: The Role and Future of NGOs in Africa, Oxford: Fahamu Books

Shivji, I. (1989) The Concept of Human Rights in Africa, Dakar: Codesria

Sholkamy, H. (2012) 'The Jaded Gender and Development Paradigm in Egypt', IDS Bulletin 43.1: 94-98

Sholkamy, H. (2013) Gender, activism and backlash: women and social mobilisation in Egypt, Brighton: BRIDGE, IDS

Simmonds, N. (2011) ‘Mana Wahine: Decolonising Politics', Womens' Studies Journal 25.2: $11-25$

Smith, A. (2007) 'Introduction: The Revolution Will not be Funded', in I. Violence (ed.), The Revolution Will Not be Funded: Beyond the Non-profit Industrial Complex, Cambridge, MA: South End Press

Smyth, I. and Turquet, L. (2012) Strategies of Feminist Bureaucrats: Perspectives from International NGOs, IDS Working Paper 396, Brighton: IDS 
Social Watch Philippines (2011) Interviews with participants at the Social Watch Global Assembly 2011, http: / / www.youtube.com/user/BRIDGEsocialmovement or http:/ / vimeo.com/bridgesocialmovements (accessed 9 July 2013)

Speed, S. (2006) 'Indigenous Women and Gendered Resistance in the wake of Acteal', in V. Sanford (ed.), Engaged Observer: Anthropology, advocacy, and activism, New Brunswick, NJ: Rutgers University Press

Stein, R. (2004). New Perspectives on Environmental Justice: Gender, Sexuality and Activism, New Brunswick, NJ: Rutgers University Press

Sumaktoyo, N.G. and Rindiastuti, Y. (2010) Religious Fundamentalisms and Student Life: A View from Indonesia, Toronto: AWID

Tadros, M. (2013) Politically motivated sexual assault: the Egypt story none want to hear, Guardian Poverty Matters blog, www.guardian.co.uk/global-development/ povertymatters / 2013/mar/11/ politically-motivated-sexual-assault-egypt (accessed 3 July 2013)

Tamale, S. (2003) 'Out of the Closet: Unveiling Sexuality Discourses in Uganda', Feminist Africa 2: 42-49

Thompson, L. and Tapscott, C. (2010) Citizenship and Social Movements: Perspectives from the Global South, London: Zed Books

Tripp, A.M. (2006) ‘The Evolution of Transnational Feminisms: Consensus, Conflict and Dynamics', in M. Feree and A.M. Tripp (eds), Global Feminism: Transnational Women's Activism, Organising and Human Rights, New York, NY: New York University Press

Uhuru-Wazobia (2006) Criminalising Homosexuality the Nigerian Way. Press release circulated by email

UN Women (2011) Progress of the World's Women 2011-2012: In Pursuit of Justice, New York, NY: UN Women

United Nations (2010) The World's Women 2010: Trends and Statistics, New York, NY: United Nations Department of Economic and Social Affairs

United Nations (2008) International Women's Day: Investing in Women and Girls, http:/ / www.un.org/events/women/iwd/2008/history.shtml (accessed 24 June 2013)

Vargas, V. (2005) ‘Feminisms and the World Social Forum: space for dialogue and confrontation', Development 48

Vergara, W.G. (2012) Nicaragua: Memories of a Feminist Generation, www.envio.org.ni/ articulo/ 4497 (accessed 15 February 2013)

Wallace, T. and Banos Smith, H. (2010) A Synthesis of the Learning from the Stop Violence Against Women Campaign, 2004-10, London: Amnesty International

Wilson, S.; Sengupta, A. and Evans, K. (2006) Defending our Dreams: Global Feminist Voices for a New Generation, London: Zed Books 
Women Human Rights Defenders International Coalition, http: / / www. defendingwomen-defendingrights.org (accessed 25 June 2013)

Yuval-Davis, N. (2006) 'Intersectionality and Feminist Politics', European Journal of Women's Studies 13: 193-210

Zimmerman, K.; Miao, V. and Khan, S. (2009) Gender, Organizing, and Movement Building at the Intersection of Environmental Justice and Reproductive Justice, San Franciso, CA: Movement Strategy Center and the Women's Foundation of California

Zimmerman, K.; Pathikonda, N., Salgado, B. and James, T. (2010) Out of the Spiritual Closet: Organisers Transforming the Practice of Social Justice, San Francisco, CA: Movement Strategy Center 


\section{Glossary}

Autonomous movement: Independent or outside formal organisational control or direction.

Backlash: A strong negative response at a popular level or among an influential group to changes in society. Typically used to describe organised responses that seek to maintain unjust power relations or reverse positive gains made towards justice or equality.

Consciousness-raising: A movementbuilding strategy common in feminist movements. It involves creating group processes to explore personal experiences of violation and/or empowerment and develop a critical understanding of the root causes of oppression, deepen knowledge of history (including activist and alternative perspectives on mainstream history) and build solidarity and a shared political commitment to changing the status quo. Consciousness-raising is commonly facilitated in a non-hierarchical way, with all people's experiences and knowledge considered valuable and relevant for learning and reflection.

Deep structure: A term used to describe the hidden layers within societies, organisations and movements where a number of unconscious or even conscious but hidden processes occur. Within the deep structure lie assumptions taken for granted about gender roles and the place of women. These assumptions are below awareness level, and are, therefore, not talked about or challenged, but they determine how people think and act. Deep structures are the sites where all sorts of informal, invisible norms and rules operate, and from where formal processes are subverted (Rao and Kelleher 2005; Srilatha Batliwala, BRIDGE e-discussion, March 2012).

Equality: An equal society is one in which everyone can flourish. The diverse needs, situations and goals of individuals are recognised, discrimination and prejudice are removed, and the economic, political, legal, social and physical barriers that limit what people can do and be are tackled (Burchardt and Vizard 2007).

Far right: A set of ideologies that espouse extreme social, political and economic conservatisms and rejection of social and cultural diversity; often linked to racist, sexist, xenophobic and homophobic views, including legitimising acts of violence against specific groups.

Feminisms: Political frameworks and social movements that identify patriarchal power as a fundamental source of injustice and inequality, and hence call to transform gender power relations in all domains. Feminisms are diverse in their origins and expressions, and include analyses and actions around how patriarchal power intersects with other systems of power such as race, class, heterosexuality and ability; and in a range of contexts such as language, the environment, technology, popular culture, and all areas of social, political and economic life. 
Feminist movements: Movements that align themselves with feminism as a political ideology and seek to challenge inequalities and injustices between women and men, framing these as a challenge to patriarchy and patriarchal power relations. Feminist movements have historically been built and constituted by women, although men and trans individuals and movements also align themselves with the politics of feminism.

Gender: The socially constructed identities, behaviours and practices tied to being a girl/woman or boy/man. There is growing acknowledgment in theory, law and social practice that the binary definition of gender (i.e. only two genders) does not fully account for the diversity of gender identities that exist, including those of trans and intersex people.

Gender equality: Enshrined in law as a basic right, gender equality refers to measurable, equal representation and status between women and men. Gender equality does not imply that women and men are the same, but that they have equal value and should be afforded equal treatment (Just Associates 2012).

Gender justice: The ending of - and if necessary the provision of redress for inequalities between women and men that result in women's subordination to men. These inequalities may be in the distribution of resources and opportunities that enable individuals to build human social economic and political capital. Or they may be in the conceptions of human dignity, personal autonomy and rights that deny women physical integrity and the capacity to make choices about how to live their lives (Goetz 2007). Gender justice encompasses but extends beyond formal equality to include transforming systems of gendered power in all domains.
Gender justice movements: Movements that challenge gender inequalities and unjust gender power relations; often used in the context of mixed-gender or men's movements and LGBTI movements that challenge gender binaries.

Gender power relations: Hierarchical relations of power between women and men that tend to disadvantage women. These gender hierarchies are often accepted as 'natural' but are socially determined, culturally based relations and are subject to change over time. They can be seen in a range of gendered practices, such as the division of labour and resources, and gendered ideologies, such as ideas of acceptable behaviour for women and men (Reeves and Baden 2000)

Gender mainstreaming: An organisational strategy to bring a gender perspective to all aspects of an institution's policy and activities, by building gender capacity and accountability. With a mainstreaming strategy, gender concerns are seen as important to all aspects of development, for all sectors and areas of activity, and a fundamental part of the planning process. Responsibility for the implementation of gender policy is diffused across the organisational structure, rather than concentrated in a small central unit (Reeves and Baden 2000:12).

Hegemony: The process through which the world view of dominant groups comes to be accepted as 'common sense' or the 'natural' order of things. Hegemony can be expressed through language, culture, patriarchy, political and economic systems, and is designed to maintain the status quo in the interest of those in power (Just Associates 2012: 13).

Heteronormativity: The assumption of universal heterosexuality and resulting beliefs and practices that only value or acknowledge sexual and emotional relations between women and men. 
Intersex: A general term used for a variety of conditions in which a person is born with a reproductive or sexual anatomy that does not seem to fit the typical definitions of female or male (Intersex Society of North America).

Instrumentalisation: The strategic use of a particular community, group or political standpoint to advance a goal in ways that do not directly benefit the people or ideas being drawn on or align with their own goals.

\section{Intersectionality: A conceptual}

framework that makes visible the multiple discriminations that people face, the ways in which systems of oppression (for example, those framing gender, race, class, sexuality, ability) interact with each other, and thus the activist imperative to name and challenge multiple inequalities as part of seeking justice for different constituencies of women.

Mainstream development: Frameworks and practices around development as defined and advanced by governmental agencies and large donor institutions. Commonly used in the context of critique and to describe frameworks derived from, or predominantly developed in, the global North and that support neo-liberal economic approaches and governance models in line with the current status quo.

Movement-building: The process of organising marginalised and / or discriminated constituencies to build their collective power towards a shared vision of transformation. This includes developing a political analysis and growing structures needed to initiate, sustain, strengthen and/or revive their movement. It also entails building and expanding political consciousness, outreach and developing popular support and membership, mobilising resources for movement activities, organisations and spaces, and forming alliances towards a movement's goals.
Movement constituencies: Individuals and groups that make up the membership of a social movement.

Neo-liberalism: A political movement that promotes economic liberalisation - for example, promoting the reduction of trade barriers, such as import tariffs, as a means to promote international trade and cooperation - as a means of promoting economic growth and securing political liberty (wiktionary.org/wiki/ neoliberalism).

NGO-isation: The process by which social movements' agendas and activities are taken up by formally constituted nongovernmental organisations, which in turn become considered representatives or leaders in voicing these agendas or implementing activities. Often used as a term of critique, pointing to the ways in which mainstream NGO approaches become valorised, resourced and promoted above more radical organisational approaches and independent activism and movement mobilisation (see Alvarez 2009: 176).

Patriarchy: Systemic and institutionalised male domination and the cultural, political, economic and social structures and ideologies that perpetuate gender inequality and women's subordination (Just Associates 2012).

Popular: Of the 'people', in the sense of the majority general population and / or or the economically, socially and politically marginalised.

Popular consciousness: Mass-based political awareness and critical understanding of the root causes of injustice, discrimination and oppression, and strategies to change this; typically used to imply popular consciousness for just, inclusive visions of society. 
Popular conservativism: Mass-based support for social, political and economic ideas that support the preservation of, or a return to, the traditional status quo and power relations.

Popular education: A community-based practice of learning and consciousnessraising where people (typically adults) analyse oppression from their own life experience and use this reflection to develop conceptual and practical methods to challenge it; an approach developed in detail through the work and practice of Brazilian educator Paulo Friere (1921-1997).

Popular progressivism: Mass-based support for social, political and economic ideas that promote justice, redistribution and the transformation of societies towards inclusion, equality and democracy.

Queer: A theoretical framework and an identity that questions the norms of heterosexuality and the idea of binary gender (only two static forms of gender identity); increasingly used in addition to, or in the place of, the category 'Lesbian, Gay, Bisexual, Transgender and Intersex'.

Religious fundamentalism: The strategic use of religious discourse and institutions to forward views and actions that are absolutist and intolerant, anti-human rights and women's rights and at their root fundamentally patriarchal (Horn 2012: 8).
Trans: Includes those people who have a gender identity which is different from the gender assigned at birth and/ or those people who feel they have to, prefer to or choose to - whether by clothing, accessories, cosmetics or body modification - present themselves differently from the expectations of the gender role assigned to them at birth. This includes, among many others, transsexual and transgender people, transvestites, travesti, cross dressers, no gender and genderqueer people (Global Alliance for Trans Equality).

Transphobia: Intolerance towards and discrimination against people who are trans.

Vanguardist: A political strategy that places a select group of people or an organisation at the forefront of a movement or change process, with the idea that they will ensure that movement politics remains consistent and will also lead in building consciousness and membership and guide movement actions.

Women's movements: Movements of women that are built and constituted by women and seek to challenge inequalities and injustice between women and men. Women's movements may have varying approaches to transforming gender power relations, from more conservative to more radical. Individuals and groups within women's movements may not always ally themselves with the political identity of 'feminism'. 


\section{List of Contributors}

Programme participants

We are very grateful to all the following people, who contributed in different ways to the programme and played key roles in generating the content of this report.

Community of practice e-discussion participants

Adriana Berdía

Alaa Murabit

Alan Greig

Alexandra Garita

Alia Khan

Almudena Cabezas

Alzima Bano

Amina Doherty

Ana Maria Nemenzo

Anu Verma

Aruna Rao

Atila Roque

Ayesha Khan

Azahalea Solis

Betty Barkha

Bondita Acharya

Bridget Burns

Burnad Fatima Natesan

Carmen Capriles

Carol Barton

Carole Osero Ageng'o

Cecilia Olea Mauleón

Cecilia Sardenberg
Charlotte Soulary

Chayanika Shah

Claudia Anzorena

Dafne Plou

Daysi Edith Osorio Alvarado

Delfa Mantilla Pacheco

Devangana Kalita

Diane Mulligan

Elham Manea

Elsa Duhagon

Elvira Quiroz

Emily Sikazwe

Enma Sofía Hernández

Ethel Tungohan

Evelin Natividad Cavero Contreras

Everjoice Winn

Ezra Mbogori

Felistah Ngui

Feng Yuan

Filomena Tuivanualevu

Georgina López

Gesa Bent

Graciela Rodríguez

Ghadeer Malek

Grace Ruvimbo Chirenje

Gricelda Cañete Ribeiro

Hania Sholkamy

Hasmida Karim

Helen Dixon

Isis Arlene Díaz-Carrión 
Joan Salvador

Joanne Sandler

Judith Arrunategui

Karen Brutas

Kate McInturff

Laura Ruiz

Larissa Arroyo Navarrete

Lara Koerner Yeo

Layali Eshqaidef

Leticia Zenevich

Lilián Celiberti

Lindsay Mossman

Lorraine Foster

Losana Tuiraviravi

Lucy Garrido

Maisa Shquier

Manjima Bhattacharjya

Margarita Aguinaga

Margarita Altamirano

Maria Ines Vasquez

María José Romero

Maria Miranda

Marisa Viana

Maria Olivella Quintana

Mary Jane Real

Masaya Llavaneras

Maura Nasly Mosquera

Michael Edwards

Michal Osterweil

Michel Friedman

Milena Páramo Bernal

Mónica Gil

Monyvann Nhean

Morna Macleod

Nadine Jubb

Nandni Vandhana

Nikita Agarwal

Norma Guillard
Nurgul Djaanaeva

Paloma Lafuente Gómez

Paolo Baleinakorodawa

Rebeca Salazar

Rieky Stuart

Roseline Nsenge

Roshni Nuggehalli

Patricia Cristaldo

Philip Otieno

Philip Thigo

Portia Tshegofatso Loeto

Roxana Reyes

Salma El Naqqash

Sandra Ljubinkovic

Setareki Macanawai

Shalmali Guttal

Shamillah Wilson

Sheherazade Jafari

Sian Rolls

Sifiso Dube

Simel Esim

Susanna George

Sylvia Estrada Claudio

Teresa Salazar Dávila

Veena Singh Bryar

Vinita Sahasranaman

Wendy Harcourt

Yarman Elaine

Yassmine Hamayel

Zohra Moosa

Community of practice e-discussion moderators

Chelsea Ricker

David Kelleher

Marivic Raquiza

Norma Sanchis

Srilatha Batliwala 
Community of practice e-discussion partners

AWID Young Feminist Initiative

SendasAL

\section{Event participants}

Atila Roque, Amnesty Brazil

Emily Sikazwe, Women for

Change, Zambia

Gigi Francisco, Development

Alternatives with Women for a New Era

(DAWN)

Lydia Alpizar Duran, Association for Women's Rights in Development (AWID)

Marivic Raquiza, Social

Watch Philippines

Roberto Bissio, Social Watch Uruguay

Simon Stocker, Eurostep

Shalmali Guttal, Focus on the Global

South

Wendy Harcourt, Institute of Social

Studies, Netherlands

Yao Graham, Third World Network-

Africa

Case study authors

David Kelleher

Hania Sholkamy

Hope Chigudu

Manjima Bhattacharjya

Pamela Caro

Solome Nakaweesi-Kimbugwe

Sharon Bhagwan Rolls

Vinita Sahasranaman

Photographers

Annie Theriault

Jessica Horn

Lorena Espinoza Peña

Marie Devers

Mindy Ko

Natashe Dekker

Pamela Caro
Raha Asgarizadeh

Reena Shadaan

Tamara Pels-Idrobo Tapia

Verónica Capriglioni

People interviewed for the programme

Abdulnabi Alekri, Bahrain Transparency Society

Abhijit Das, Centre for Health and Social Justice, India

Adriana Mezadri, rural women's movement, Brazil

Akhter Hossain, Unnayan Shamanmay, Bangladesh

Aldo Callari, Centre of Concern, USA

Alfredo Chub, Mayan movement leader, Guatemala

Alicia Muñoz, Chile

Alvaro Pop, Member of UN Permanent Forum on Indigenous Issues, Guatemala

Anannya Bhattacharjee, Society for Labour and Development and Asia Floor Wage Campaign, India

Annie Raja, National Federation of Indian Women, India

Azahálea Solís, attorney, Nicaragua

Barbara Adams, Global Policy Form, USA

Catalina, Maya Mam leader

Cinthya Gonzalez, CONAMURI, Paraguay

Cirilo Otero, Director of the Centre for Environmental Policy Initiatives, Nicaragua

Dean Peacock, Sonke Gender Justice Network, South Africa

Domingo Hernández Ixcoy, Mayan movement leader

Emely Flores, activist, El Salvador

Esperanza Cardona, National Association of Campesinos, Honduras

Florencia Aróstica, Chile

Francisca Rodriguez, National

Association of Chilean Rural and 
Indigenous Women (ANAMURI)

Gilda Parducci, activist, El Salvador

Gina Vargas, feminist and member of Articulacion Feminista Marcosur, World Social Forum

Jason Nardi, Social Watch Italy

Jerker Edstrom, Institute of Development Studies, UK

Julie Lalonde, Feminist Alliance for International Action, Canada

Kuhu Das, Association for Women with Disabilities, India

Laila Hussein Ali, Human Rights Information and Training Centre, Yemen

Leonor Briones, Social Watch Philippines

Lourdes Huanca, FEMUCARINAP, Peru

Loyda Olivo, rural women's movement, Ecuador

Madhuresh Kumar, National Association of People's Movements, India

Margarita Fernández, activist, El Salvador

Martha Yllescas Altamirano, feminist economist, Nicaragua

Members of the youth group Iguana, Guatemala

Milena Kadieva and Melen Meykov, Bulgarian Gender Research Foundation

Mirjam van Reisen, EEPA, Belgium

Mirta Coronel, MOCASE campesino movement, Argentina

Nalú Farias, Marcha Mundial de Mujeres

Norayda Arabella Ponce Sosa,

CONGCOOP, Guatemala

Roberto Bissio, Social Watch Uruguay

Roukiattou Ouedraogo, journalist, Burkina Faso

Sariah Acevedo, indigenous activist and sociologist, Guatemala

Simon Cazal, LGBT activist, Paraguay

Simona Yaguenova, academic, Guatemala
Thida Khus, SILAKA, Cambodia

Patricia Orozco Andrade, feminist journalist, Nicaragua

Petronila Morales, Mayan movement leader, Guatemala

Philip Thigo, Social Development

Network, Kenya

Philip Otieno, Men for Gender Equality

Now, Kenya

Princess Nemenzo, Women

Health Philippines

Sofía Montenegro, journalist, Nicaragua

Sunita Kujur, CREA, India

Yanira Argueta, activist, El Salvador

\section{Interviewers}

Jessica Horn

Marcos Nascimento

Pamela Caro

Patricia Ardón

Translation

Angela de Prairie

Aurélie Cailleaud

Helen Dixon

Laura E. Asturias 



\section{CUTTING EDGE PROGRAMMES}

\section{Gender and Social Movements OVERVIEW REPORT}
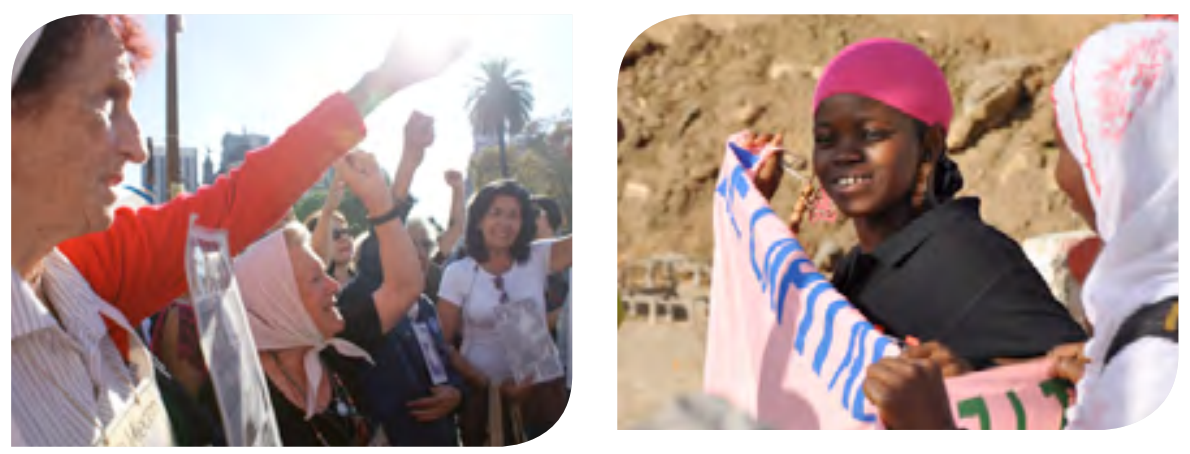

Across the world there is an active, mass-based demand for an end to gendered injustice in all domains of our social, economic, political and cultural lives. Social movements led by feminist, women's and gender justice activists and movements - have been pivotal in demanding, making and sustaining these changes. However, while women's rights and gender justice are 'on the agenda' in many arenas, activists still encounter strong resistance to changing gendered politics and practices within movements and allied organisations.

This Overview Report makes the case for engaging with questions of women's rights and transforming gender power relations across social movements committed to progressive visions of society. It draws on effective and promising strategies and reflects on challenges from existing movement practice.

It incorporates both social movement theory and experience and analysis from social justice activists from across the world, who are engaged in supporting the advancement of women's rights and gender justice as part of women's movements and other social movements working towards development, human rights, justice, sustainability and peace.

BRIDGE

Institute of Development Studies University of Sussex

Brighton BN1 9RE

UK

Tel: $+44(0) 1273606261$

Fax: $+44(0) 1273621202$

Email: bridge@ids.ac.uk www.bridge.ids.ac.uk

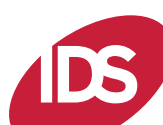

Institute of

Development Studies

IDS is a charity registered in England and Wales no. 306371 